\title{
QUALITY AND QUANTITY: GENDER REPRESENTATION IN TEACHER DISCOURSE AND KINDERGARTEN MATH CURRICULUM
}

\author{
A Dissertation \\ presented to \\ the Faculty of the Graduate School \\ at the University of Missouri-Columbia \\ In Partial Fulfillment \\ of the Requirements for the Degree \\ Doctor of Educational Leadership and Policy Analysis \\ by \\ ALEXANDRIA OTIS \\ Dr. Lisa Dorner, Dissertation Supervisor \\ MAY 2021
}


The undersigned, appointed by the dean of the Graduate School, have examined the dissertation entitled

\section{QUALITY AND QUANTITY: GENDER REPRESENTATION IN TEACHER DISCOURSE AND KINDERGARTEN MATH CURRICULUM}

presented by Alexandria Otis,

a candidate for the degree of doctor of education,

and hereby certify that, in their opinion, it is worthy of acceptance.

Professor Lisa Dorner

Professor Zandra de Araujo

Professor Se Woong Lee

Professor Jeni Hart 


\section{DEDICATION}

I would like to dedicate this dissertation to my partner, Robert. His love and support enabled me to continue when I thought I could not. I appreciate his constant listening and feedback as I completed this journey. I would also like to acknowledge my parents as they encouraged a love of learning from a young age and have supported my studies and ambitions throughout my adolescence and adulthood. I cannot thank them enough for their unconditional love and support during this stage of my life. Finally, I would like to acknowledge my in-laws, grandparents, other family members, friends, and fellow EdD cohort members for their constant support over the past few years. They took on various roles throughout this process:

cheerleaders, therapists, and comforters. I am grateful to have a village of people whose support helped me accomplish this goal. Thank you all. 


\section{ACKNOWLEDGEMENTS}

I would like to thank my incredible advisor, Dr. Lisa Dorner for all of her time, expertise, and support. I feel so grateful to have had an advisor who encouraged me to try new things and supported changes in my career. This dissertation would not have been possible without her support and expertise. I would also like to thank my committee members, Dr. Jeni Hart, Dr. Zandra de Araujo, and Dr. Se Woong Lee. I feel lucky to have committee members who helped me grow in areas with which I was less familiar during this process. I appreciate their time and willingness to share their knowledge. Finally, I would like to acknowledge all of the professors who taught me throughout this program: Dr. Douglas, Dr. Lee, Dr. Dache, Dr. Dorimé-Williams, Dr. Fellabaum-Tosten, Dr. Sebastian, and Dr. Mendoza. Thank you all for guiding me in this process and teaching me the tools needed to earn this degree. 


\section{TABLE OF CONTENTS}

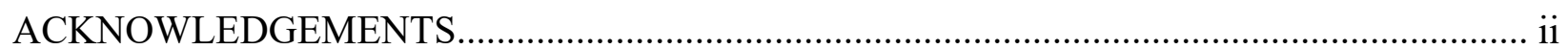

LIST OF ILLUSTRATIONS.................................................................................... viii

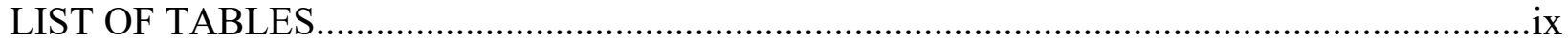

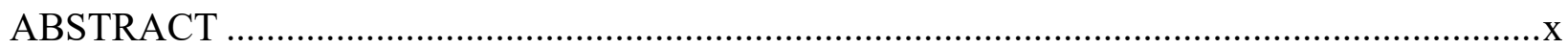

Section One: Quality and Quantity: Gender Representation in Teacher Discourse and

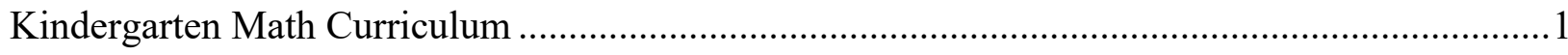

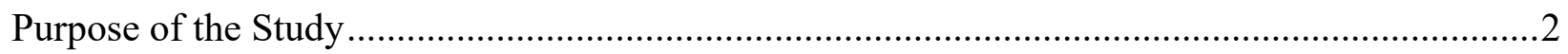

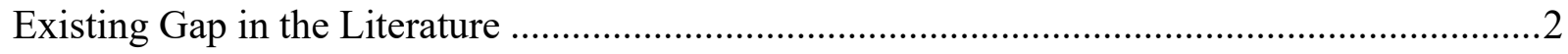

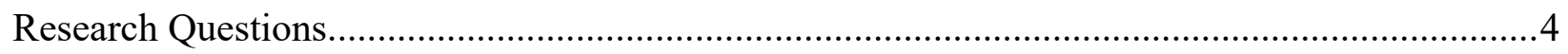

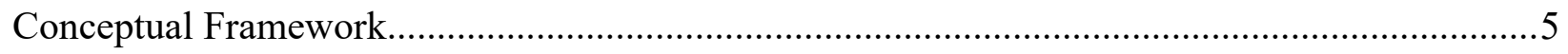

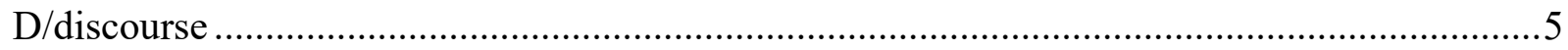

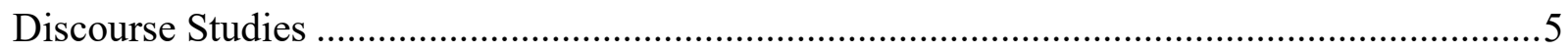

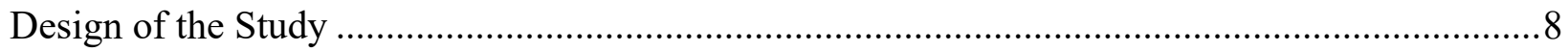

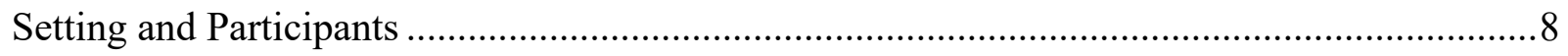

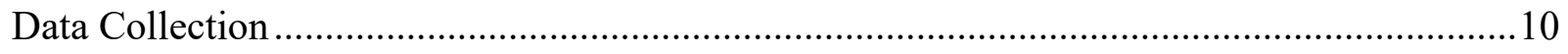

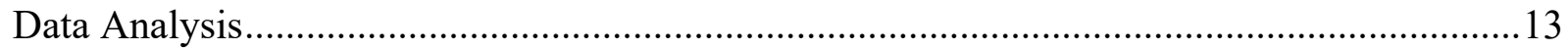

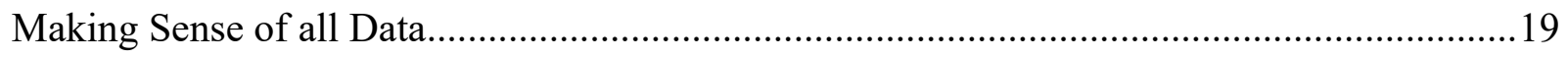

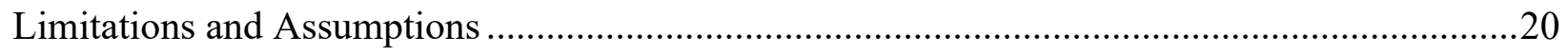

Statement of Positionality: Ethics and Trustworthiness .................................................21 
Validity

Reliability

Gender as the Focus.

Assumptions

Significance of the Study.......

Summary

Section Two: An Organizational and Leadership Analysis

History of Organization

Organizational Analysis

Structural Framework

Context for Participants 36

Background of Participants' Educational Experience and Perceptions of Math and Gender ...36

Implications for Research

Conclusion.

Section Three: Scholarly Context for the Study

Gender Schema Theory

The Construction of Gender Identity-Gender Schema Theory

Trends in Gender and Mathematics

Intended Curriculum Analysis 
Societal Stereotypes about Gender and Mathematics

Roles of Teachers and Instruction

Summary

Implicit and Explicit Gender Stereotyping-Studies with Children.

Conclusion

Section Four: Contribution to Scholarship .73

Conceptual Framework

Types of Curriculum.

$\mathrm{D} /$ discourse

Critical Discourse Analysis

Gender Schema Theory .76

Methods .77

Setting and Participants

Data Collection .78

Data Analysis. .80

Making Sense of all Data.. .86

Findings .87

Intended Curriculum: Quantity and Quality of Gendered Representation .87

Conclusions from Curriculum Analysis 107 


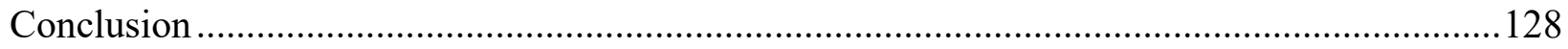

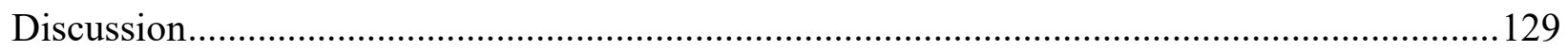

Teachers and Curriculum Predominantly use Inclusive and Non-gendered Language............130

Teachers and Curriculum Represent Girls and Boys Similarly..............................................131

Gender Bias through Language and Illustrations is Subtle ...................................................133

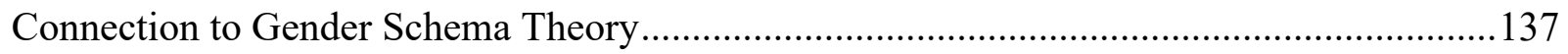

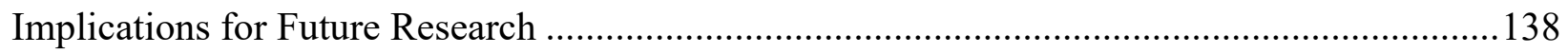

Connection Between Intended Curriculum, Teacher Perception and Enacted Curriculum ....139

Intersectional Analysis of Curriculum and Supplemental Materials .......................................139

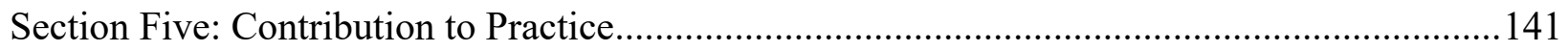

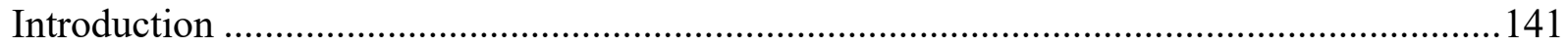

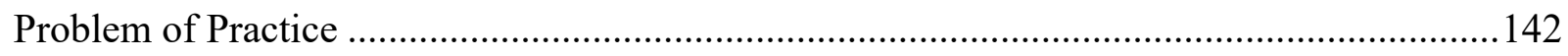

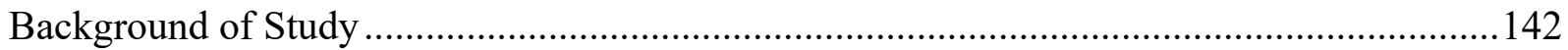

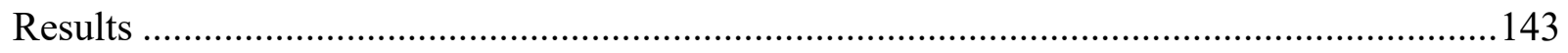

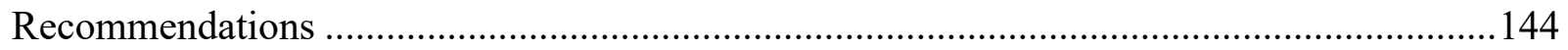

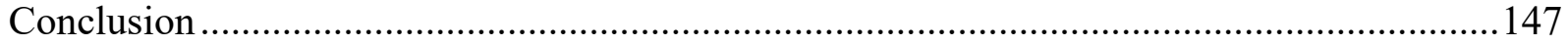

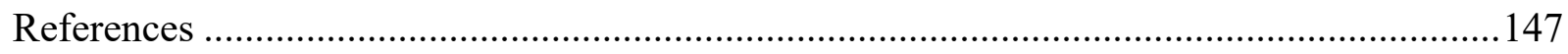

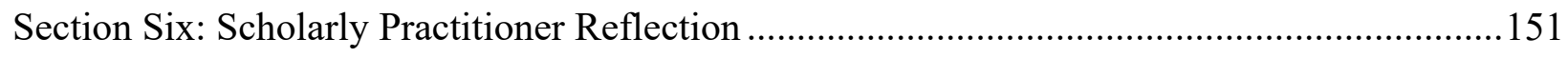


Increased Cultural Awareness

Transforming from Leader of Children to Leader of Adults..................................................152

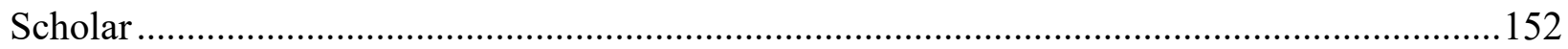

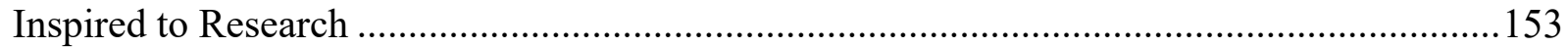

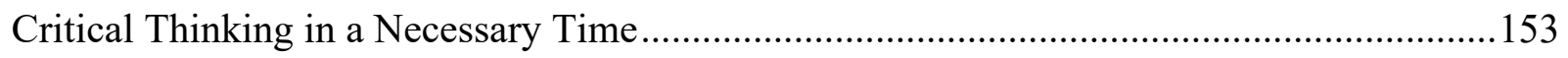

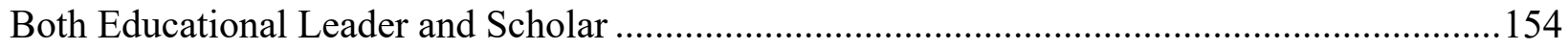

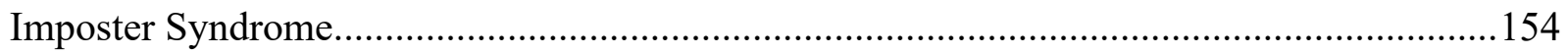

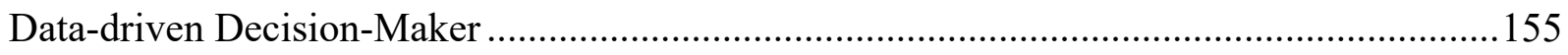

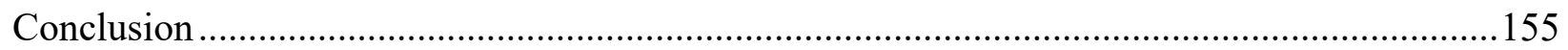

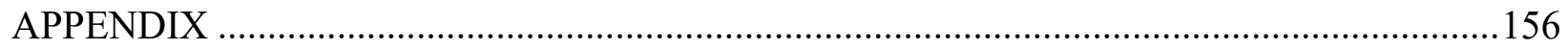

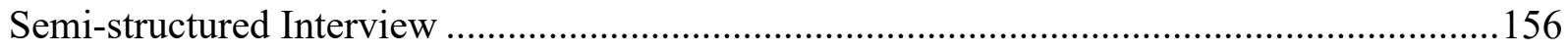

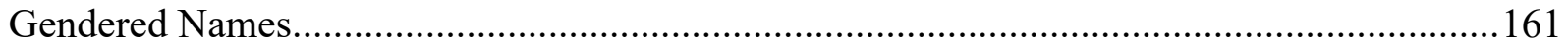

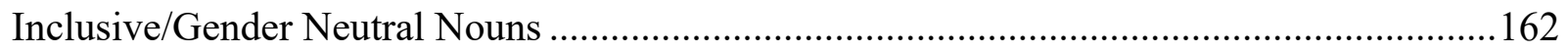

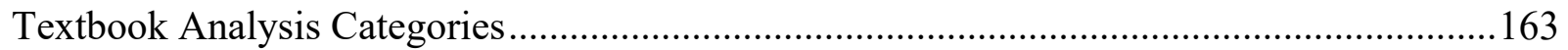

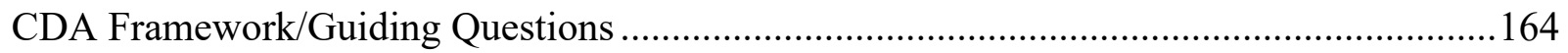

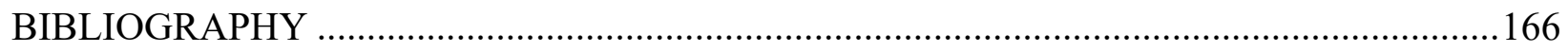

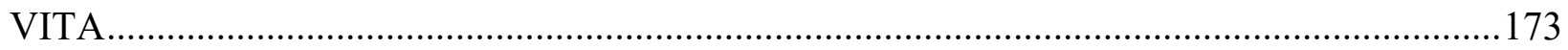




\section{LIST OF ILLUSTRATIONS}

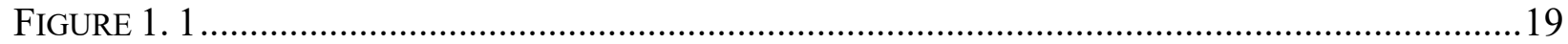

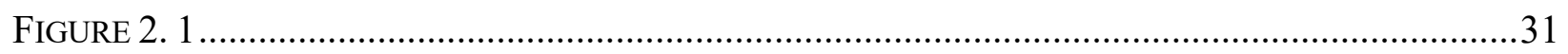

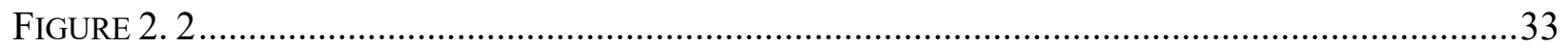

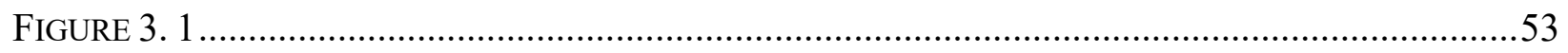

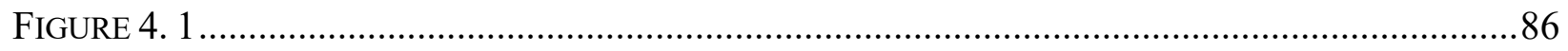

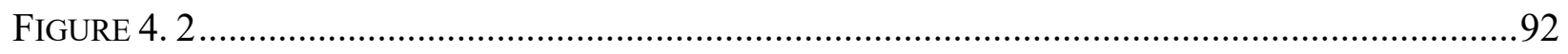

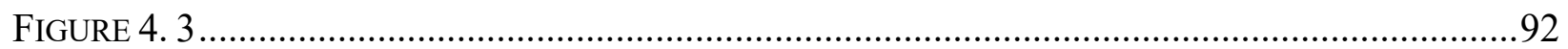

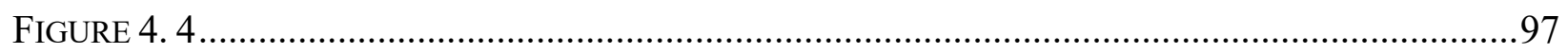

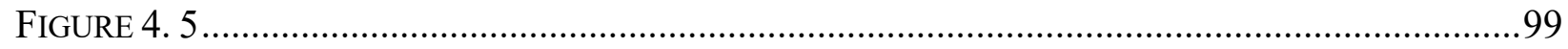

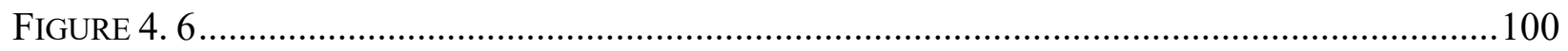

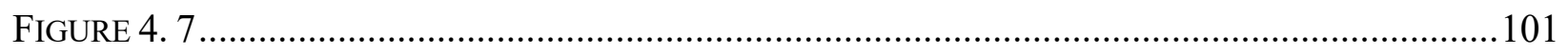

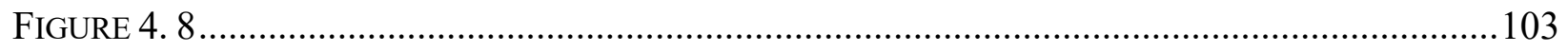

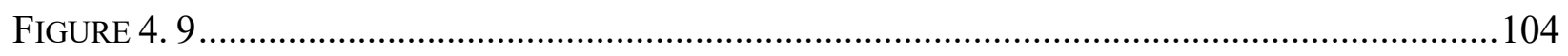

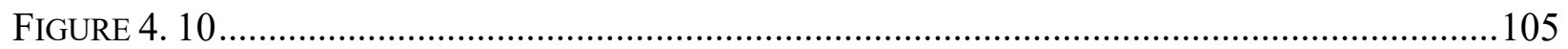

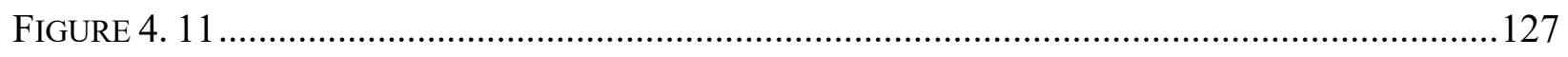

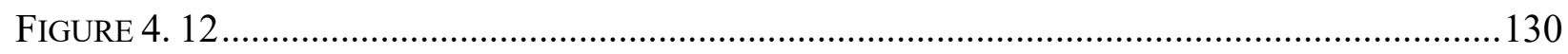

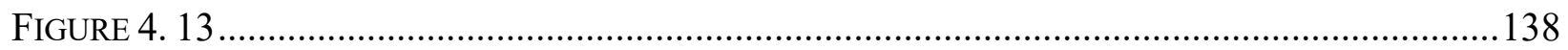




\section{LIST OF TABLES}

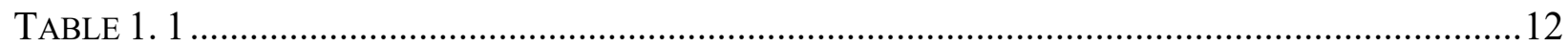

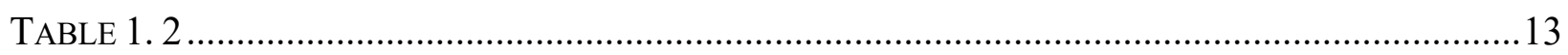

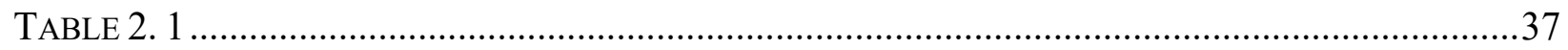

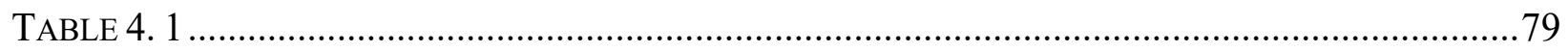

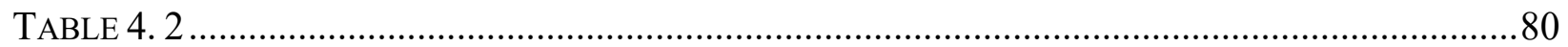

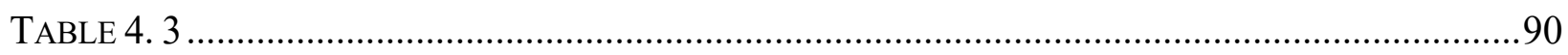

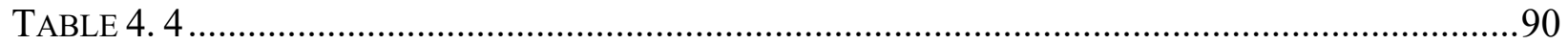

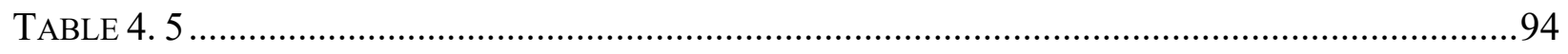

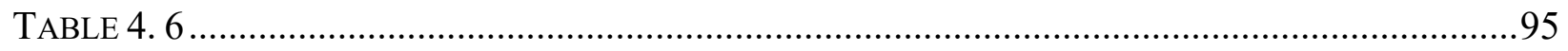

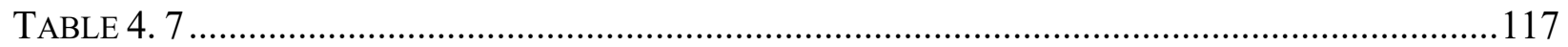

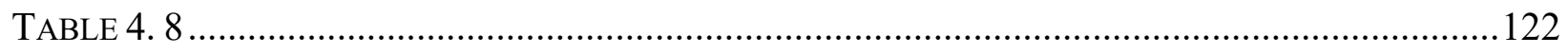

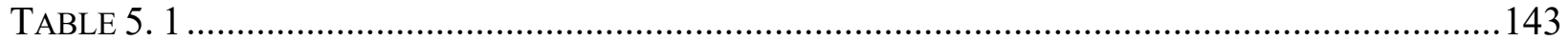




\title{
QUALITY AND QUANTITY: GENDER REPRESENTATION IN TEACHER DISCOURSE AND KINDERGARTEN MATH CURRICULUM
}

\author{
Alexandria Otis \\ Dr. Lisa Dorner, Dissertation Supervisor
}

\begin{abstract}
We know that women are underrepresented in math-intensive fields despite marginal gender differences in mathematical performance. Some researchers believe that societal factors contribute to this problem and have called for more nuanced methodologies to examine why underrepresentation and gender stereotypes about math continue to persist. The purpose of this study was to examine what messages teachers and instructional materials convey in a kindergarten mathematics classroom through discourse analysis of the intended curriculum and teacher perceptions guided by the following research questions: (1) How does the Everyday Mathematics kindergarten curriculum and supplemental curriculum materials position and write about girls in comparison to boys? and (2) How do teachers describe girls in comparison to boys and position them when discussing their beliefs about mathematics instruction and equity in the kindergarten classroom?
\end{abstract}

Findings from the intended curriculum and teacher interviews include: (1) teachers and curriculum predominantly use inclusive and non-gendered language, (2) teachers and curriculum represent girls and boys similarly; however, subtle gender bias in language and illustrations persists. Further examination of subtle gender bias revealed that boys are privileged in language and illustrations, and that intentional non-stereotypical representations of girls are more prevalent than non-stereotypical representations of boys. In conclusion, teachers and curriculum materials represent girls and boys more equitably than found in previous studies; however, subtle gender bias persists. These findings extend conversations of diversity and inclusion currently conducted 
at the study site by intentionally focusing on gender in addition to other identities. In turn, curriculum developers could consider less privileging of boys in language and illustrations, and teachers and curriculum writers could more intentionally represent both girls and boys more frequently in non-stereotypical roles and ways.

Keywords: gender bias, discourse analysis, kindergarten, math education, intended curriculum 


\section{Section One: Quality and Quantity: Gender Representation in Teacher Discourse and Kindergarten Math Curriculum}

For 30 minutes, I listened to seven boys enthusiastically solve math problems together. It was the first time they experienced math as an all-boy group, and they discussed and laughed freely. Subsequently, seven girls worked silently and independently for 30 minutes. They were quiet and did not collaborate with one another. I noticed how my demeanor changed as I tried to comfort the seemingly challenged and anxious girls. After reflecting on these 60 minutes, I started to wonder what role I played in exacerbating these feelings. The aforementioned lesson has been the catalyst for my dedication to gender studies in the classroom. After reflecting on my role in this scenario, I believe that instructors can and do impact the way students receive instruction by either reinforcing stereotypes and bias or challenging stereotypes and bias on a daily basis.

The story above illustrates what Sadker and Sadker (1994) found in their classroom observations - teachers subtly treat girls and boys differently in the classroom. Sadker and Zittleman (2009) extended the research of Sadker and Sadker (1994) and continued to find patterns of inequity between the treatment of girls and boys in the classroom setting. Several studies have found that teachers give more attention and feedback to boys compared to girls, asking boys better questions and giving them more precise and helpful feedback (Altermatt et al., 1998; Sadker \& Zittleman, 2009; Sadker \& Sadker, 1994). When girls experience microinequality day after day, year after year for a minimum of 13 years of formal schooling, the cumulative effects can influence their self-esteem and overall achievement in academics and the workplace (Sadker \& Zittleman, 2009). This may especially be the case in elementary math lessons, the focus of this dissertation. 


\section{Purpose of the Study}

We know that women are underrepresented in math-intensive fields (Khan et al., 2020) despite marginal gender differences in mathematical performance (National Assessment of Educational Progress, 2019). Researchers have identified several areas that may contribute to the underrepresentation of women in science, technology, engineering, and math (STEM) fields: societal stereotypes about gender and math, role of teachers and instruction, climate and postsecondary mathematics, attitudes, beliefs, and values, verbal skills, and spatial thinking (Lubienski \& Ganley, 2017). The purpose of this study is to examine the messages teachers and instructional materials convey in a kindergarten mathematics classroom through discourse analysis of the intended curriculum and teacher perceptions. These terms will be defined in connection to this study later. Such a study will help us to explore micro-level elements that may contribute to gender inequities in the early-childhood math classroom.

\section{Existing Gap in the Literature}

Researchers have examined the relationship between gender and mathematics extensively over several decades from various perspectives (Lubienski \& Ganley, 2017). Despite only narrow sex disparities in performance favoring males in math (National Assessment of Educational Progress, 2019), women continue to be underrepresented in STEM field (Wang \& Degol, 2017). Much research has been dedicated to exploring why women are underrepresented in STEM (Lubienski \& Ganley, 2017). After reviewing literature examining why this disparity persists, recent literature reviews of research on gender and mathematics have called for future researchers to use more nuanced methods for exploring the "why" behind such disparities (Lubienski \& Ganley, 2017; Leyva, 2017). 
One method for exploring microlevel elements that may contribute to inequities in the classroom is D/discourse analysis. D/discourse refers to both language and non-language "stuff" in texts and interactions (Gee, 2014, p. 7). Classroom D/discourse can include a variety of elements, but for the purposes of this study, I focused on the school-intended curriculum and teacher discourse. Researchers have studied the mathematics classroom and curriculum for several decades using various methodologies: quantitative, qualitative (including discourse analysis), and mixed methods.

Although there are many studies concerning gender and mathematics, fewer studies have been conducted in the kindergarten setting. Lubienski and Ganley (2017) wrote in their review of literature on gender and math that the majority of mathematics research is conducted with participants between first and twelfth grade and measurable differences in attitudes and beliefs between girls and boys emerge by first grade. Studies of explicit and implicit gender bias have been inconsistent in their findings depending on tool of measurement and setting of study (Lubienski \& Ganley, 2017; Vuletich et al., 2020), but Cvencek et al. (2011) showed that students as young as first and second grade recognize the stereotype that math is for boys.

Therefore, my study starts to fill this gap by focusing on the kindergarten math classroom, including curriculum materials and teacher discourse. This study may potentially add to multiple fields: education, gender, curriculum analysis, and discourse analysis. Examining teacher and curriculum discourse may illuminate how teachers subtly reinforce or challenge gender stereotypes in the kindergarten math classroom through use of curriculum and beyond the curriculum. 


\section{Research Questions}

The first research question focuses on the school-intended curriculum: How does the Everyday Mathematics kindergarten curriculum and supplemental curriculum materials position and write about girls in comparison to boys? According to Lloyd et al. (2017), "the intended curriculum refers to educational-system level (e.g., national, district, or school level) expectations for mathematics learning, including textbooks and standards" (p. 825). This research question is connected to the intended curriculum because the curriculum in this study is provided by the school and the expectation is that it is utilized as the main source of math instruction (A. Administrator, personal communication, December 21, 2021) at the study site. Exploring these questions will provide a deeper understanding of kindergarten math teachers' discourse related to math and gender in the classroom in connection with how kindergarten math curriculum materials represent girls in comparison to boys. Together, findings from these questions may illuminate how teacher discourse and course material work together to shape young students' understanding of gender and gender roles, especially in connection with math.

The second research question guiding this study is related to teacher perceptions: How do teachers describe girls in comparison to boys and position them when discussing their beliefs about mathematics instruction and equity in the kindergarten classroom? Although I was unable to observe these teachers in the classroom due to the Covid-19 pandemic, teacher participants were asked to describe how they have taught or would teach a lesson from the intended curriculum. The assumption is that their discourse with me is related to and possibly a window into the discourse they use in the actual classroom setting. 


\section{Conceptual Framework}

The conceptual frameworks underpinning this study are discourse analysis (Gee, 2014), Critical Discourse Analysis (CDA) (Fairclough, 2010), and gender schema theory (Bem, 1993). The following is a brief review of all three frameworks, including how I define the use of the term "gender" in this study. Discourse analysis and CDA underpin this study because the focus of this study is the messages conveyed through discourse in the intended curriculum and teacher perceptions. This brief review discusses how the frameworks are utilized in this dissertation. As further developed in Section III, combining this work into a conceptual framework helps to fill the gap in research and address a persistent problem in the classroom.

\section{D/discourse}

The definitions of D/discourse draw heavily on the work of James Gee (2014). According to Gee (2014), language is more than words, it is saying, doing, and being. In order to make meaning from these interactions, researchers use discourse analysis to study language in use, or discourse with a little "d" (Gee, 2014). Furthermore, Gee (2014) defined Discourse with a big "D" as the melding of language-in-use and "non-language stuff" to enact larger identities and activities (p. 7). This includes the ideologies, values, stereotypes, and meta-narratives. In this study, Discourse with a big " $D$ " might include patriarchal, androcentric and feminist ideologies, gender stereotypes, educational values, and gendered meta-narratives. All discourse with a small "d" occurs within a larger big "D" discourse and can be interpreted through those lenses.

\section{Discourse Studies}

Discourse studies shape the methodological and analysis choices of this study. Although definitions of discourse are drawn from work by James Gee (2014), methodological and analysis choices are drawn from discourse analysis (Gee, 2014) and Critical Discourse Analysis (CDA) 
(Fairclough, 2010). Together, concepts and tools from these theories enable me to answer my research questions.

As stated previously, Gee (2014) defined discourse as language-in-use and Discourse as the combination of discourse and "non-language stuff." Additionally, Gee (2014) suggested that discourse analysis should be critical because "language itself is...political" (p. 9). From this idea that language is political emerges another branch of discourse analysis, CDA, introduced by Fairclough (2010). The application of CDA may then lead to insights of power dynamics and representations within the classroom. Thus, a CDA of curriculum and teacher discourse can support our understanding of how schools/teaching/learning are connected to larger systems of power.

\section{Critical Discourse Analysis}

CDA is not limited to analysis of texts or speech, but is part of a larger system of analysis, which includes discourse and components of social justice (Fairclough, 2010). Additionally, CDA addresses "social wrongs in their discursive aspects and possible ways of righting or mitigating them" (Fairclough, 2010, p. 11). Similar to Gee (2014), Fairclough (2010) separated language into genre (ways of interacting), discourse (ways of representing), and style (ways of being). Genre includes "structures such as turn-taking/interruptions" (e.g., topic, cohesion, and intertextuality); discourse "constructs ideas about the world within the interactional space" (e.g., information/theme, lexicalization/pronouns, and exclusion); and style includes "positions or identities" (e.g., voice, modality, and mood) (Rogers \& Wetzel, 2014). In order to explore genre, discourse, and style on a microlevel, I adapted guidelines from CDA (Rogers \& Wetzel, 2014). I further elaborate on the specific tools used for analysis in my data analysis section. 


\section{Gender Schema Theory}

Although discourse analysis provides a framework for methodological and analysis choices, gender schema theory provides a framework to couple a discourse analysis with a feminist analysis and position the study of a classroom within a broader society. Even though gender has sometimes been used synonymously with biological sex, in this study, the term gender will only be used to refer to the socially constructed view of girls and boys. Although the traditional view of gender in the United States is limited to girls and boys, I recognize there are growing numbers of individuals who publicly identify with a gender separate from the traditional girl or boy, if they identify as a specific gender at all. However, I will use the terms girl and boy to denote the socially constructed view of female and male rather than the biological sex. Throughout the literature review, the terms female and male may be used to reflect the terminology in those studies and do not reflect the definition of gender I have just described.

In order to connect teacher perception and curriculum $\mathrm{D} /$ discourses to the formation of gender schema, I rely on Bem's (1993) gender schema theory. Because I elaborate on the history of this theory in Section III, I will only provide a brief explanation of the theory here. Gender schema theory provides two assumptions for how young children construct their own understanding of gender:

(1) There are gender lenses embedded in cultural discourse and social practice that are internalized by the developing child; and (2) Once these gender lenses have been internalized, they predispose the child, and later the adult, to construct an identity that is consistent with them (Bem, 1993, pp. 138-139).

$\mathrm{D} /$ discourse is related to gender schema theory because cultural discourse is the avenue through which cultured representations are communicated and subsequently contribute to larger gendered 
Discourses in society. Bem's (1993) gender lenses become internalized through enculturation, which is a process where cultural lenses are transferred to the individual and can be expanded beyond gender lenses.

\section{Design of the Study}

Because the focus of this study is to critically explore the intended curriculum and teacher perceptions through discourse of the school-intended curriculum and kindergarten teachers while they describe how they have taught or would teach a lesson from the curriculum and address and introduce equity in their classroom, this is a discourse study using qualitative methods. The following is a description of the setting and participants, data collection methods, and data analysis methods. Data collection and data analysis methods are separated by research question for clarity. Because I was the only person analyzing the data, I detail how I constructed interpretations using various linguistic, sociolinguistic, and discourse tools.

\section{Setting and Participants}

This study was conducted with participants who teach or who have taught kindergarten on the campus of a private school in the Midwest. The institution has a relatively small population of fewer than 400 students and fewer than 50 faculty members. This organization serves students in junior kindergarten through twelfth grade. The school is tuition-based, and is the only independent, non-parochial school in the community. The participants in this study are the two current kindergarten teachers and two former kindergarten teachers who now work in other positions at the organization.

After receiving approval from the International Review Board (IRB) at my institution, I shared a post about my research on social media, and colleagues and friends shared that post with potential participants. Of the four participants, I had a professional relationship with three 
participants prior to the study. I asked the fourth participant if she would participate in the study after meeting her through summer school at the organization. Each participant has been assigned a pseudonym to protect their confidentiality (Merriam \& Tisdell, 2016).

All of my participants identify as females. Mrs. Smith, Mrs. Johnson, and Mrs. Cooper are all veteran teachers who have at least 16 years of teaching experience. All of these participants have taught kindergarten for at least 8 years or more in both private and publicschool settings. Mrs. Wilson is a younger teacher who has less than 5 years of teaching experience, but has worked in both private and public-school settings, with only some of those years in kindergarten. I will describe the participants in more detail in Section II of this dissertation.

I chose to study kindergarten math materials and kindergarten teachers for two reasons: (1) a recent review of mathematics research literature stated that the majority of mathematics research is conducted with participants between grades 1 through 12, and measurable differences in attitudes and beliefs between girls and boys emerge by first grade (Lubienski \& Ganley, 2017), and (2) gender schema theory suggests young children construct their understanding of gender through cultural discourse and social practices (Bem, 1993). If measurable differences in attitudes and beliefs about math between girls and boys emerge by first grade, then it is reasonable to assume that something happens before first grade, possibly kindergarten, that shapes the formation of these beliefs and attitudes. Therefore, I have chosen kindergarten for this setting because there may be factors that influence the mathematical beliefs of students before first grade and young children, including kindergarteners, are continuing to construct their understanding of gender. 
In order to study the school-intended curriculum, I have chosen to collect data from the Everyday Mathematics kindergarten curriculum. I have chosen this curriculum for two reasons: (1) it is the math curriculum used at the setting, and (2) according to the Everyday Mathematics website, this curriculum is used in about 220,000 classrooms across the United States (The University of Chicago Mathematics Project, n.d). Additionally, this curriculum is a researchbased curriculum, developed by "mathematicians, mathematics educators, classroom teachers, and experienced mathematics textbook writers and editors" (The University of Chicago Mathematics Project, n.d.). Because this curriculum is research-based and developed by the University of Chicago School Mathematics Project, I expect this to be a model example of what an inclusive, carefully developed curriculum looks like. Now, I will detail what specific data were collected.

\section{Data Collection}

The first research question in this study focused on the math curriculum, the intended curriculum at the study site: How does the Everyday Mathematics kindergarten curriculum and supplemental curriculum materials position and write about girls in comparison to boys? The second research question focused on teacher perception and discourse: How do teachers position and describe girls in comparison to boys when discussing their beliefs about mathematics instruction and how they teach? I collected data from the teacher participants and the intended curriculum in order to answer each research question.

\section{First Research Question: Data from the School-intended Curriculum}

I collected textual data from the school intended curriculum, which included several resources. I explored the kindergarten Everyday Mathematics teacher manual (The University of Chicago School Mathematics Project (UCSMP), 2012d), math masters workbook (The 
University of Chicago School Mathematics Project (UCSMP), 2012b), activity cards (The University of Chicago School Mathematics Project (UCSMP), 2012a), and student workbook (The University of Chicago School Mathematics Project (UCSMP), 2012c). I chose to explore these resources because these are the curricular pieces most seen and utilized by the teacher and students; therefore, they may have the most influence on how teachers and students view girls and boys in relation to mathematics and mathematical tasks. The Everyday Mathematics teacher manual (UCSMP, 2012d) is a resource that teachers may use to guide their everyday instruction. This resource includes guidelines for pacing, instructional choices, and extra practice and enrichment opportunities.

The other three resources are recommended for use in sections A and B of most lessons (UCSMP, 2012d). Section A in the Everyday Mathematics teacher manual is called Core Activities - the "main instruction for the activity. New content is introduced and previously covered content is revisited" (UCSMP, 2012d, p. xii). Section B is called Teaching Options, which "includes activities to meet individual and classroom needs throughout the kindergarten day. Teaching Options include English Language Learner support, Cross-Curricular Connections, Centers, Technology, and Readiness, Enrichment, and Extra Practice activities" (UCSMP, 2012d, p. xiii). The math masters pages (UCSMP, 2012b), student workbook (UCSMP, 2012c), and center activity cards (UCSMP, 2012a) are used during the Teaching Options portion of the lesson.

When collecting data, I explored every page of the math masters workbook (UCSMP, 2012b), activity cards (UCSMP, 2012a), and student workbook (UCSMP, 2012c). When examining the teacher manual (UCSMP, 2012d), I collected data from the lesson pages and section projects. I limited my collection to lessons and projects because they are the pages most 
likely seen and used by the teacher and are the least repetitive. The section opener pages and the reference areas are repetitive and less likely to be read regularly. I did not collect data from the early childhood teacher's reference manual or the minute math booklet, both supplemental materials. I did not collect data from the early childhood teacher's manual because it was not referenced in the teacher manual (UCSMP, 2012d). Although the minute math resource is recommended for use in some lessons, I was unable to find a copy of the 2012 edition that would correspond with the other materials. Therefore, in order to answer my two research questions, I analyzed data from teacher interviews and the kindergarten Everyday Mathematics curriculum and supplemental curriculum materials (See Table 1.1).

\section{Table 1. 1}

Summary of Collected Data

Research Questions Data: Curriculum

\begin{tabular}{|c|c|c|c|c|}
\hline $\begin{array}{l}\text { How does the Everyday } \\
\text { Mathematics kindergarten } \\
\text { curriculum and supplemental } \\
\text { curriculum materials position } \\
\text { and write about girls in } \\
\text { comparison to boys? }\end{array}$ & $\begin{array}{l}\text { Teacher } \\
\text { Manual }\end{array}$ & $\begin{array}{l}\text { Math Master } \\
\text { Workbook }\end{array}$ & $\begin{array}{c}\text { Student } \\
\text { Workbook }\end{array}$ & $\begin{array}{c}\text { Activity } \\
\text { Cards }\end{array}$ \\
\hline How do teachers describe girls & \multicolumn{4}{|c|}{ Data: Interviews } \\
\hline $\begin{array}{l}\text { their beliefs about mathematics } \\
\text { instruction and equity in the } \\
\text { kindergarten classroom? }\end{array}$ & Ms. Smith & Ms. Johnson & Ms. Cooper & Ms. Wilson \\
\hline
\end{tabular}

Second Research Question: Data from Kindergarten Teachers

Before each semi-structured interview, I provided participants with an informed consent describing the study, risks and benefits of participation. I developed and utilized an interview protocol for each interview (See Appendix A). The interview protocol was split into two interviews, the first designed to familiarize the participant and researcher and the second to discuss a specific math lesson and discuss stereotypes and equity in the math classroom. Two 
participants were interviewed using the two-interview protocol. Two participants were interviewed only once each. In these cases, they answered questions for both sections of the interview in one sitting. Each interview varied in time-length, ranging from 25 minutes to about 80 minutes. The interviews took place via Zoom because they were conducted during the Covid19 pandemic.

\section{Data Analysis}

Like the data collection section, this section is organized by research question. I detail the data analysis methods used for each research question. Although I used counts in my data analysis, my study is a qualitative study. The qualitative methodology includes discourse analysis because according to Gee (2014) "discourse analysis can illuminate problems and controversies in the world" (p. 10). I analyzed the data by conducting a Critical Discourse Analysis (CDA) of a portion of the interview transcripts and the curricular materials. In order to conduct a CDA, I adapted guidelines and strategies suggested by Rogers and Wetzel (2014) and Gee (2014) .

\section{First Research Question: Analysis of Intended Curriculum}

In order to answer my first research question, I examined text and illustrations in the following resources: the kindergarten Everyday Mathematics teacher manual (UCSMP, 2012d), math masters workbook (UCSMP, 2012b), activity cards (UCSMP, 2012a), student workbook (UCSMP, 2012c), and picture books recommended during the lessons (See Table 1.2). For the purposes of this study, any references to "curriculum" included the aforementioned Everyday Mathematics texts.

\section{Table 1.2}

\section{Details of Analyzed Curriculum Resources}

Teacher and/or Student Analyzed Resource Number of Pages or Units Resource 


\begin{tabular}{ccc}
\hline Everyday Mathematics teacher & 8 units (128 lessons) and 8 & Teacher \\
manual & Projects & Teacher and Student \\
math masters workbook & 143 & Teacher and Student \\
activity cards & 38 & Student \\
student workbook & 36 & \\
\hline
\end{tabular}

1. Count of Gendered and Non-gendered Figures in Text. After an initial read of the curriculum, I counted all text representations of gendered figures. In text format, I determined whether or not a figure was represented as a girl or boy by examining pronouns and proper nouns. All uses of she and her were coded as girl and all uses of he and him were coded as boy. If a figure was named, then I coded as girl if the name was typically feminine in its native language and boy if the name was typically masculine in its native language. I determined the gender of English-sounding names using my background knowledge of feminine and masculine names in the United States and conducted Internet searches on baby name websites to determine the typical gender of names from other cultures or names in question (See Appendix B for full list of categorized names). The text includes gendered and non-gendered representations and the frequency of non-gendered representations is an important part of showing how girls and boys are represented; therefore, I also counted all gender-neutral or ambiguous pronouns and collective nouns as non-gendered and/or collective representations. Examples of these included: they, them, each, students, class, partners, groups, etc. (See Appendix C for full list).

2. Count of Gendered and Non-gendered Figures in Illustrations. Bohnsack (2009) stated, "Pictures provide orientation for our everyday practice on the quite elementary levels of understanding, learning, socialization and human development...” (p. 298). Therefore, I believed examination of illustrations was an important element to include in order to better understand "ways of being" and "ways of interacting" in the math resources. First, I counted gendered and non-gendered representations in illustrations. I used three codes during this process: girl, boy, 
and unsure. In illustrations, I identified girls by hair length, clothing choice (dress, skirt, bows, earrings, etc.), stereotypically feminine colors (pink, purple, etc.), stereotypically feminine patterns (butterflies, hearts, etc.), and in connection with pronouns and proper nouns in the text. I identified boys by hair length, clothing choices (shorts, pants, polo, etc.), stereotypically masculine colors (red, blue, orange, etc.), and in connection with pronouns and proper in the text. In the absence of gendered visuals, I coded the figure as unsure, which will be hereby referenced as gender neutral or gender ambiguous.

I counted representations individually. For example, if there were a group of children, I coded each child in the illustration instead of identifying the illustration as mostly feminine or mostly masculine. After counting girls, boys, and the collective/unsure, I determined the frequency of representations by summing the amount of coded girls, boys, and gender neutral and gender ambiguous in both text and illustrations. The frequency of representations does not include references to the recommended picture books, references to recommended song titles or game titles, or representations of adults. I did not include any references to the picture books because the character names and descriptions will be included in a separate study. I separated the counts of the songs and games because they often represented adults. Likewise, I separately counted representations of adults.

3. Beyond the Count: How Girls and Boys were Represented. From there, I examined how girls and boys were represented. In order to determine how girls and boys were represented, I adapted categories from a study of primary math texts in the U.K. by Northam (1982):

(a) part of setting, observed someone else, received help, (b) taught, explained processes to others, (c) made something, displayed a skill, (d) planned, initiated, invented, (e) performed, played tricks, boasted, (f) competed, (g) repeated or elaborated upon a process 
already learned, (h) cooperated, shared, helped, complied, (i) corrected another's behavior, ex., calm down, said Ann, and (j) identification, setting and solving of problems (p. 13, see Appendix D).

I adapted these categories by adding to the definitions and examples of the already defined categories and added a tenth category. I used the same codes for songs and games and adults. After categorizing the representations, I then summed the frequency of each category for girls, boys, collective/unsure in each category. Finally, I compared the frequencies to determine how girls were represented in comparison to how boys were represented. Not only was I able to compare how girls were represented in comparison to boys using the adapted categories mentioned previously, but I also examined the positioning and agency of girls and boys in illustrations. For example, I examined which figures were centered and/or active in the illustration.

After examining how girls were represented and positioned in comparison to boys in illustrations, I noticed a pattern that needed to be further investigated. Therefore, I then compared categories of representation for girls, boys, and gender-neutral or ambiguous using an adaptation of Northam's (1982) categories in each resource separately instead of across all four resources. I chose to disaggregate my findings by resource because the audiences differ between resources. The teacher, of course, sees the material in all four resources. She or he mostly likely views and or utilizes pages from the teacher manual (UCSMP, 2012d) and math masters workbook (UCSMP, 2012b) on days when math lessons are taught. Representations in those resources may subtly influence how the teacher views girls in comparison to boys in relation to mathematical learning and tasks. In contrast, students are most likely to see the center activity cards (UCSMP, 2012a), the student workbook (UCSMP, 2012c), and some pages from the math 
masters workbook (UCSMP, 2012b) on a regular basis (See Appendix D). I detail the frequency of those instances in my findings because the representations in those resources may influence how the students view girls in comparison to boys in relation to mathematical tasks and learning.

\section{Second Research Question: Teacher Perceptions of Gender and Equity}

In order to answer the second research question, I conducted a Critical Discourse Analysis (CDA) of a portion the interview transcripts. I chose to focus on the second portion of the interview for my CDA because that is the portion where participants discussed how they have taught or would teach the lesson from the Everyday Mathematics curriculum and how they introduce and reinforce equity in their classroom. In order to conduct this analysis, I adapted guidelines provided by Rogers and Wetzel (2014). The steps are as follows:

(1) develop research questions, (2) create a transcript, (3) segment the data into stanzas and clauses, (4) locate narrative structure, (5) survey linguistic features, line by line, (6) consult, develop theory, (7) organize coding of linguistic features using "orders of discourse." Take "order of discourse" separately and move through the data set, asking: How are "ways of interacting" (genre) expressed? What "ways of representing" (discourse) are represented? How are "ways of being" (style) communicated?, (8) locate patterns within and across "orders of discourse," especially places of overlap between all three domains, create summary charts to illustrate the analysis, (9) look across local, institutional, and societal levels of analysis to contextualize the discourse practices under examination, and (10) represent the findings in a way that balances between the micro and macro and makes connections to existing research (Rogers \& Wetzel, 2014, p. 139).

The research question connected with this data analysis is: How do teachers describe girls in comparison to boys and position them when discussing their beliefs about mathematics 
instruction and equity in the kindergarten classroom? In order to answer this question, I utilized the steps detailed in Rogers and Wetzel (2014) as a guide. For example, I segmented the interview transcripts into stanzas, but did not segment text from the curriculum into stanzas. I further adapted this tool by using some of the questions presented in the tool to guide my analysis rather than using all questions.

After interviewing participants, I used a transcription service to transcribe the interviews. Then, I examined the transcripts more closely, adjusting the transcripts as I relistened to interviews and separating the participants' responses into stanzas and clauses. I segmented the transcripts into stanzas and clauses using Gee's (2014) Stanza Tool as guidance, meaning I segmented the narrative into blocks of ideas. By segmenting the narrative in this way, I organized the ideas through my interpretation. After I segmented the transcripts into stanzas and clauses, I classified my analysis strategy as a combination of narrative and structural analysis. I chose to conduct a narrative and structural analysis because I wanted to examine both what was said among the interviewees and how the participants responded to questions. For example, I examined placement of proper nouns and pronouns in sentences, word choice in connection with gendered individuals, and inclusive and exclusive language.

I used a deductive method to code the transcripts and the approach detailed previously, which covered steps 5 through the first part of step 8 from Rogers and Wetzel (2014). For example, I coded mentions of girls and/or boys as girls, boys, or both and stories of inclusion or exclusion based on gender as gender segregation or gender desegregation. After initial coding, I consulted previous studies of femininity and masculinity, and examined transcripts for adjectives and nouns that were gendered. For example, if a participant mentioned a boy as good at math or a girl as good at coloring, I coded those instances as stereotypically feminine or stereotypically 
masculine. Likewise, I coded instances that countered stereotypical descriptions and nouns as non-stereotypically feminine or masculine.

In order to organize the coding of linguistic features into a CDA framework, I explored each transcript using questions provided by Rogers and Wetzel (2014) (See Appendix E). I examined each stanza, asking questions such as, "What information is foregrounded by being in the theme position?"; "Which pronouns are used and where?"; and "Are participants agents or recipients of actions?" Asking these questions enabled me to position linguistic features such as pronoun usage within "ways of representing," a component of CDA. Finally, as I examined the interviews, I added codes as I noticed patterns within and among interview responses. After coding the transcripts and organizing linguistic features within a CDA framework, I created graphs, tables and summary charts to illustrate the analysis.

\section{Making Sense of all Data}

Finally, in order to make sense of how curriculum and teacher discourse work together to influence how young children form their understanding of gender and gender roles, specifically in connection to math, I rely on previously published literature and Bem's (1993) gender schema theory. Because young children form their understanding of gender through discourse (Bem, 1993) and often through text (Scardina, 1972), gendered discourses may lead adults to perpetuate gendered discourses through their resources and classroom discourse (See Figure 1.1). The current study helps us better understand the messages teachers and curriculum may be conveying to kindergarteners, but it does not help us understand how kindergarteners are impacted by those messages.

\section{Figure 1. 1}

Formation of Gender Schema 


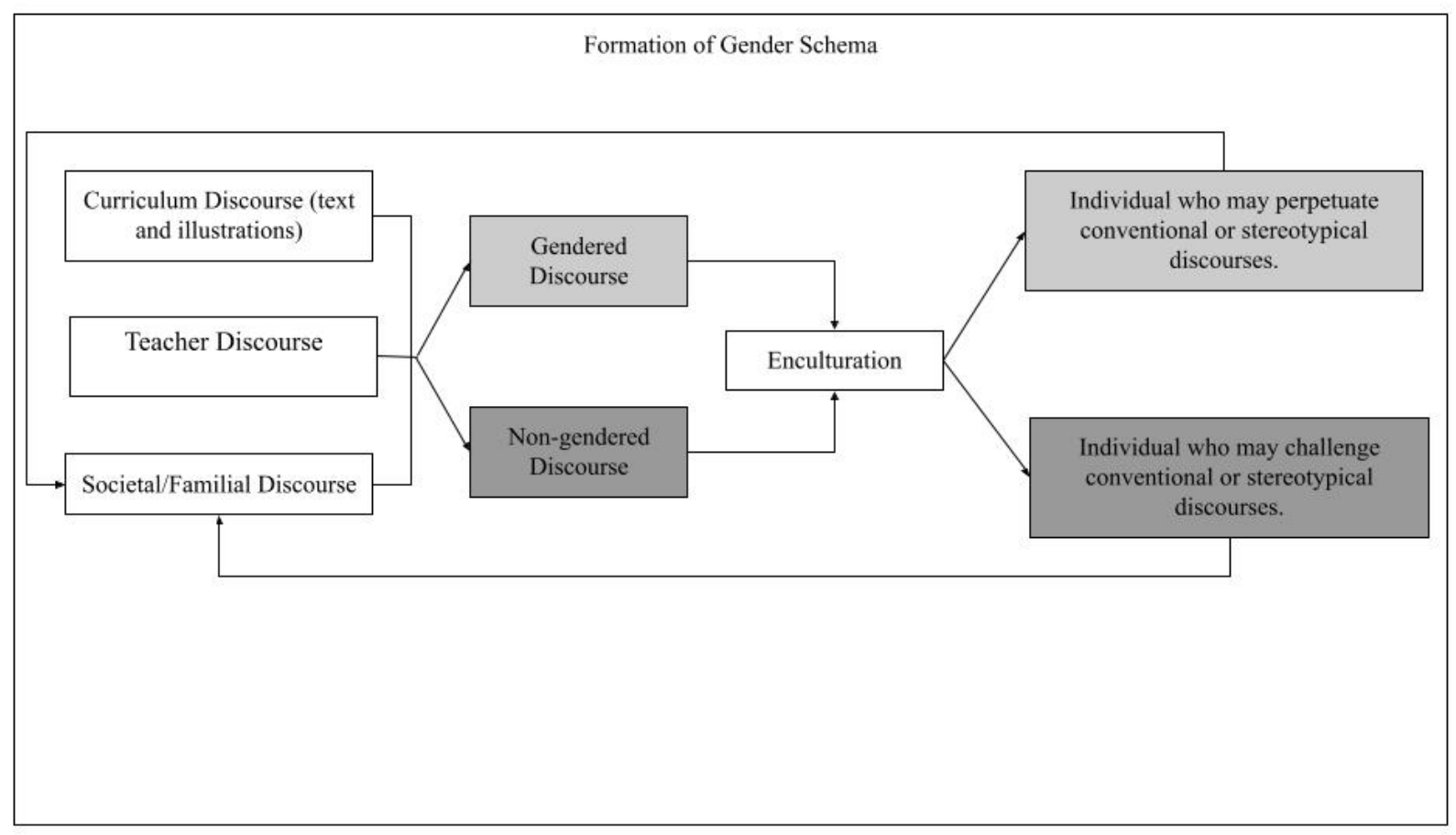

Note. Developed by the author after reading Bem, 1993.

This cycle of gendered discourses may be learned and repeated both in the classroom and the outside world. Therefore, I examined how teacher discourse connects with classroom resources to influence kindergartener's understanding of gender and gender roles as they pertain to math.

\section{Limitations and Assumptions}

Qualitative research is inherently subjective as the researcher is constructing meaning from observations, interviews, and other data points (Merriam \& Tisdell, 2016). Because this is a qualitative discourse study with few participants, there are limitations. Discourse analysis is subjective and I recognize my positionalities shape my interpretation; therefore, there may be challenges to the ethics, trustworthiness, validity, and reliability in this study. In order to address those challenges, I have provided a detailed statement of positionality, limitations stemming from my positionality and chosen methodologies, and how I addressed those limitations. Finally, I have described the assumptions underpinning this study. 


\section{Statement of Positionality: Ethics and Trustworthiness}

I do not believe individuals can completely remove themselves or their beliefs from their interpretation and work. In order to conduct an ethical, trustworthy, reliable, and valid qualitative study, I believe it is important to disclose the positionalities that shape my interpretations and share my connection to the participant teachers. It is important to note that I am a white woman who self-identifies as a feminist. I taught in an elementary school similar to the study site for 7 years and informally reflected on my interactions with students daily. I formally reflected on my interactions through written self-evaluations of my teaching every 3 years and occasionally during teacher work-days. I have been an advocate for equitable treatment of students, especially girls, in my classroom and in my school.

I believe my own experience with math instruction and my growth as a math instructor have shaped my beliefs and perceptions. Like so many girls, I felt confident in my math abilities as an elementary student, but my interest and ability greatly waned throughout middle and high school. I avoided taking higher level math courses in college even though I now believe I was capable of doing well in those classes. When I first interviewed for my fifth grade teaching position, I revealed to administration that I was least confident teaching math, but that because of my lack of confidence, I knew I would work harder to master teaching math than any other subject. By my last year of teaching in fifth grade, I favorited math and looked forward to teaching it every day. My reignited passion for math inspired me to pass that passion along to all of my students, which is when I noticed such a difference between my treatment of the girls and boys in my classes.

In my practice as an educator and beyond, I often notice subtle and explicit gender inequalities in media, books, and social interactions. I have not been as intentional at noticing 
gender inequities where boys are the recipients of gender bias. Through this research, I have made it a point to become more intentional when examining gender bias and practice examining bias against boys more closely. I believe this increase in intentionality has influenced my analysis in this study and makes it more ethical and trustworthy.

Finally, I would like to disclose that I have a professional relationship with three of the four participants in this study. I have had many conversations about education with those participants over several years. Not only do I know those participants well, but I continue to have close ties with families and students who belong to the organization in this study. My relationship with some of the participants most likely influenced our interactions.

\section{Validity}

Gee (2014) states that "a discourse analysis is itself an interpretation, an interpretation of the interpretative work people have done in specific contexts" (p. 141); therefore, the validity of studies utilizing discourse analysis methodologies may come into question. According to Gee (2014), validity for any discourse analysis consists of four elements: convergence, agreement, coverage, and linguistic details. The validity of my study relies mostly on coverage and linguistic detail.

Gee (2014) described how coverage increases the validity of a study: "The analysis is more valid the more it can be applied to related sorts of data. This includes being able to make sense of what has come before and after the situation being analyzed and being able to predict the sorts of things that might happen in related sorts of situations" (pp. 142-143). In my study, I based my interpretation of what is feminine and masculine on descriptions from my understanding as a cultural native, which aligned with interpretations from previous studies of gender representations (Diekman \& Murnen, 2004). I have provided the examples I used to 
inform my interpretations of gender and excerpts from the texts and interviews in order to allow the reader to trace my interpretation and form their own interpretation.

Gee (2014) describes how attention to linguistic details increases the validity of a study:

The analysis is more valid the more it is tightly tied to details of linguistic structure...Part of what makes a discourse analysis valid, then, is that the analyst is able to argue that the communicative functions being uncovered in the analysis are linked to grammatical devices that manifestly can and do serve these functions, according to the judgements of "native speakers" of the social languages involved and the analyses of linguists (p. 143). By conducting a CDA, I have attempted to closely tie grammatical structures and linguistic features to "ways of interacting," "ways of being," and "ways of representing." In addition to validity, a study must be reliable.

\section{Reliability}

According to Merriam and Tisdell (2015), "reliability refers to the extent to which research findings can be replicated" (p. 250). To increase the level of reliability in this study, I have used tools adapted from other studies to guide analysis and provide those tools in the appendices for the reader. Finally, I have included the interview protocol used in all interviews in the appendices.

\section{Gender as the Focus}

A limitation of this study is that it focuses on gender with little consideration for the multiple identities humans possess. Race or ethnicity, culture, class, and sexuality all shape how we perceive, are perceived, interact, and are interacted with in different spaces. Class and racial diversity were brought up in participant interviews. Likewise, there is racial and ethnic diversity in the names and illustrations in the Everyday Mathematics curriculum. In the findings, I did 
point out considerations for race; however, for the purposes of this study, I have chosen to limit the scope of my discussion to interpretations of gender. An intersectional analysis of the data in this study could be performed in the future.

\section{Assumptions}

In addition to limitations, I also have assumptions related to this topic of study. According to Simon and Goes (2017), assumptions are "things that are somewhat out of your control, but if they disappear your study would become irrelevant" (p. 292). One assumption is that society will continue to believe that all students should receive equitable math instruction through teaching and text materials. Another assumption is that girls and boys are treated differently in Western society on the basis of their gender. Finally, this dissertation is based in the assumption that teacher beliefs and discourse during the interview relate to their teaching in

the classroom to some degree; thereby, their conversations with me provide insight into how they teach. That assumption will be further explored in Section III. If any of these assumptions cease to exist, then this study would be irrelevant.

\section{Significance of the Study}

This study is significant because it begins to fill a gap in early-childhood mathematics research. As stated previously, most research on gender and mathematics does not include kindergarten curriculum, teachers, or students (Lubienski \& Ganley, 2017). According to Bem's (1993) gender schema theory, children's understanding of gender can be influenced in early childhood and this study may illuminate what messages kindergartners are receiving about gender and further our understanding of how children with a more flexible understanding of gender become rigid in their definitions within a few years of kindergarten. There are clear differences in attitudes towards math by first grade, and an exploration into the messages 
children receive through teacher discourse and curriculum discourse may help us better understand how those disparities come to exist.

Not only will this study contribute to the existing literature base but could also contribute to the practice of educational leaders and policy writers such as instructional leaders or department chairs who choose textbooks and write policies at the current organization. Beyond the community, this curriculum is used in over 200,000 classrooms each year (The University of Chicago School Mathematics Project, n.d.). Although the analyzed curriculum in this study is an older edition of the Everyday Mathematics curriculum, I argue that the 2012 edition is still widely used as the Everyday Mathematics website continues to offer virtual worksheets connected with that edition in addition to virtual worksheets and activities connected to the 2016 or most current edition. Resources for other editions are not provided through their website. Therefore, a close examination of this text is necessary due to the range of learners who may be using this text every day.

Because the participants all work within the same organization, this study could contribute to the practice of educational leaders at all levels in that organization. First of all, the findings from this study could influence the teachers in this study by affirming or challenging the assumptions they hold regarding gender and math. If their assumptions are challenged, the teachers may decide to make modifications in their practice. This study may create opportunities to explore how math is being taught in other classrooms. Therefore, this study could potentially inform the practice of the participant teachers, other teachers, and administration/policy makers.

\section{Summary}

Inequitable representations of girls and boys in text coupled with the continued stereotyped perceptions of teachers contribute to short and long-term negative consequences for 
students, especially girls (Sadker \& Zittleman, 2009). Teachers and authors contribute to inequitable treatment of students through the use of language (Rogers \& Wetzel, 2014). Because language contributes to ways of being, ways of interacting, and ways of representing (Gee, 2014), I have explored teacher perceptions of equity in the math classroom through interviews and the discourse of a kindergarten math curriculum in order to make sense of the discourse in those spaces. I have used research questions to guide the data I collected and how I interpreted speech, interactions, text, and illustrations. Finally, I explored connections between existing literature and the findings from this study, enabling me to provide implications for future research, recommendations in practice within classrooms at the study site, and modifications to policy related to textbook selection within the organization. 


\section{Section Two: An Organizational and Leadership Analysis}

After teaching fifth grade for 7 years, I had the opportunity to substitute teach in the same school. Within the span of 3 days, I took on the role as a junior kindergarten teacher one day and a high school geometry teacher another day. Teaching pre-school aged children is very different from teaching high schoolers, and both are different from teaching pre-teenagers. As a leader of children, I had to draw on my knowledge of leadership theory and my prior experiences in the classroom to become a teacher who worked in a developmentally appropriate way with the students I was tasked with teaching. Likewise, I transitioned between two different divisions: lower and middle/upper school. Those divisions are led by different administrators and the expectations and duties required of teachers in those divisions differ. Even though both divisions are within the same organization, and in fact in the same building, there are differences in the structure and expectations within those divisions. Understanding the differences within the organization is integral to performing tasks as a teacher and substitute teacher.

Context matters. The context matters when taking leadership style into account, and it matters when making choices within an organizational setting. Just as the context mattered for how I taught in different grade levels and divisions, context matters when conducting research. In order to understand how the setting and the participants of the current study were chosen it is important to know the history of the organization, how the organization functions, who the adult participants are as leaders in their classrooms and as women who teach math, and why research should be conducted in this setting.

\section{History of Organization}

In the mid-1990s, a group of families came together to design a new educational opportunity in the Midwest. Not long after its conception, Midwest School, a pseudonym used to 
protect the confidentiality of the school and faculty, opened towards the end of the 1990s, offering grades six through nine. At its start, the organization enrolled 55 students and employed 16 faculty members (Midwest School, 2019). Each year, a grade was added as classes advanced. By the early 2000s, the school expanded to include junior kindergarten (JK) through fifth grade. As enrollment increased, the school grew larger than its space and moved to its current location around 2010. At this location, all students in grades JK through 12 were united under one roof. More than 20 years later, the school now houses over 350 students spread across three divisions: lower (Junior Kindergarten-5), middle (6-8), and upper (9-12), and employs about 40 full-time faculty, 11 part-time faculty, and numerous staff members (Midwest School, 2019). Although young, this school, founded as an alternative to the parochial and public schools in the area, has grown to become a competitive educational choice for families in the area.

Over the years, the mission of the school has been modified to fit the current needs and aspirations of the school. The current mission details how the school and faculty are dedicated to preparing young minds for a global society, while taking into account a child's physical, emotional, and academic well-being. In addition to its mission, the school emphasizes nine philosophical principles. These principles focus on a commitment to the entire school, personalized learning, conceptual learning, development of the whole child, attention to emotional and physical health of students, development of a trusting culture, creation of a teacher/parent partnership, creating an inclusive environment, and modeling life-long learning (Midwest School, 2019). In order to meet these principles, the school has often afforded faculty much pedagogical freedom. According to a leader in the math department, denoted as Ms. Lovelace in personal communication to protect the confidentiality of the participant, the Lower School did not have a standard curriculum across grades for multiple subjects when she began 
working at the school. Now, 8 years later, most faculty members follow a standard curriculum for most subjects, with options to modify based on what they see as best practice for their students.

For at least the past 9 years, the Lower School has used the Everyday Mathematics curriculum as its main source for mathematics instruction (M. Lovelace, personal communication, September 19, 2019). Even though the curriculum has been updated with newer editions over the years, the math department has had few conversations about using alternative math curriculum or how this curriculum was chosen. Around 2015, this leader in the math department started a conversation about using Everyday Mathematics after hearing that Lower School faculty were concerned about the scope and sequence of this curriculum. From that discussion, the leader and faculty realized that faculty had never been trained to use this curriculum and were not implementing it as intended; therefore, Ms. Lovelace arranged for faculty members to receive professional development and training using Everyday Mathematics. Although faculty discussed transitioning to another math curriculum, the conversation always centered around the pacing and resources in the curriculum. To her knowledge, Ms. Lovelace said that she does not believe faculty have ever looked critically at the math texts or discussed equitable math instruction (M. Lovelace, personal communication, September 19, 2019).

In the spring of 2016, one faculty member, given the pseudonym Ms. Tyler to protect her confidentiality, wrote a textbook selection policy that was added to the school's policies (M. Tyler, personal communication, September 19, 2019). The textbook selection policy does not include any consideration for gender representation when selecting a textbook. There is only one statement that addresses equity and diversity in the process and it is located in the "Objectives of Selection" section: "To provide materials representative of the many religious, ethnic, and 
cultural groups that contribute to our national heritage and the world community" (Midwest

School, n.d., p. 1). In order to ensure equity in representation, adding language that includes gender representation and other historically underrepresented and/or marginalized identities as an integral part of the textbook selection process seems necessary, but has yet to be included.

Even though there has been a textbook selection policy at the school since 2016, to Ms. Lovelace's knowledge, no department has followed this policy when selecting a text. Over the past 4 years, multiple texts and curricula have been replaced in all divisions of the school, but no textbook selection committee has been formed to research options. Usually, the department chair in that subject will select a text. In some cases, teachers have asked for input from administrators, but some administrators prefer not to be involved in the selection process (M. Lovelace, personal communication, September 19, 2019). In order to understand how teachers, administrators, and policy writers work together to create policies and make decisions, it is necessary to provide a structural analysis of the organization.

\section{Organizational Analysis}

The current study explores the discourse in the kindergarten math curriculum and discourse of kindergarten math teachers. The following is a structural analysis of the organization. The structure of the organization details how the parts work together and the delineation of decision-making power.

\section{Structural Framework}

This organization is most similar to Mintzberg's (1979) professional bureaucracy in divisionalized form as presented in Bolman and Deal (2013) (See Figure 2.1). At the top of the hierarchy is the strategic apex (Mintzberg, 1979) that includes the Head of School (HOS) and Board. The technostructure and support staff are part of the administrative component and 
support the function of the organization at all levels (Bolman \& Deal, 2013). The technostructure (Mintzberg, 1979) includes the Director of Advancement, Business Manager, Director of Admissions and Marketing, Communications and Advancement Assistant, and Technology Specialist. The support staff (Mintzberg, 1979) includes the Learning Specialist, the Testing Coordinator, counselors, tutors, janitors, maintenance workers, security workers, lunch staff, the nurse, and secretaries.

\section{Figure 2. 1}

Structure of Organizational Setting

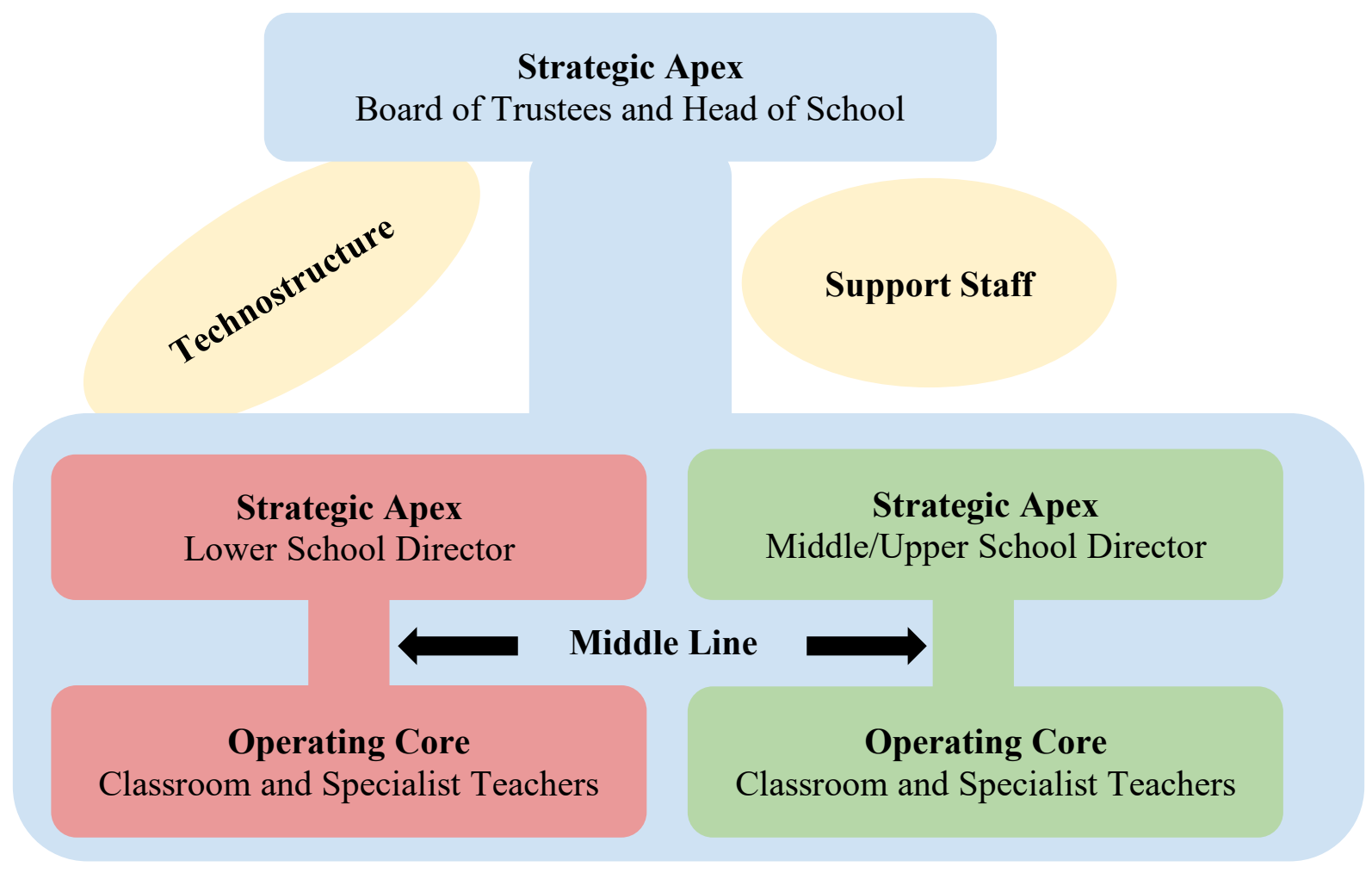

Note. Adapted from Mintzberg (1979, p. 393).

Because the organization is divisionalized, there are two hierarchies within the main hierarchy - the Lower School (elementary) and the Middle/Upper School (middle and high school). All members of the technostructure and support staff belong to both of these smaller hierarchies as well. At the top of the Lower School hierarchy is the Lower School (LS) Director 
and at the top of the Middle/Upper School hierarchy is the Middle/Upper School Director. The Department Chairs, who chair different subjects like social studies, math, and science, are part of the middle line (Mintzberg, 1979). Finally, all teachers and coaches are part of Mintzberg's (1979) operational core. All members work together to operate the JK through $12^{\text {th }}$ grade school.

\section{Vertical and Lateral Coordination}

The adult participants in this study are, or have been, kindergarten teachers in this organization. In order to protect their confidentiality, every participant has been given a pseudonym: Ms. Smith, Ms. Johnson, Ms. Cooper, and Ms. Wilson. As kindergarten teachers they have all been or currently are part of the operating core (Mintzberg, 1979) of the organization. As part of the operating core, kindergarten teachers coordinate vertically and laterally with colleagues and superiors (See Figure 2.2). Similar to the entire organization, the HOS is at the top of the hierarchy, with the LS Director as a subordinate of the HOS and as a superior to the teacher participants. Both the LS Director and Head of School do or have vertically coordinated with teacher participants. According to Bolman and Deal (2013), vertical coordination requires those at higher levels to coordinate and control the work of those at lower levels in the organization. Decisions and suggestions about curriculum and instruction often come from the LS Director and Head of School.

Teachers rotate between departments depending on curriculum goals and staffing each year. At least some of the participants have been part of the math department during their time in the organization, but not all of them. The Math Department Chair does not supervise the teacher participants, but in her role as department chair, she is positioned higher in the organization than the kindergarten teachers who are not department chairs; therefore, the Math Department Chair both vertically and laterally coordinates with the teacher participants. The Math Department 
Chair is positioned to make suggestions and minor decisions about curriculum and instruction through vertical coordination, but the teacher participants and others in the department are welcome to make suggestions that inform decisions through lateral coordination with the Math Department Chair. Figure 2.2 illustrates how the teacher participants coordinate with one another and other employees at the organization. Lateral coordination is less formal and more flexible than vertical coordination (Bolman \& Deal, 2013).

\section{Figure 2. 2}

\section{Coordination Map}

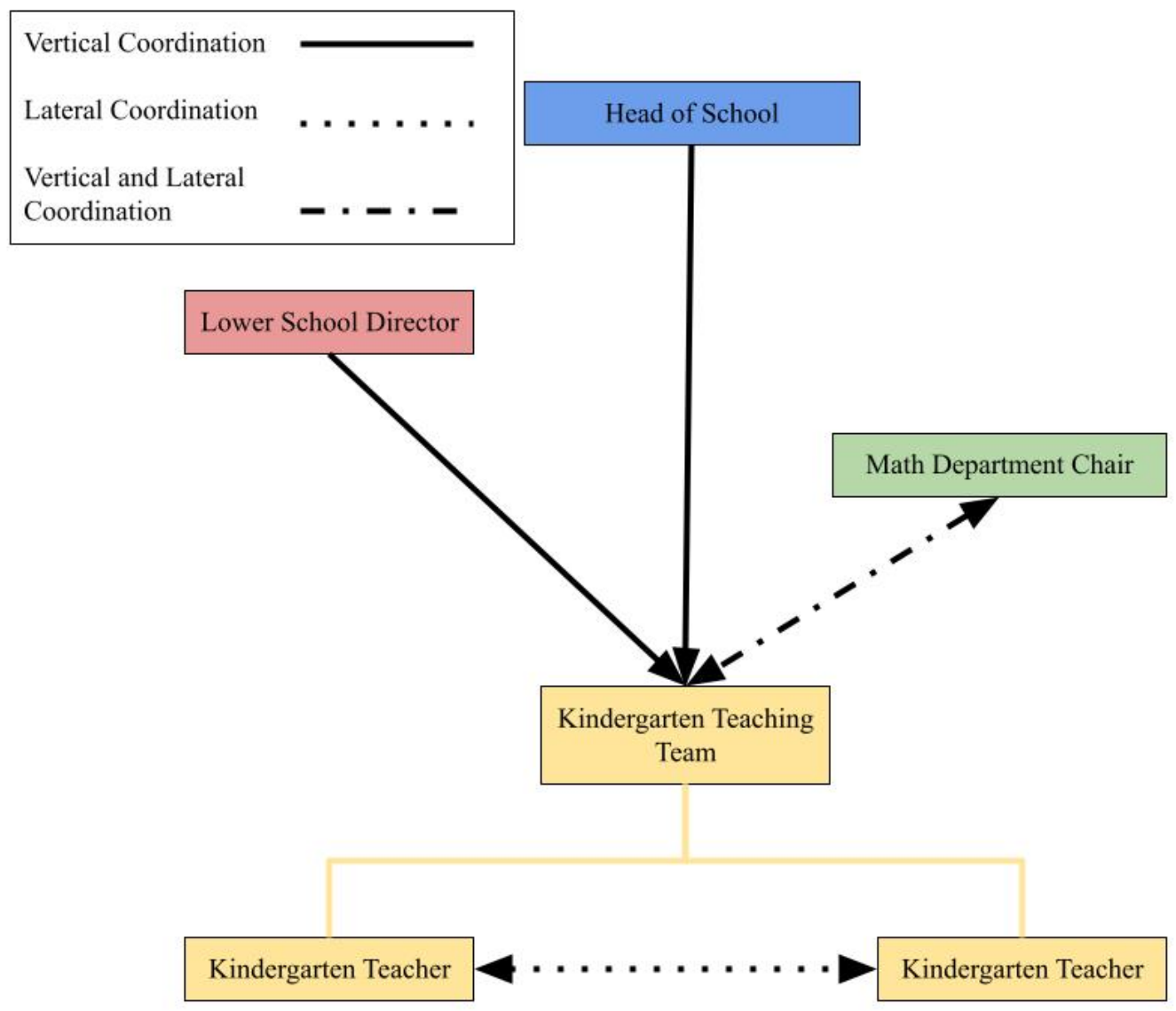

Note. Developed by the author after reading Bolman \& Deal, 2013. 
Although educational organizations are often hierarchical and include much vertical coordination, there are multiple opportunities for lateral coordination beyond faculty-led departments. Teachers laterally coordinate with their teaching partners and other colleagues frequently. A teaching partner is the teacher who teaches the other section of the same grade level. For example, in this study, the participant teachers have all taught one section of kindergarten, while coordinating with another kindergarten teacher in an adjacent room. Teaching partners do not co-teach within the same classroom, but they do coordinate planning in order to offer similar instruction throughout the year. The teacher participants have all worked closely with their teaching partners, often leaning on them for support with families and students. They make decisions about kindergarten curriculum and instruction daily.

Other types of lateral coordination come from small committees. Throughout the school year, faculty members can join various committees that are often convened to solve issues in the school. For example, as mentioned earlier, per the textbook selection policy (Midwest School, n.d.), a committee of administrators, department chairs, and faculty may be gathered to research and choose a new textbook. Even though there is a policy in place, department chairs have not always been required to follow the policy (M. Lovelace, personal communication, September 19, 2019). Structurally, the LS Director and/or HOS should be positioned to monitor whether or not a department chair is following policy when making decisions. Although teachers have some opportunity to impact what and how texts are used, the HOS, Division Directors, and Department Chairs are responsible for overseeing when, how, and if texts are being selected using the textbook selection policy. Additionally, they are responsible for observing how teachers implement the text through daily lessons. Although the structure allows for oversight, 
other factors impact the amount and frequency of oversight the Division Directors and HOS have over curriculum and instruction decisions.

\section{Structural Dilemmas}

The lack of communication that resulted in department chairs not using the textbook selection policy could be caused by a structural problem. Bolman and Deal (2013) stated that one common structural dilemma is "gap versus overlap" (p. 71). This dilemma occurs when "key responsibilities are not clearly assigned, and important tasks fall through the cracks" (p. 71). In the school, there seems to be much lateral coordination through meetings and committees, but no one has the role of connecting the information from lateral coordination across divisions or the school. Some schools employ a curriculum coordinator or assistant principal/directors for each division who are responsible for overseeing lateral coordination and connecting that coordination vertically. Because the school does not have a coordinator and has only one assistant director, this task would most likely be given to division directors; however, giving the task of overseeing the implementation of policies and keeping faculty accountable to the division directors presents another structural dilemma — underuse versus overload. Essentially, this dilemma occurs when faculty have too little work or are overwhelmed with tasks. Without more assistants or a coordinator, the division directors take on many tasks that would be delegated to other roles. Because they already take on more responsibilities than what might be expected if the school employed more assistants or coordinators, they are overloaded. The lack of communication most likely results from a combination of unclear responsibilities and overloaded division directors.

\section{Hierarchy in the Classroom}

In addition to the organizational hierarchy, teachers often experience a hierarchy within their own classroom. As a leader of children, the teacher participants are part of a classroom 
hierarchy that can be defined as "One Boss" (Bolman \& Deal, 2013, p. 99). In this arrangement, the teacher participants are at the top of the hierarchy and all their students are subordinates to them. They are the keepers of information and make nearly all of the decisions in their classrooms, especially in early/primary grades in the Lower School. In this structure, Bolman and Deal (2013) stated that "group members offer information to and communicate primarily with the official leader rather than with one another" (p. 99). While interviewing the teacher participants, three of them suggested that kindergarten students often look up to the teacher and will follow her lead. This structure has informed the way the teacher participants lead in their classrooms.

\section{Context for Participants}

Just as understanding the context for the organization is important to this study, so is the context for the participants. I will describe the background and experience of each participant. Then, I will detail how they perceived themselves as mathematicians and teachers of math. Delving into participants' backgrounds and perceptions concerning math are an important backdrop to this dissertation, as I interpreted how they approach gender, equity, and math through discourse analysis.

\section{Background of Participants' Educational Experience and Perceptions of Math and Gender}

As stated previously, I interviewed four participants—Ms. Smith, Ms. Johnson, Ms.

Cooper, and Ms. Wilson. All participants teach or have taught kindergarten at some point in their career at the study site. I will briefly describe the educational experience of each participant (See Table 2.1) before detailing her perceptions of math and gender. I believe it is important to understand how these participants perceive their own math ability, their ability to teach math, and their perceptions of stereotypes in math in tandem with their educational experiences. Their 
awareness of ability and stereotypes in combination with their educational experiences can influence how they analyzed a lesson from the Everyday Mathematics textbook (UCSMP, 2012d) and how they described equity in their classrooms.

\section{Table 2. 1}

Participant Overview

\begin{tabular}{ccccc}
\hline Participant & $\begin{array}{c}\text { Racial and } \\
\text { Gender Identity }\end{array}$ & $\begin{array}{c}\text { Veteran Status } \\
\text { Number of } \\
\text { Years in } \\
\text { Kindergarten }\end{array}$ & $\begin{array}{c}\text { Years using } \\
\text { Everyday } \\
\text { Mathematics } \\
\text { Curriculum }\end{array}$ \\
\hline Ms. Smith & white woman & Veteran Teacher & $>8$ & 8 \\
Ms. Johnson & white woman & Veteran Teacher & $>8$ & $18-19$ \\
Ms. Cooper & white woman & Veteran Teacher & $>8$ & 6 \\
Ms. Wilson & white woman & Non-veteran & $<5$ & 2 \\
& & Teacher & & \\
& & &
\end{tabular}

\section{Ms. Smith: Educational Background}

Ms. Smith is a veteran teacher who identifies as a white woman. She has taught for more than 16 years with experience in both private and public-school settings. Additionally, she has taught kindergarten for at least 8 years with teaching experiences in other elementary grades. She has led by example and believes her enthusiasm and love for learning transfer to her students. In an interview with her, she stated:

I think my kids can see that I love what I do, so no matter the subject area...I'm just an encourager to all the kids that are struggling...I know what I'm teaching so, um, you now, I can encourage that ability that they may or may not have.

Based upon my interview with Ms. Smith, one part of her leadership style aligns closely with the "One Boss" description detailed in Bolman and Deal (2013). She expressed that students would follow the expectations stated and modeled by the teacher because of their age. She did suggest there are "challenges along the way," but that "for the most part they're going to, at this age, they're going to do what you want them to do." Ms. Smith seems to be a teacher who leads by 
example, provides clear expectations, and expects that children will follow those expectations most of the time because they were set by the teacher.

\section{Ms. Smith: Perceptions of Math and Gender}

Ms. Smith considers her math ability to be average, especially when discussing higherlevel math. Math has never been a subject that "came easy" to her, but she "studied hard." Math was not her favorite subject as a student, but she clearly stated that "no one ever said [she] couldn't do it." She does not identify as a mathematician.

As a kindergarten math teacher, she is comfortable with the curriculum and content. She suggested that she may feel differently if she were teaching older students. Ms. Smith struggles most with differentiation of math instruction, especially for her higher-level students.

Differentiation of math instruction means modifying instruction to meet all students where they are in their learning instead of providing the exact same activities for all students for every lesson. She believes her strengths lie in how she presents the material. She made note of doing a "variety of activities," making it "fun [using] manipulatives [to] play games." As she said, "it's not all you know paper pencil stuff.” She equated the best parts of her math instruction with hands-on, fun activities that keep students engaged and working with concrete representations.

When questioned about stereotypes in math ability and interest, Ms. Smith was the only participant to mention stereotypes that included race. She believes common stereotypes of math suggest that students of "Asian descent have a higher-level math ability than someone else" and that "people think that boys are better." On more than one occasion, she mentioned that she believes that these stereotypical perceptions of math ability and interest are connected with a person's age or the generation in which they were raised. She stated that she recognizes that these stereotypes are present in society but doesn't "see them in [her] class" and "[hasn't] 
experienced it." She questioned whether her teenaged children would view these stereotypes the same way because they are in a different generation.

\section{Ms. Johnson: Educational Background}

Likewise, Ms. Johnson is also a veteran teacher who identifies as a white woman. She has taught for more than 16 years, with experience in both private and public-school settings. Additionally, she has taught kindergarten for at least 8 years, with teaching experiences in other grades and specialties. She does not currently teach kindergarten but has taken on another role in the same organization. Ms. Johnson also hinted at the power dynamics that come from Bolman and Deal's (2013) “One Boss” hierarchy. When giving advice to new teachers, she stated, "if you're a brand-new teacher, and you're going in the classroom, make sure you know, um, what you believe and how you believe and know that you're, you're such a huge influence on these children." This line suggests she believes that the teacher has a lot of power in her actions and words to influence the students in her classroom.

\section{Ms. Johnson: Perceptions of Math and Gender}

Ms. Johnson believes that "basic math comes pretty easy" to her, but that she has always "struggl[ed] to explain her process." She suggested that her own higher education experience shaped how she viewed her strengths and weaknesses as a math student. She values the explanation process over procedural-only instruction.

As a kindergarten math teacher, she felt "it's easy to teach" the content. Similar to Ms. Smith, Ms. Johnson mentioned she struggles most with differentiation of math instruction for her higher-level students. She always wanted to keep them "moving forward" but "that is a challenge." She made it clear that she values fun and engaging math lessons. Even if the content is not necessarily exciting, she mentioned that she is able to model enthusiasm in order to make 
an activity more enticing. She did this by creating cross-curricular experiences, focusing on the "why" behind learning a skill, and facilitating concrete, hands-on experiences. Ms. Johnson also mentioned not utilizing only paper-pencil methods in math instruction. She believes the concrete experiences she provided helped her students build connections between their lives and the content.

When questioned about stereotypes in math ability and interest, Ms. Johnson also mentioned that people think "males...tend to do better in math and science areas." She is the only participant to reference data, "surveys," as a reason why this stereotype exists and continues to be reproduced. However, she "beg[ed] to differ with [those surveys]." She supported her statement by expressing that her experience as a teacher show both girls and boys doing well in those areas. She did mention that "surveys support [the stereotype];" however, she questioned the sampling of surveys that support the stereotype stating that, "I don't know that they're surveying all, all students, like students that go to private schools, or students that are not attending public schools." Similar to Ms. Smith, she suggested that time and generations may influence perception of stereotypes in math. She "see[s] changes, changes for the better" and "think[s] it'll continue to change" as "you see more and more women out and showing themselves as scientists, as mathematicians, things like that, I think you're going to see more and more of that as, as we open ourselves up to it." Ms. Johnson continued to reinforce the idea that representation matters and positively influences the growth of girls in these fields. Finally, she echoed Ms. Smith's notion of hard work. Ms. Johnson suggested a "boot-strap mentality" in education where students can overcome their circumstances through hard work.

\section{Ms. Cooper: Educational Background}


Similar to Ms. Smith and Ms. Johnson, Ms. Cooper is a veteran teacher who identifies as a white woman. She has taught for more than 16 years with experience in both private and public-school settings. She has taught kindergarten for at least 8 years in addition to other educational experiences with elementary and middle school students. She does not currently teach kindergarten, but has taken on another role in the same organization. Similar to Ms. Smith and Ms. Johnson, Ms. Cooper also mentioned that her demeanor and excitement could easily be transferred to kindergarten students, reinforcing the power dynamics between the "One Boss" and the students - "You can convince them to get excited about anything." She also believes she was a strong influence on her students.

\section{Ms. Cooper: Perceptions of Math and Gender}

Unlike the other participants, Ms. Cooper considers her math ability to be "above average," stating that math was "always [her] favorite subject in school" and "continues to be [her] favorite subject to teach." She mentioned that she always received good grades in math and enjoys the challenge of it. Finally, she expressed how much she appreciates both the process and the reward of figuring out correct answers in math.

As a kindergarten math teacher, she felt she "was a strong math teacher." Similar to Ms. Johnson, Ms. Cooper discussed the importance of understanding math as a process rather than a set of procedures. She noted that she always tried to help "students understand that math is a process where it's a creative process, and you can think about it student to student in lots of different ways." Additionally, she felt that her organizational skills were a strength in her math teaching because she was able to facilitate station work on a regular basis. Station work includes creating and facilitating learning stations that might include games, identification of numbers, or

counting items that students rotate through. Ms. Cooper's challenges as a math teacher align with 
the challenges mentioned by Ms. Smith and Ms. Johnson. She described how most kindergarten students are not reading independently, so finding and creating work to enrich students who are ready for more challenge is difficult. Even though she felt that she was able to organize stations to help students review concepts at different levels, this continued to be challenging because students were not yet reading independently.

When questioned about stereotypes in math ability and interest, Ms. Cooper mentioned that girls may have more math anxiety and say, "they're not good at math." However, she quickly stated that both boys and girls feel that way and vocalize their anxieties when they aren't good at something. Similar to Ms. Johnson, she believes that society is "moving in a good direction though. And getting away from girls in particular, not feeling like they're good at math." She supported her thought by describing how she thinks there are more opportunities for women now than a few decades ago; however, she cited her own experiences as a former woman college student who loved math to show that idea did not apply to all women. In elementary and secondary school settings, Ms. Cooper believes that providing Science, Technology, Engineering, and Mathematics (STEM) opportunities for all students and showing that those activities are natural for both girls and boys are ways to influence students' perceptions of math ability and interest.

\section{Ms. Wilson: Educational Background}

Ms. Wilson is a newer teacher who identifies as a white woman. She has taught for fewer than 5 years with experience in both private and public-school settings. Additionally, she has taught kindergarten for 2 years. She has had teaching experience in other elementary grades. Unlike the other three participants, Ms. Wilson does not seem to reinforce the "One Boss" hierarchy in her classroom. Although she is the teacher of students, her answers to interview 
questions were student-centered and suggested more of a partnership or conversation with students rather than a one-way influence. The only time she touched on how she might influence students' math perceptions or abilities was if she did not know the material well. She connected her lack of knowledge with her students' struggle to understand a concept.

\section{Ms. Wilson: Perceptions of Math and Gender}

Similar to Ms. Smith, Ms. Wilson considers her math ability to be average. She mentioned that math was never a subject where she felt she excelled or possessed the most ability. Similar to Ms. Cooper, Ms. Wilson suggested that her grades impacted her perception of her own math ability. She "always did, like average on math" and compared herself to friends who "were great at math."

As a kindergarten math teacher, she is less confident teaching math than teaching other subjects, such as reading. Unlike the other participants, Ms. Wilson is not a veteran teacher and has not had consistent experience teaching in the same grade or with the same curriculum. She mentioned that she does not "feel like lessons for math come easily to [her] as they do like lessons for ELA (English Language Arts) or things like that." Some of the challenges she faces when teaching math are "making sure that like, [she] fully grasp[s] what [she] wants to teach and how [she] want[s] to teach it when it comes to math." Similar to Ms. Johnson, Ms. Wilson focused on building connections between math and her students' lives in her classroom. She considered this to be a strength of her teaching. She believes that by connecting math to their lives, students will be more engaged. Additionally, she also believes that including hands-on opportunities helps students understand and engage with math. Unlike the other participants who felt they were strong math teachers regardless of how they identified as a mathematician, Ms. Wilson believes that her perception of herself as a mathematician "goes hand in hand" with how 
she perceives her ability as a math teacher. However, she reframed her lack of confidence in her math ability as an opportunity to convey a growth mindset and acceptance of making mistakes to her students.

When questioned about stereotypes in math ability and interest, Ms. Wilson referenced older students she has taught:

I would say that one I see sometimes and I think I saw more when I taught older kids than younger kids was like boys being more into math than girls was one I definitely saw or yeah, just boys feeling more confident or like that more abilities in math sometimes even if that wasn't necessarily true.

Her observations align with what some researchers (e.g., Sadker \& Sadker, 1994) have observed in classrooms across the United States, boys feeling "more excited or more enjoying math or feeling more confident in math even if the girls in [the] class had like the same ability level as them." Similar to Ms. Johnson and Ms. Cooper, Ms. Wilson believes that representation of women in math or science roles influences the reproduction of this stereotype.

\section{Implications for Research}

There are a few implications for conducting research in this setting with the chosen participants. As stated previously, the textbook selection policy at the study site does not include any consideration for gender representation when selecting a textbook. This is probably similar to most schools, making it a "typical" place to study. In turn, the findings from this study might encourage administrators and educational leaders at this site to modify the policy for selecting textbooks and curriculum to also include gender representation as a consideration. The current study might contribute to that process by demonstrating the importance of textbook analysis and interpretation, which may have a direct impact on how lessons are taught and received. 
During conversations with an administrator at the school, I learned that the school has been conducting book audits in classrooms and have started to intentionally focus on who is represented in books (A. Administrator, personal communication, December 21, 2020). Additionally, she mentioned that conversations extend to decorations in the classroom and on bulletin boards. The focus of these audits has been mostly limited to ethnic and racial diversity (A. Administrator, personal communication, December 21, 2020). The timing for this study seems to extend the work that is already being undertaken at the study site by including textbooks and curriculum materials. This study contributes to that conversation because it includes gender representation, an aspect of identity and representation that is not being intentionally discussed at this time.

Because the study site is relatively small, this study could contribute to the practice of educational leaders at all levels in the organization. This study may expand the organization's book audit to include textbooks and gender representation. Therefore, this study could potentially inform the practice of the participant teachers, other teachers, and administration/policy makers in the organization.

\section{Conclusion}

The context for a study is integral to understanding how and why a study was conducted in a specific setting and with a certain sample of participants. This organization often utilizes a hierarchical model for decision-making, which mirrors the hierarchy within the classroom. The teacher participants in this study are both leaders and followers in the organization. In the classroom, they are the boss and outside the classroom, they have varying leadership and following roles. In conducting this study at this setting, I have an opportunity to influence the way the participant teachers view gender, math, and curriculum. Additionally, this study could 
impact the organization by encouraging administrators to rethink the textbook selection policy as it currently does not include gender representation as a consideration. Finally, this study could contribute to the research on mathematics textbooks, examining them in a way that has not yet been explored. 


\section{Section Three: Scholarly Context for the Study}

In this review, I expanded upon Bem's (1993) gender schema theory and examined existing literature related to the methodology and research questions of the current study. Because the scope of research on gender and mathematics is broad and often include frameworks rooted in biological essentialism, androcentrism, and gender polarization, I first summarized and expanded upon the gender schema theory framework created by Sandra Lipsitz Bem (1993). Then, I examined the trends in research on gender and mathematics over several decades. Similarly, in connection with my first research question, How does the Everyday Mathematics kindergarten curriculum and supplemental curriculum materials position and write about girls in comparison to boys?, I explored literature related to curriculum analysis including studies of mathematics curriculum analyzed through a variety of lenses and with a variety of methodologies.

In connection with my second research question, How do teachers describe girls in comparison to boys and position them when discussing their beliefs about mathematics instruction and equity in the kindergarten classroom?, I examined the existing literature on the enacted curriculum and role of the teacher in the mathematics classroom including studies of teachers' perceptions, stereotyping, and interactions, which include discourse studies. Finally, I explored research about explicit and implicit gender stereotyping conducted with children and connected those findings with Bem's (1993) gender schema theory to support the setting of the current study.

\section{Gender Schema Theory}

After decades of research on gender and androgyny, Bem (1993) created a theoretical framework to describe how humans, including young children, construct their own gendered 
identities through enculturation of societal constructs of gender. She argued that cultural lenses such as biological essentialism, androcentrism, and gender polarization shape the way people construct their identities. In this section, I will define the terms androcentrism, gender polarization, and biological essentialism, recount studies that introduced and extended these cultural lenses and summarize how these cultural lenses combine to support Bem's (1993) gender schema theory.

\section{Androcentrism}

Androcentrism is the notion that the world is centered around males and maleness (Bem, 1993). Bem argued that androcentrism extends terminology to describe sexism in society by not only "telling who is in power" but "how their power is culturally and psychologically reproduced" (p. 40-41). Androcentrism is culturally and psychologically reproduced by both privileging males as superior to females and defining males and maleness as the "norm" while “othering” females (Bem, 1993).

Bem (1993) stated that "the concept of androcentrism was first articulated in the early 20th century by Charlotte Perkins Gilman" (p. 41). She suggested that Simone de Beauvoir also describe androcentrism in The Second Sex, published in 1949, without ever mentioning the term: "He is the Subject, he is the Absolute - she is the Other" (Beauvoir, 1952, p. xv-xvi, as cited in Bem, 1993, p. 42). Bem (1993) explained how androcentrism came into existence and how it was reinforced throughout history by referencing ideologies, traditions, and policies stemming from Judeo-Christian theology, ancient Greek Philosophy, Freudian Psychoanalytic Theory, and American Equal Rights Laws. 


\section{Gender Polarization}

Bem (1993) defined gender polarization as "the ubiquitous organization of social life around the distinction between male and female" (p. 80). In other words, the distinction between male and female is so pervasive that it encompasses every area of social life. Studies of gender polarization seem to have stemmed from studies of sexuality. Bem reinforced that gender polarization privileging heterosexuality over homosexuality is called heterosexism. Scores of psychologists, psycho-analytic researchers, and sociologists including Sigmund Freud, Havelock Ellis, and Alfred Kinsey have studied sexual inversion and sexuality throughout the mid-19th and 20th centuries.

Bem (1993) explained that "the scientific discourse on the inversion of gender and sexuality split into two independent branches, the first concerning homosexuality as a sexual orientation and the second concerning the masculinity or femininity of the individual psyche" (p. 101). Researchers studied the masculinity or femininity of the individual psyche through assessments of traditionally gendered traits, "treatment of masculinity-femininity disorders," and the development of gendered traits in "normal" children (Bem, 1993, p. 102). Bem challenged and extended previous work using tools to assess masculinity and femininity by developing her own inventory, the Bem Sex Role Inventory (BSRI) in 1971. This study categorized respondents as "sex-typed, cross-sex-typed, or androgynous on the basis of their Femininity-MinusMasculinity Difference Score, with small difference scores indicating androgyny and large difference scores indicating either sex-typing or cross-sex-typing” (Bem, 1993, p. 120). Bem’s (1993) interest and focus on androgyny in the 1970s led her to shift focus to gender schematicity in 1977.

Bem defined gender schematicity as: 
...the internalizing of the gender polarization in the culture, the learned readiness to see reality as carved naturally into polarized sex and gender categories, not carved—whether naturally or unnaturally-into some other set of categories. It is the imposition of a genderbased classification on social reality, the sorting of persons, attributes, behaviors, and other things on the basis of the polarized definitions of masculinity and femininity that prevail in the culture, rather than on the basis of other dimensions that could serve equally well (p. $125)$.

In other words, adults take on masculine or feminine traits not because of some innate eventuality, but because gendered cultural lenses are so imbedded in society that masculinity and femininity seem like the only natural options. Gender schematicity is what "helps lead children to become conventionally sex-typed" (p. 125). Bem's (1993) argument that gender is culturally constructed counters research conducted by biological essentialists who believed that sex differences were inevitable and created through biological differences.

\section{Biological Essentialism}

Bem (1993) argued that biological essentialism legitimizes both androcentrism and gender polarization by "treating them as the natural and inevitable consequences of the intrinsic biological natures of women and men" (p. 2). Biological essentialists have used research focused on biological differences between groups of people to "naturalize, and thereby perpetuate" the destructive and inequitable treatment of African Americans, immigrants from Eastern Europe and Asia, and women throughout United States history (Bem, 1993, p. 6). Bem explained that in the 1870s, "biological theorizing about women and men intensified" in response to the Women's Suffrage Movement and other feminist challenges (p. 9). She cited Edward Clarke, Herbert Spencer, Charles Darwin, and Patrick Geddes and J. Arthur Thomson as notable scientists 
responsible for conducting research rooted in biological essentialism, much of which was used to push conservative social agendas (Bem, 1993).

\section{The Construction of Gender Identity-Gender Schema Theory}

Cultural lenses come together to influence the construction of a gendered identity. In contrast to arguments made by biological essentialists who view gender polarization as caused by innate, biological differences, "gender schema theory argues that because American culture is so gender polarizing in its discourse and its social institutions, children come to be gender schematic (or gender polarizing) themselves without even realizing it” (Bem, 1993, p. 125). Although gender identity and schema construction are complex processes with roots in psychology and sociology, gender schema theory provides two assumptions for how young children construct their own understanding of gender:

(1) There are gender lenses embedded in cultural discourse and social practice that are internalized by the developing child; and (2) Once these gender lenses have been internalized, they predispose the child, and later the adult, to construct an identity that is consistent with them (Bem, 1993, pp. 138-139).

Bem's (1993) gender lenses become internalized through enculturation, which is a process where cultural lenses are transferred to the individual and can be expanded beyond gender lenses. Therefore, discourse, including teacher and curriculum discourse, is integral to gender schema theory because cultural discourse is the avenue through which cultured representations are communicated and subsequently contribute to larger gendered Discourses in society. 


\section{The Cycle of Gender Stereotyping}

Bem (1993) suggested that construction of a gendered identity is both a product and a process, which suggests a cyclical nature. Society, parents and teachers contribute to this cycle by perpetuating cultural discourses they themselves have experienced. Bem (1993) stated:

The kinds of human beings that children and adults become depend on their daily social experiences; and these social experiences are, in turn, preprogrammed by institutionalized social practices - which are themselves but one embodiment of the same cultural lenses that are also embodied in cultural discourse (p. 140).

In other words, she suggested that children form their gender schema through cultural cues, which become individual beliefs through enculturation. Continued exposure to gendered or nongendered roles enculturates the child and transforms them into a cultural native, a person who reflects the culture in which they have been situated (Bem, 1993). Children may reproduce cultural cues either implicitly or explicitly reinforcing or challenging gender roles in their culture. As adults, these individuals may then continue to perpetuate or challenge stereotypes in their own life, which contributes to a societal view of gender (See Figure 3.1). 


\section{Figure 3. 1}

Formation of Gender Schema

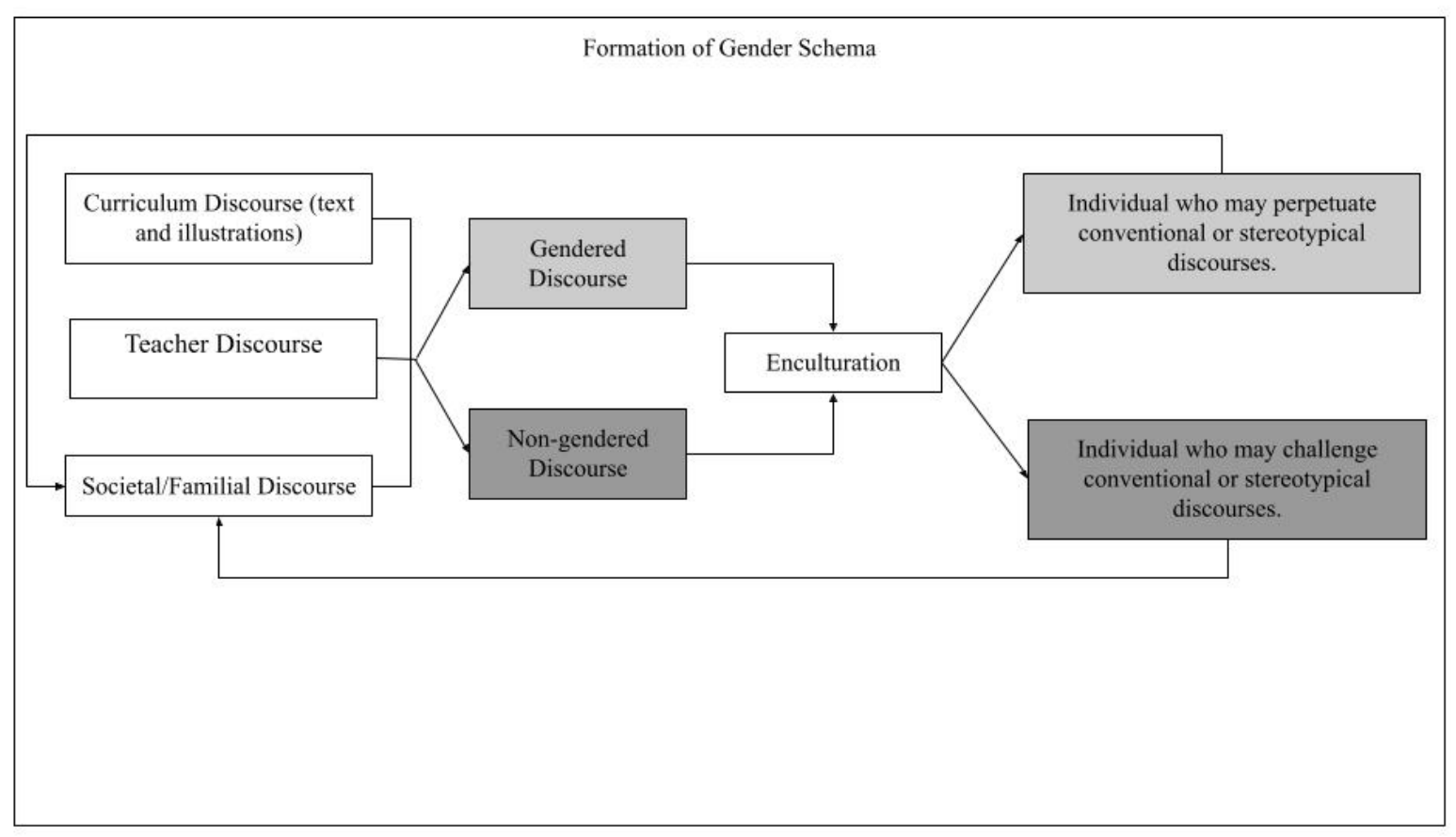

Note. Developed by the author after reading Bem, 1993.

Cultural lenses such as androcentrism, gender polarization, and biological essentialism do not only support Bem's (1993) understanding and theory of gender schematicity. Connections to those lenses are apparent in the research of gender and mathematics throughout the 20th and 21 st centuries. The current study assumes that androcentrism and gender polarization contribute to stereotyping in math.

\section{Trends in Gender and Mathematics}

Researchers have examined the relationship between gender and mathematics extensively over several decades. In the 1990s, researchers focused on "sex differences in performance, attitudes, and participation in advanced high school mathematics courses" (Lubienski \& Ganley, 2017, p. 649). According to the most recent results of the mathematics test measured by the National Assessment of Educational Progress (NAEP), composite scores in mathematics for 
males and females vary only slightly in grades 4 and 12 and not at all in grade 8 on a national level (National Assessment of Educational Progress, 2019); however, women continue to be underrepresented in STEM (Science, Technology, Engineering, and Mathematics) fields, specifically math-intensive careers such as engineering, computer and mathematical scientists, and physical scientists (Khan et al., 2020).

Research has shifted to exploring why women continue to be underrepresented in certain math-intensive fields when sex disparities in performance in mathematics are small (Lubienski \& Ganley, 2017). In their comprehensive review of literature, Lubienski and Ganley (2017) suggested several areas of research that aim to better understand this phenomenon: societal stereotypes about gender and math, role of teachers and instruction, climate and postsecondary mathematics, attitudes, beliefs, and values, verbal skills, and spatial thinking. Because the current study focuses on teacher and curriculum discourse, I will expand on studies concerning math curriculum, societal stereotypes about gender and math, and the role of teachers and instruction.

\section{Intended Curriculum Analysis}

The school-intended curriculum, the textbook and other curricular materials, shape the $\mathrm{D} /$ discourse in the classroom. In her report on the status of gender equity research in American schools, Bailey (1993) stated that:

The content of formal school curricular materials sends powerful messages to students. These are, after all, the materials their teachers have chosen for them to study, and thus what textbooks and other supplemental materials include and do not include about the world and its people signal to students what is and is not valued by the schools they are attending (p. 327). 
Weiss (1987) found that up to $90 \%$ of teachers rely solely on the textbook for instruction, and Banilower et al. (2013) found that $85 \%$ of teachers do the same, which shows how reliance on textbooks for instruction has minimally changed in the United States. Studies of the intended curriculum utilize qualitative, quantitative, and mixed-method methodologies. The following is a review of literature specifically concerning analysis of textbooks.

\section{Historical Context-Math Curriculum Trends}

Research concerning intended mathematics curriculum and textbooks has been studied for almost 100 years, with the earliest study dating back to the early 1920 s. The first study in this area examined the number and frequency of problems in relation to student difficulty (e.g., Clapp, 1924). Hamann and Ashcraft (1986) replicated this study and discovered similar findings about the relationship between frequency of problems in relation to student difficulty. Since the early 1900s, curriculum analysis has become widely accepted as a form of scholarly inquiry (Lloyd et al., 2017).

According to Lloyd et al. (2017), studies of math curriculum have "provided new insights into the content and design of mathematics textbooks and generated important questions about relationships between written curricular materials and students' opportunities to learn" (p. 826). The focus of these analyses has been on mathematical content with little consideration for critical gender analysis. Specifically, in a review of math curriculum studies published since 2005, Lloyd et al. (2017) found three trends related to research on the intended math curriculum: (a) analysis of the problems in written curricula, (b) analysis of specific content areas, and (c) analysis of the historical development of mathematics textbooks. Even though curriculum analysis for gender representation has not been considered a trend in curriculum analysis, it is the topic of the current study and I will elaborate on its history and prominent studies in that area. 


\section{Historical Context-Gender and Curriculum}

Researchers and activists have examined the frequency and quality of gender representation in curriculum texts for decades both in the United States and Internationally (Sadker \& Zittleman, 2009). Studies concerning gender and curriculum texts have not been limited to the field of mathematics nor the elementary level. Researchers have studied curriculum texts in psychology (e.g., Gray, 1977); history (e.g., Clark \& Mahoney, 2004; Clark et al., 2005; Tracker, 1971); geography; and economics and across grade-level divisions — primary, secondary, and post-secondary. In a report of gender bias in textbooks conducted as a background paper to assist in the drafting of the Education for All Global Monitoring Report 2008, Blumberg (2007) found that more recent studies of gender representation in textbooks of varying subjects and intended audiences used in the United States showed modest improvements in the frequency of gender representation and near elimination of the "worst examples of sexism" of gender stereotyping (p. 19). The trends in gender representation of curriculum texts in the United States align with trends in gender representation of math curriculum texts in the United States and other countries (e.g., Northam, 1982; Scardina, 1972; Walkerdine, 1998; Weitzman \& Rizzo, 1976). The following are summaries of notable studies of gender and elementary textbooks, some of which include other subjects in addition to math.

\section{Content Analysis of Elementary Textbooks}

In Scardina's (1972) report of 36 elementary textbooks used in Pittsburgh, PA public schools, she and others examined how the texts represented girls in comparison to boys and women in comparison to men in textbooks from the following subjects: language, reading, science, social studies, and mathematics. Although unstated, they seemed to examine both text and illustrative representations. The only kindergarten textbook included in this study was one 
dedicated to science instruction. Scardina (1972) reported findings from three mathematics texts serving students in grades 3,4 , and 6 . In those texts, she reported that boys were represented as more active. Additionally, she reported that both boys and girls are represented engaging with math in stereotypical situations such as solving money and percentage problems for boys and measuring fabric and ingredients for cakes for girls.

Since Scardina's (1972) report, I have found four studies of elementary textbooks that contain analysis of at least one math textbook, two set in the United Kingdom, one set in the United States, and one set in Qatar (e.g., Northam, 1982; Walkerdine, 1998; Weitzman \& Rizzo, 1976; Yasin et al., 2012). Northam (1982) studied five series of elementary math texts used in the United Kingdom, examining how girls were represented in comparison to boys through a content analysis of the text and illustrations. The textbooks chosen for this analysis included texts for ages 3 through 13 and were published throughout the 1970s. She found that in the textbooks used in early childhood, "women dominate the child's world," often identifying unnamed teachers and parents as she, which contrasts the overwhelming use of "he" to identify unnamed children in the text (Northam, 1982, p. 12). In these texts, mothers are depicted stereotypically, while fathers are largely absent or rarely mentioned. Many illustrations in the text depicted stereotyped familial roles, which included a "father, mother, brother, sister and baby in descending order of height" (Northam, 1982, p. 12).

Although adults were identifiable through gendered representations, children were represented as gender ambiguous in illustrations. However, in some early childhood texts, this did not hold true, and illustrations of girls and boys were more sex-typed in their "dress, demeanour and sex-typical behavior" (Northam, 1982, p. 13). As Northam evaluated texts for older children, she noted an absence of adult women, with many more references to men. She 
argued that "a marked sexist bias characterizes primary math texts so that mathematical skills become increasingly defined as masculine as children move through junior and middle schools" (Northam, 1982, p. 11). About 15 years later, Walkerdine (1998) expanded upon Northam's study.

In her book, Counting Girls Out, Walkerdine (1998) describes a study of primary and secondary math texts in the United Kingdom. She utilized the same categories as Northam (1982) to conduct her analysis. Additionally, she focused on texts used with older elementary students instead of texts used with early childhood students. In her examination of primary math texts, she found many similarities to representations of girls in comparison to boys as Northam (1982); however, one major difference is that Walkerdine (1998) found that "girls and boys were equally represented" in solving problems and teaching or explaining a process to others.

\section{Critical Discourse Analysis of Elementary Math Texts}

Walkerdine (1998) and Northam (1982) both used content analysis as part of their methodology to examine elementary textbooks. Their analysis included textbooks from early elementary grades, but mostly focused on an older elementary audience when examining math textbooks. The only study of elementary math texts I could find that utilized CDA as a methodology was set in Qatar. In this study, Yasin et al. (2012) intended to raise awareness about gender stereotyping and sexist linguistics in school mathematics textbooks through a mixed-methods study. The researchers used Wordsmith Tools 5.0 for the quantitative portion and Fairclough's (1989) CDA for the qualitative portion. They examined 24 primary mathematics textbooks used in independent schools in Qatar. Although they explored primary mathematics textbooks, they did not provide the specific audience ages for the texts; therefore, they may or may not have examined textbooks used with children equivalent in age to U.S. kindergarteners. 
They used the quantitative software to count frequencies and calculate percentages of the following characteristics:

(a) representation of male and female human characters, adults and children as well as masculine and female animals and inanimate objects; (b) terms of address and referencing devices; (c) social roles depicted for male and female characters; (d) activities associated with male and female characters depicted including those involving professions, sports, games, and hobbies and leisure activities; and (e) types of linguistic structures and language used for males and females (Yasin et al., 2012, p. 59). Some of the linguistic features that were categorized were male and female pronouns, terms of addresses/salutations, male and female nouns with regard to the family, words related to occupations/professions, and words related to hobbies. This study included three major findings:

(a) there is a preference of males over females where males are represented as standard, (b) there is a bias towards the portrayal of males over females in the depiction of characters in social and occupational activities; and (c) there is a bias in the portrayal of personality characteristics (Yasin et al., 2012, p. 60).

Unlike my study, this study is entirely focused on the language, does not include analysis of visuals, and set in a different cultural context.

Illustration Analysis. Considered a landmark study in gender representation in elementary textbooks (Sadker \& Zittleman, 2009), Weitzman and Rizzo (1976) examined illustrative representations of girls and boys in elementary school textbooks used in first through sixth grade. Like Scardina (1972) their study was not limited to mathematics texts, but instead included textbooks from the following subject areas: science, mathematics, reading, spelling, and social studies. Weitzman and Rizzo examined about 8,000 illustrations in popular elementary 
textbooks in the United States. They created a tool with 50 descriptors to code the illustrations. These descriptors included attributes related to class, race, and sex. When the data were aggregated, they found that boys were represented more frequently than girls at all levels of textbook and found a decreasing number of representations of girls as the age of the audience of the textbook increased. Not only were boys represented more frequently than girls, but also girls and boys were depicted engaging in stereotypical activities and traits. For example, boys were often shown as outdoors and adventurous, while girls were shown "as passive, watching and waiting for boys" (Weitzman \& Rizzo, 1976, p. 7).

In addition to examining the representation of boys and girls, Weitzman and Rizzo also examined images of men and women. They found that men are shown in a greater variety of occupations, while women are shown almost exclusively as mothers and housewives. They argued that although boys were shown many options for occupations as adult men, the message was that they "must have jobs." They argued that both girls and boys are limited by the stereotyped messages in these textbooks.

Although a small section of their report is dedicated to findings in math textbooks, some of their findings align with what other scholars have found. Weitzman and Rizzo (1976) found that adult women in math textbooks are represented stereotypically. For example, adult women are shown "only with math problems of dividing pies and shopping" (p. 9). Weitzman and Rizzo (1976) also found that girls are represented as less mathematically competent. Finally, they found that a common way to divide people is by sex categories. Although this study analyzed illustrations and did not include textual analysis, its findings align with textual representations of girls and boys. 


\section{Summary of Curriculum Analysis}

Analysis of gender bias in textbooks for all audiences and in all subjects seemed to gain speed and recognition during the second wave of the feminist movement in the United States. Researchers have long examined the frequency and representation of gender in textbooks used in the United States with similar findings - a gradual increase in frequency and elimination of explicit sexism in both text and illustrations; however, most researchers agree that curriculum does not equitably represent girls and boys. There seem to be few studies of elementary mathematics curriculum set in the United States where women continue to be underrepresented in STEM fields and gender inequities in society persist. A more recent study of gender representation in elementary mathematics textbooks, including texts used in early childhood, is necessary to better understand the messages curriculum materials convey about gender and mathematics to both teachers and students.

\section{Societal Stereotypes about Gender and Mathematics}

Textbooks are likely a product of an androcentric society and societal stereotypes about gender and math are integral to better understanding representation in texts and in classrooms. Because current reports show small disparities in mathematics performance favoring males (National Assessment of Educational Progress, 2019) but an underrepresentation of women in STEM fields (Wang \& Degol, 2017), Lubienski and Ganley (2017) suggested the natural question is, "Why do we see these differences?" (p. 653). They indicate six areas that may help explain why. Of those six areas, the suggestions that connect most with the current study are societal stereotypes and the role of teachers and instruction. In order to understand how societal stereotypes about gender and mathematics may contribute to women's underrepresentation in 
STEM, I explored literature related to factors that influence student understanding of gender and math, teacher and curriculum discourse.

\section{Roles of Teachers and Instruction}

Much research has been conducted that measure teacher perceptions, stereotyping, gender, and interactions with students (for reviews see Gunderson et al., 2012; Li, 1999; Sabbe \& Aelterman, 2007). In connection with my second research question, How do teachers describe girls in comparison to boys and position them when discussing their beliefs about mathematics instruction and equity in the kindergarten classroom?, I examined literature related to teacher beliefs about gender before describing studies connected with the enacted curriculum, studies of teacher-student interactions. Although many of these studies do not utilize discourse analysis as their methodology or name discourse in their studies, they are connected to teacher discourses at work within larger societal Discourses.

\section{Impacts of Gender Stereotyping-Parents and Teachers}

In a review of the role teachers and parents play in the development of gender-related math attitudes, Gunderson et al. (2012) stated, “parents' and teachers' expectancies for children's math competence are often gender-biased and can influence children's math attitudes and performance" (p. 153). Some studies conducted in elementary math settings include Fennema et al. (1990) and Tiedemann (2002). In their study of 38 first-grade teachers situated around the U.S., Fennema et al. (1990) gathered information about teachers' beliefs through attribution interviews and a sex-role stereotype questionnaire. Additionally, they gathered data of student mathematics learning through a three-part test, including math facts and problem-solving items. Data collected about teacher beliefs were compared to student scores on the mathematics learning tests. Fennema et al. found that teachers "had more knowledge about highly successful 
girls than about highly successful boys and about equal knowledge of low achieving girls and boys" (p. 65). Additionally, the teacher participants attributed boys' success more to ability, while girls' success was more attributed to effort. Finally, Fennema et al. found that the "teachers did stereotype girls and boys differently in relation to mathematics" when they examined results from the sex-role stereotype questionnaire (p. 66). These beliefs may shape interactions with students.

Similarly, in Germany, Tiedemann (2002) conducted a study of 288 third and fourthgrade students and their 48 elementary school teachers. In this study, Tiedemann also asked teachers to identify students in their math class, three girls and three boys, and then categorize them by ability, two in the high achievement group, two in the middle achievement group, and two in the low achievement group. Similar to Fennema et al. (1990), Tiedemann required teacher participants to fill out questionnaires about the children they chose. They filled out two questionnaires, scale mathematical abilities and scale effort resources. Finally, each teacher participant filled out a questionnaire concerning their own gender stereotypes. This study also included some performance data. The teachers provided the child's most recent math report card grade. Tiedemann (2002) found that "teacher beliefs such as ability—attributions and attributions of effort—resources showed a clear perceptual bias that could be more detrimental to girls' achievement than to boys" (p. 58). They also found that teachers who held strong gender-role beliefs perceived student abilities and effort through that dominant stereotype "to a greater extant" than teachers who did not hold strong gender role beliefs (Tiedemann, 2002, p. 59). Gunderson et al. (2012) pointed out that although research "establishes that adults' math attitudes can affect children, it doesn't reveal how this process occurs" (p. 162). Gunderson et al. (2012) suggested three mechanisms through which transmission of math-gender stereotyping 
may occur: direct teaching, differential treatment, and modeling. Therefore, in addition to examining literature related to teacher beliefs and bias, it is integral to examine teacher-student interactions, which include direct teaching, differential treatment and modeling, in the classroom as these interactions may illuminate processes through which this transfer of beliefs occur.

\section{Teacher-student Interactions-Math Discourse}

In 1974, the United Nations Educational, Scientific and Cultural Organization (UNESCO) in cooperation with other organizations sponsored a symposium called Interactions Between Linguistics and Mathematical Education, which "contributed to the launch of a new line of research in mathematics education focused on language and communication and mathematics education" (Herbel-Eisenmann et al., 2017, p. 722). Early prominent studies in this area include Austin and Howson (1979); Cuevas (1984); Carraher et al. (1987); and Pimm's (1987) landmark book, Speaking Mathematically. Studies of mathematics classroom discourse have grown rapidly since the 1980s. Several researchers have reviewed studies of mathematics classroom discourse over the years, often focusing on different aspects of discourse (e.g., Herbel-Eisenmann et al., 2017; Ryve, 2011; Walshaw \& Anthony, 2008). Studies of mathematics classroom discourse utilize various tools for analysis including, but not limited to: systemic functional linguistics (Halliday, 2004), interactional sociolinguistics (Walshaw \& Anthony, 2008), CDA (Fairclough, 2010), discourse analysis (Gee, 2014), and positioning (Herbel-Eisenmann et al., 2017).

Through D/discourse, teachers utilize pedagogic strategies to facilitate participation, discussion, and argumentation, which are necessary components for learning mathematics (Walshaw \& Anthony, 2008); however, through D/discourse, teachers also communicate cultural cues, including gendered cultural cues. Although I have found no studies of elementary math classroom discourse analyzed using discourse analysis or CDA and with a focus on gender, there 
are several studies of teacher-student interactions that relate to discourse even when discourse is not named as an analysis choice. Therefore, I reviewed studies of teacher-student interactions as they encompass teacher discourse.

\section{Teacher-student Interactions-Gendered D/discourse}

Gunderson et al. (2012) suggested there are three mechanisms through which gendered stereotypes may be transferred from adults to children: direct teaching, differential treatment, and modeling. For the purposes of the current study, I have focused on studies of direct teaching and differential treatment of girls and boys. However, many researchers have examined the role of teacher gender and modeling in connection with student interactions (see review in Sabbe \& Aelterman, 2007).

Direct teaching. Teachers may use explicit or implicit language that suggests genderstereotyped behavior or categories. Although it is well documented that children often selfsegregate in classroom settings (Sadker \& Zittleman, 2009), Bigler (1995) suggested that anecdotal stories often shows categorization by gender in academic settings. Her study examined how categorizing students by gender influenced student gender stereotyping.

Bigler (1995) used Bem's gender schema theory in combination with intergroup theory to support how environmental factors such as categorizing students by gender influence their understanding of gender stereotyping. In this study, 66 white, middleclass children attended a summer school program in the Midwest. The students ranged in age from 6 years and 9 months to 11 years and 4 months. Researchers pretested students' classification skills and gender stereotyping, randomly assigned students to rooms with different experimental conditions, and then post-tested students' gender stereotyping and intergroup attitudes. The rooms were separated by condition: color condition, gender condition, and control condition. 
In the color condition rooms, students were assigned to groups named by color through random selection. In the gender condition rooms, students were assigned to groups "on the basis of their self-reported gender" (Bigler, 1995, p. 1077). Students in the control condition rooms were to be referred to only by their names and treated as a unit. Researchers found that students in all rooms were "similar in their initial level of gender stereotyping" (Bigler, 1995, p. 1079). However, aligning with her hypothesis, children in the gender condition room showed "greater stereotyping of occupations," and were more likely to rate occupations as appropriate for men only or women only (Bigler, 1995, p. 1083). Therefore, researchers found that students who experienced more categorization on the basis of gender in their classroom showed more gender stereotyping than students in classrooms that were categorized differently. Similarly, Hilliard and Liben (2010) "found that teachers merely mentioning 'boys' and 'girls' as groups in the classroom (e.g., when greeting children or lining them up) produces more rigid stereotyping among students" (as cited in Lubienski \& Ganley, 2017, p. 654). These studies illustrate how seemingly innocuous gendered language can contribute to young children's gender stereotyping. In addition to direct teaching, differential treatment of girls and boys has also been studied in connection with perpetuating gender stereotypes in the classroom.

Differential treatment. Research concerning gender equity in classrooms through teacher-student interactions has been conducted for decades at primary, middle, and secondary settings . Much of this research has included observations using tools to measure the frequency and type of interactions (Altermatt et al., 1998; Duffy et al., 2002; Harrop \& Swinson, 2011; Sadker \& Sadker, 1986). Often, these studies use quantitative measures to make sense of the counts from their observations. The following are studies from early childhood, primary, middle, and secondary settings. 
Sadker and Sadker (1994) and Sadker and Zittlman (2009) suggested that girls and boys receive very different educations throughout their schooling, due in part to the quantity and quality of teacher interactions. Throughout the 1980s and early 1990s, Myra and David Sadker conducted multiple studies where they observed teacher-student interactions in classrooms. They developed a tool called the interactions for sex equity in classroom teaching (INTERSECT) observational instrument to measure differences in interactions. In 1994, they published a book that shared some of the results from their studies in addition to other studies conducted in classrooms. In 2009, Sadker and Zittleman published an updated edition of the book that included studies conducted by the Sadkers and studies conducted by other researchers between 1994 and 2009. Between 1980 and 1984, Sadker \& Sadker (1986) conducted observations in fourth, sixth, and eighth-grade classrooms. They found that boys get more attention from teachers, both positive and negative and high-achieving boys receive more valuable and precise feedback (Sadker \& Zittleman, 2009).

Studies of middle and secondary classrooms show similar results (e.g. Altermatt et al., 1998; Duffy et al., 2002). Duffy et al. (2002) conducted a study in a secondary setting using the INTERSECT tool created by Sadker and Sadker (1986). In their study of almost 600 high school students and 36 teachers, they found that "female mathematics teachers, male literature/language teachers, and female literature/language teachers tended to interact somewhat more with male students than with female students" (p. 579). Similarly, Altermatt et al. (1998) found in their study of six high school science classrooms that teachers called on male students more frequently than expected based on the ratio of the class; however, in contrast to other studies (e.g., Becker, 1981; Good et al., 1973; Scantlebury \& Kahle, 1993 as cited in Altermatt et al., 1998), they did not find that males and females were asked different levels of questions. Conflicting with other 
studies, Harrop \& Swinson (2011) did not find any statistically significant difference in the interactions with boys in comparison to girls at the secondary level.

Teacher-student Interactions-Gendered Discourse in Early Childhood. Although much research of teacher-student interaction does not include kindergarten or early childhood, there are three studies of teacher-student interactions conducted in early childhood that suggest differences in treatment on the basis of sex (e.g., Fagot, 1977; Fagot \& Hagan, 1985; Hale, 1993). In their study of infants and toddlers, Fagot et al. (1985) studied how adults reacted to infants' attempts at communication and followed up with those same children and adults to study reactions and behaviors when the children were toddlers. As infants, girls and boys exhibited similar ways of communicating with adults and "adults responded to girls' assertive behaviors far less of the time than to boys' assertive behaviors" (p. 1499). In their study of those same participants as toddlers, Fagot et al. found that boys were more assertive while girls talked more to the teachers. At that time, the teachers no longer responded in sex-differentiated ways, but rather behavior-differentiated ways. Because of these results, Fagot et al. suggested that response from adults contributed to more gender stereotypic communication patterns as toddlers; however, they do mention that adult responses to behavior should not be considered the only factor that contributes to children's understanding of gender specific behaviors.

Another study conducted by Fagot (1977) explored how adults and peers responded to preschool children's gender-typed and cross gender-typed behaviors. In her study of over 200 preschool children over a 6-year period, she found that "boys received significantly more peer and teacher criticism for engaging in stereotypic feminine behaviors, but more favorable reactions when engaging in task behaviors" (p. 902). In contrast, "girls with cross-gender preferences did not receive differential peer reaction" (p. 902). In other words, boys were 
conditioned to assimilate to gender-stereotyped behaviors in the classroom to avoid criticism, while girls were allowed more flexibility in their gendered behaviors.

Although not generalizable to other studies, Hale's (1993) study of a student teacher in a kindergarten classroom showed that even at a young age, some kindergarteners experience differences in interaction on the basis of sex. In her study, she recorded the frequency of interactions between the student teacher and girls and the student-teacher and boys. She found that the student teacher interacted with only boys 42 times while the student teacher interacted with girls only seven times during a 30-minute lesson (Hale, 1993). Frequency is only one way to measure equity in the classroom, and observations of more nuanced elements of classroom discourse are needed to support studies of gender equity in kindergarten classrooms.

\section{Summary}

Although research about direct teaching and differential treatment has not been limited to early childhood or the math classroom, these studies do show a trend in differences in interaction based on gender that begin in early childhood. Overall, many studies have found that boys receive more attention from teachers, more precise and valuable feedback, and more time to talk in class (D. Sadker \& Zittleman, 2009). These studies do not use discourse analysis as a tool to examine interactions, but they do concern teacher discourse and connect to societal Discourses. Therefore, I believe these studies are integral to understanding teacher discourse even in the absence of studies specifically related to discourse analysis.

\section{Implicit and Explicit Gender Stereotyping-Studies with Children}

Teachers and parents may wonder why teacher and curriculum discourse matter when working with such young students. Many researchers have wondered at what age children are able to identify and understand gender stereotypes, particularly in relation to math and language 
education (Vuletich et al., 2020). Researchers have conducted studies of implicit and explicit gender stereotyping with children as young as first grade (e.g., Cvencek et al., 2011; Vuletich et al., 2020).

Critiques of using tools measuring explicit gender bias with young children have led to studies using tools measuring implicit gender bias either in combination with explicit measures or alone. Researchers have used different tools to measure implicit bias in children: child Implicit Association Test (IAT) (Cvencek et al., 2011) and Affect Misattribution Procedure (AMP) (Vuletich et al., 2020). According to Lubienski and Ganley (2017), implicit bias testing with children has yielded inconsistent results based on the setting of the study and the tool used to measure implicit bias. In the United States, Cvencek et al. (2011) conducted a study with elementary-aged children using both implicit measures, IAT, and explicit self-reporting. In their study, Cvencek et al. (2011) sampled 247 American children between the ages of 6 and 10. They tested the following associations: "(a) me with male (gender identity), (b) male with math (mathgender stereotype), and (c) me with math (math self-concept)" (p. 766). They reported two major findings: (1) "as early as second grade, children demonstrated...that math is for boys on both implicit and explicit measures," and (2) "elementary school boys identified with math more strongly than did girls on both implicit and self-report measures" (p. 766). The findings from the study do not align with a more recent study using a different tool for measuring implicit bias.

Vuletich et al. (2020) conducted a study with children ages 8 to 15 . In this study, they measured children's implicit and explicit beliefs concerning gendered stereotypes. Their study extended beyond stereotypes in math and language but results from the portion that assessed stereotypes in academics in comparison to sports was not thoroughly discussed in this study. In this study, they used the AMP to measure implicit bias and a visual analog scale (VAS) to 
measure explicit beliefs. One difference between the IAT and the AMP that was noted by the authors is that the AMP separates math and language in a way that the IAT does not. They claim this separation creates a more accurate picture of how children understand gender in relation to math and language. In contrast to studies that use the IAT, (Vuletich et al., 2020) found that: boys showed neither math nor language implicit gender biases, whereas girls implicitly favored girls in both domains and both boys' and girls' primary tendency was to favor girls in math and language ability, with the exception of elementary school boys, who rated genders equally (p. 1).

This study counters previous studies in two important ways: (1) it showed no bias in favor of boys and (2) it showed bias favoring girls at several levels. These findings are interesting and may show a change in stereotyping at the grade-school level.

\section{Existing Literature and Gender Schema Theory}

Despite inconsistencies in results from implicit and explicit gender bias studies with children, studies of child development and Bem's (1993) gender schema theory help support why gendered messages may still contribute to children's understanding of gender and gendered stereotypes at a young age. In a review of literature concerning gender development, Martin and Ruble (2010) cited studies that demonstrated that children as young as two and three develop basic stereotypes (e.g., Kuhn et al., 1978; Signorella et al., 1993 as cited in Martin \& Ruble, 2010). These studies align with Bem's (1993) suggestion that formation of gender schema begins at an early age. Perhaps social movements concerning equity have begun to positively influence young children's understand of gender and stereotyping; however, further research with implicit bias tools are needed to better understand at what age children acquire knowledge of gender stereotypes and how they enact those stereotypes. 


\section{Conclusion}

Because children's understanding of gender is developing in early childhood, I chose to explore the discourse of kindergarten teachers and kindergarten curriculum resources for gendered discourses. Such a study may illuminate what messages these children are receiving about gender and further our understanding of how children with a more flexible understanding of gender become rigid in their definitions within a few years of kindergarten. There are clear differences in attitudes towards math by first grade, and an exploration into the messages children receive through teacher discourse and curriculum discourse may help us better understand how those disparities come to exist. 


\section{Section Four: Contribution to Scholarship}

We know that women are underrepresented in math-intensive fields (Khan et al., 2020) despite marginal sex differences in mathematical performance (National Assessment of Educational Progress, 2019). Researchers have identified several areas that may contribute to the underrepresentation of women in science, technology, engineering, and math (STEM) fields: societal stereotypes about gender and math, role of teachers and instruction, climate and postsecondary mathematics, attitudes, beliefs, and values, verbal skills, and spatial thinking (Lubienski \& Ganley, 2017). The purpose of this study was to examine the intended curriculum and teacher perceptions in a kindergarten mathematics classroom through discourse analysis using the following research questions: (1) How does the Everyday Mathematics kindergarten curriculum and supplemental curriculum materials position and write about girls in comparison to boys?, and (2) How do teachers describe girls in comparison to boys and position them when discussing their beliefs about mathematics instruction and equity in the kindergarten classroom?

The purpose of this section, following the guidelines of the EdD dissertation structure, is to write this section like a publishable article. As will become clear, I have separated my findings by research question before integrating them in my discussion as I hope to publish two separate articles in Sex Roles: A Journal of Research. After analyzing the text and illustrations in the four curriculum pieces, in connection with the first research question, I determined five findings: (1) textual representations of students and adults are predominantly non-gendered; (2) when feminine and masculine pronouns are used, the masculine pronoun is always positioned first; (3) girls and boys are represented similarly in terms of frequency and intensity in both text and illustrations; (4) the illustrations in the resources predominantly used by the teacher represent girls observing boys more often than boys observing girls; and (5) adult women are represented 
while adult men are not represented. After analyzing the data from the teacher participant interviews, three major themes emerged in connection with the second research question: (1) teachers and books play an integral role in shaping kindergarteners' understanding and schema; (2) teachers witness gender segregation and sexist comments in kindergarten while simultaneously expressing that kindergarteners are too young to recognize gender stereotypes; and (3) when gender segregation does come up in the classroom, teachers reinforce gender desegregation and equitable treatment for all students. This section includes a brief review of the conceptual frameworks and methods before describing the findings from this study. The findings pertaining to both research questions are integrated together to illustrate the connection between teacher and curriculum discourse. I end this section with a discussion of the findings and implications for future research.

\section{Conceptual Framework}

The conceptual frameworks underpinning this study are discourse analysis (Gee, 2014), Critical Discourse Analysis (CDA) (Fairclough, 2010), and gender schema theory (Bem, 1993). The following is a brief review of all three frameworks. Discourse analysis and CDA underpin this study because the focus of this study is the messages conveyed through discourse in the intended curriculum and teacher interviews. This brief review discusses how the frameworks are utilized in this dissertation. For a deeper review of gender schema theory (Bem, 1993), see Section III of this dissertation.

\section{Types of Curriculum}

According to Lloyd et al. (2017), "the intended curriculum refers to educational-system level (e.g., national, district, or school level) expectations for mathematics learning, including textbooks and standards," while "the enacted curriculum refers to the processes of teaching and 
learning mathematics that emerge as teachers and students interact with curricular materials and tasks in classrooms" (p. 825). Intended and enacted curriculum come together to influence student learning and thinking. Both types of curriculum can be explored through discourse analysis and CDA.

\section{D/discourse}

According to Gee (2014), language is more than words; it is saying, doing, and being. In order to make meaning from these interactions, researchers use discourse analysis to study language in use, or discourse with a little "d" (Gee, 2014). Furthermore, Gee (2014) defined Discourse with a big "D" as the melding of language-in-use and "non-language stuff" to enact larger identities and activities (p. 7). This includes the ideologies, values, stereotypes, and meta-

narratives. In this study, Discourse with a big " $\mathrm{D}$ " might include patriarchal or androcentric and feminist ideologies, gender stereotypes, educational values, and gendered meta-narratives. For example, $\mathrm{D} /$ discourses are communicated through conversations with educators and through the school-intended curriculum. All discourse with a small "d" occurs within a larger big "D" discourse and can be interpreted through those lenses. These $\mathrm{d} /$ Discourses are related to the intended and teacher perceptions, the focus of this study.

\section{Critical Discourse Analysis}

Although definitions of discourse are drawn from work by James Gee (2014), methodological and analysis choices are drawn from Gee (2014) and Critical Discourse Analysis (Fairclough, 2010). Gee (2014) suggested that discourse analysis should be critical because "language itself is...political" (p. 9). From this idea that language is political emerges another branch of discourse analysis, Critical Discourse Analysis (CDA), introduced by Fairclough (2010). CDA is not limited to analysis of texts or speech, but is part of a larger system of 
analysis, which includes discourse and components of social justice (Fairclough, 2010).

Additionally, CDA addresses "social wrongs in their discursive aspects and possible ways of

righting or mitigating them" (Fairclough, 2010, p. 11). Similar to Gee (2014), Fairclough (2010) separated language into genre (ways of interacting), discourse (ways of representing), and style (ways of being). Genre includes "structures such as turn-taking/interruptions" (e.g., topic, cohesion, and intertextuality); discourse "constructs ideas about the world within the interactional space" (e.g., information/theme, lexicalization/pronouns, and exclusion); and style includes “positions or identities" (e.g., voice, modality, and mood) (Rogers \& Wetzel, 2014). In order to explore genre, discourse, and style on a microlevel, I adapted guidelines from CDA (Rogers \& Wetzel, 2014). I further elaborate on the specific tools used for analysis in my data analysis section.

\section{Gender Schema Theory}

Although discourse analysis provides a framework for methodological and analysis choices, gender schema theory provides a framework to couple a discourse analysis with a feminist analysis and position the study of a classroom within a broader society. Gender schema theory provides two assumptions for how young children construct their own understanding of gender:

(1) There are gender lenses embedded in cultural discourse and social practice that are internalized by the developing child; and (2) Once these gender lenses have been internalized, they predispose the child, and later the adult, to construct an identity that is consistent with them (Bem, 1993, pp. 138-139).

$\mathrm{D} /$ discourse is related to gender schema theory because cultural discourse is the avenue through which cultured representations are communicated and subsequently contribute to larger gendered 
Discourses in society. Bem's (1993) gender lenses become internalized through enculturation, which is a process where cultural lenses are transferred to the individual and can be expanded beyond gender lenses.

\section{Methods}

Because the focus of this study is to critically explore the intended curriculum and teacher perceptions through discourse of the school-intended curriculum and kindergarten teachers while they describe how they have taught or would teach a lesson from the curriculum and address and introduce equity in their classroom, this is a discourse study using qualitative methods. The following is a description of the setting and participants, data collection methods, and data analysis methods (also described in Sections I and II). Data collection and data analysis methods are separated by research question for clarification. Because I was the only person analyzing the data, I detail how I constructed interpretations using various linguistic, sociolinguistic, and discourse tools.

\section{Setting and Participants}

This study was conducted with participants who teach or who have taught kindergarten on the campus of a private school in the Midwest. The institution has a relatively small population of fewer than 400 students and fewer than 50 faculty members. This organization serves students in junior kindergarten through twelfth grade. The school is tuition-based, and is the only independent, non-parochial school in the community. The participants in this study are the two current kindergarten teachers and two former kindergarten teachers who now work in other positions at the organization.

Upon approval from the International Review Board (IRB), I recruited participants through convenience sampling. I have a professional relationship with three of the four 
participants, which allowed for a deeper analysis of the data than I would have otherwise been able if all participants were strangers to me. In order to study the intended curriculum, I have chosen to collect data from the Everyday Mathematics kindergarten curriculum. I have chosen this curriculum for two reasons: (1) it is the math curriculum used at the setting, and (2) according to the Everyday Mathematics website, this curriculum is used in about 220,000 classrooms across the United States (The University of Chicago Mathematics Project, n.d). Now, I will detail what specific data were collected.

\section{Data Collection}

The first research question guiding this study focused on the intended curriculum: How does the Everyday Mathematics kindergarten curriculum and supplemental curriculum materials position and write about girls in comparison to boys? The second research question focused on teacher perception and discourse: How do teachers position and describe girls in comparison to boys when discussing their beliefs about mathematics instruction and how they teach? I collected data related to perceptions from the teacher participants and the intended curriculum in order to answer each research question.

\section{First Research Question: Data from the School Intended Curriculum}

I collected textual data from the school-intended curriculum, which included several resources. I explored the kindergarten Everyday Mathematics teacher manual (UCSMP, 2012d), math masters workbook (UCSMP, 2012b), activity cards (UCSMP, 2012a), and student workbook (UCSMP, 2012c). When collecting data, I explored every page of the math masters workbook (UCSMP, 2012b), activity cards (UCSMP, 2012a), and student workbook (UCSMP, 2012c). When examining the teacher manual (UCSMP, 2012d), I collected data from the lesson 
pages and section projects. I limited my collection to lessons and projects because they are the pages most likely seen and used by the teacher and are the least repetitive.

\section{Second Research Question: Data from Kindergarten Teachers}

I conducted semi-structured interviews via Zoom with four participants using an interview protocol (See Appendix A). The interview protocol was split into two interviews, the first designed to familiarize the participant and researcher and the second to discuss a specific math lesson and discuss stereotypes and equity in the math classroom. Each interview varied in time-length, ranging from 25 minutes to about 80 minutes. Before each interview, I provided participants with an informed consent describing the study, risks and benefits of participation.

The interviews took place via Zoom because they were conducted during the Covid-19 pandemic. Therefore, in order to answer my two research questions I analyzed data from interviews and the kindergarten Everyday Mathematics curriculum and supplemental curriculum materials (See Table 4.1).

Table 4. 1

Summary of Collected Data

\begin{tabular}{|c|c|c|c|c|}
\hline Research Questions & \multicolumn{4}{|c|}{ Data: Curriculum } \\
\hline $\begin{array}{l}\text { How does the Everyday } \\
\text { Mathematics kindergarten } \\
\text { curriculum and supplemental } \\
\text { curriculum materials position } \\
\text { and write about girls in } \\
\text { comparison to boys? }\end{array}$ & $\begin{array}{l}\text { Teacher } \\
\text { Manual }\end{array}$ & $\begin{array}{c}\text { Math Master } \\
\text { Workbook }\end{array}$ & $\begin{array}{c}\text { Student } \\
\text { Workbook }\end{array}$ & $\begin{array}{l}\text { Activity } \\
\text { Cards }\end{array}$ \\
\hline How do teachers describe girls & \multicolumn{4}{|c|}{ Data: Interviews } \\
\hline $\begin{array}{l}\text { their beliefs about mathematics } \\
\text { instruction and equity in the } \\
\text { kindergarten classroom? }\end{array}$ & Ms. Smith & Ms. Johnson & Ms. Cooper & Ms. Wilson \\
\hline
\end{tabular}




\section{Data Analysis}

Like the data collection section, this section is organized by research question. I detail the data analysis methods used for each research question. Then, I present an account of findings from both research questions.

\section{First Research Question: Analysis of School-intended Curriculum}

In order to answer my first research question, I examined text and illustrations from the following resources: the kindergarten Everyday Mathematics teacher manual (UCSMP, 2012d), math masters workbook (UCSMP, 2012b), activity cards (UCSMP, 2012a), student workbook (UCSMP, 2012c), and picture books recommended during the lessons (See Table 4.2). For the purposes of this study, any references to "curriculum" included the aforementioned Everyday Mathematics texts.

Table 4. 2

Details of Analyzed Curriculum Resources

\begin{tabular}{ccc}
\hline Analyzed Resource & Number of Pages or Units & $\begin{array}{c}\text { Teacher and/or Student } \\
\text { Resource }\end{array}$ \\
\hline Everyday Mathematics teacher & 8 units (128 lessons) and 8 & Teacher \\
manual & Projects & Teacher and Student \\
math masters workbook & 143 & Teacher and Student \\
activity cards & 38 & Student \\
student workbook & 36 &
\end{tabular}

1. Count of Gendered and Non-gendered Figures in text. After an initial read of the curriculum, I counted all text representations of gendered figures. In text format, I determined whether or not a figure was represented as a girl or boy by examining pronouns and proper nouns. All uses of she and her were coded as girl and all uses of he or him were coded as boy. If a figure was named, then I coded as girl if the name was typically feminine in its native language and boy if the name was typically masculine in its native language. I determined the gender of English-sounding names using my background knowledge of feminine and masculine names in 
the United States and conducted Internet searches on baby name websites to determine the typical gender of names from other cultures or names in question (See Appendix C for full list of categorized names). The text includes gendered and non-gendered representations and the frequency of non-gendered representations is an important part of showing how girls and boys are represented; therefore, I also counted all gender-neutral or ambiguous pronouns and collective nouns as non-gendered and/or collective representations. Examples of these included: they, them, each, students, class, partners, groups, etc. (See Appendix D for full list).

2. Count of Gendered and Non-gendered Figures in Illustrations. Bohnsack (2009) stated, "Pictures provide orientation for our everyday practice on the quite elementary levels of understanding, learning, socialization and human development...” (p. 298). Therefore, I believed examination of illustrations was an important element to include in order to better understand "ways of being, "ways of representing," and "ways of interacting" in the math resources. First, I counted gendered and non-gendered representations in illustrations. I used three codes during this process: girl, boy, and unsure. In illustrations, I identified girls by hair length, clothing choice (dress, skirt, bows, earrings, etc.), stereotypically feminine colors (pink, purple, etc.), stereotypically feminine patterns (butterflies, hearts, etc.), and in connection with pronouns and proper nouns in the text. I identified boys by hair length, clothing choices (shorts, pants, polo, etc.), stereotypically masculine colors (red, blue, orange, etc.), and in connection with pronouns and proper nouns in the text. In the absence of gendered visuals, I coded the figure as unsure, which will be hereby referenced as gender neutral or gender ambiguous.

I counted representations individually. For example, if there was a group of children, I coded each child in the illustration instead of identifying the illustration as mostly feminine or mostly masculine. After counting girls, boys, and the collective/unsure, I determined the 
frequency of representations by summing the amount of coded girls, boys, and gender neutral and gender ambiguous in both text and illustrations. The frequency of representations does not include references to the recommended picture books, references to recommended song titles or game titles, or representations of adults. I did not include any references to the picture books because the character names and descriptions will be examined in a separate study. I separated the counts of the songs and games because they often represented adults. Likewise, I separately counted representations of adults.

3. Beyond the Count: How Girls and Boys were Represented. From there, I examined how girls and boys were represented. In order to determine how girls and boys were represented, I adapted categories from a study of primary math texts in the U.K. by Northam (1982):

(a) part of setting, observed someone else, received help, (b) taught, explained processes to others, (c) made something, displayed a skill, (d) planned, initiated, invented, (e) performed, played tricks, boasted, (f) competed, (g) repeated or elaborated upon a process already learned, (h) cooperated, shared, helped, complied, (i) corrected another's behavior, ex., calm down, said Ann, and (j) identification, setting and solving of problems (p. 13, see Appendix E).

I used the same codes for songs and games and adults. After categorizing the representations, I then summed the frequency of each category for girls, boys, collective/unsure in each category. Finally, I compared the frequencies to determine how girls were represented in comparison to how boys were represented.

Not only was I able to compare how girls were represented in comparison to boys using the adapted categories mentioned previously, but I also examined the positioning and agency of 
girls and boys in illustrations. I mainly examined which figures were centered and/or active in the illustration.

After examining how girls were represented and positioned in comparison to boys in illustrations, I noticed a pattern that needed to be further investigated. Therefore, I then compared categories of representation for girls, boys, and gender-neutral or ambiguous using an adaptation of Northam's (1982) categories in each resource separately instead of across all four resources. The categories and examples can be found in Appendix E. I chose to disaggregate my findings by resource because the audiences differ between resources. The teacher, of course, sees the material in all four resources. She or he mostly likely views and or utilizes pages from the teacher manual (UCSMP, 2012d) and math masters workbook (UCSMP, 2012b) on days when math lessons are taught. Representations in those resources may influence how the teacher views girls in comparison to boys in relation to mathematical learning and tasks. In contrast, students are most likely to see the center activity cards (UCSMP, 2012a), the student workbook (UCSMP, 2012c), and some pages from the math masters workbook (UCSMP, 2012b) on a regular basis. I detail the frequency of those instances in my findings because the representations in those resources may influence how the students view girls in comparison to boys in relation to mathematical tasks and learning.

\section{Second Research Question: Analysis of Kindergarten Teacher Discourse}

In order to answer the second research question, I conducted a Critical Discourse Analysis (CDA) of a portion the interview transcripts. I chose to focus on the second portion of the interview for my CDA because that is the portion where participants discussed how they have taught or would teach the lesson from the Everyday Mathematics curriculum and how they 
introduce and reinforce equity in their classroom. In order to conduct this analysis, I adapted guidelines provided by Rogers and Wetzel (2014). The steps are as follows:

(1) develop research questions, (2) create a transcript, (3) segment the data into stanzas and clauses, (4) locate narrative structure, (5) survey linguistic features, line by line, (6) consult, develop theory, (7) organize coding of linguistic features using "orders of discourse." Take "order of discourse" separately and move through the data set, asking: How are "ways of interacting" (genre) expressed? What "ways of representing" (discourse) are represented? How are "ways of being" (style) communicated?, (8) locate patterns within and across "orders of discourse," especially places of overlap between all three domains, create summary charts to illustrate the analysis, (9) look across local, institutional, and societal levels of analysis to contextualize the discourse practices under examination, and (10) represent the findings in a way that balances between the micro and macro and makes connections to existing research (Rogers \& Wetzel, 2014, p. 139). The research question connected with this data analysis is: How do teachers describe girls in comparison to boys and position them when discussing their beliefs about mathematics instruction and equity in the kindergarten classroom? In order to answer this question, I followed a modified version of the steps detailed in Rogers and Wetzel (2014).

After interviewing participants, I used a transcription service to transcribe the interviews. Then, I examined the transcripts more closely, adjusting the transcripts as I relistened to interviews and separating the participants' responses into stanzas and clauses. I segmented the transcript into stanzas and clauses using Gee's (2014) Stanza Tool as guidance, meaning I segmented the narrative into blocks of ideas. By segmenting the narrative in this way, I organized the ideas through my interpretation. 
After I segmented the transcripts into stanzas and clauses, I classified my analysis strategy as a combination of narrative and structural analysis. I chose to conduct a narrative and structural analysis because I wanted to examine both what was said among the interviewees and how the participants responded to questions. For example, I examined placement of proper nouns and pronouns in sentences, word choice in connection with gendered individuals, and inclusive and exclusive language.

I used a deductive method to code the transcripts and the approach detailed previously, which covered steps 5 through the first part of step 8 from Rogers and Wetzel (2014). For example, I coded mentions of girls and/or boys as girls, boys, or both and stories of inclusion or exclusion based on gender as gender segregation or gender desegregation. After initial coding, I consulted previous studies of femininity and masculinity, and examined transcripts for adjectives and nouns that were gendered. For example, if a participant mentioned a boy as good at math or a girl as good at coloring, I coded those instances as stereotypically feminine or stereotypically masculine. Likewise, I coded instances that countered stereotypical descriptions and nouns as non-stereotypically feminine or masculine.

In order to organize the coding of linguistic features into a CDA framework, I explored each transcript using questions provided by Rogers and Wetzel (2014) (See Appendix E). I examined each stanza, asking questions such as, "What information is foregrounded by being in the theme position?"; "Which pronouns are used and where?"; and "Are participants agents or recipients of actions?" Asking these questions enabled me to position linguistic features such as pronoun usage within "ways of representing," a component of CDA. Finally, as I examined the interviews, I added codes as I noticed patterns within and among interview responses. After 
coding the transcripts and organizing linguistic features within a CDA framework, I created graphs, tables and summary charts to illustrate the analysis.

\section{Making Sense of all Data}

Finally, in order to make sense of how curriculum and teacher discourse work together to influence how young children form their understanding of gender and gender roles, specifically in connection to math, I relied on previously published literature and Bem's (1993) gender schema theory. Because young children form their understanding of gender through discourse (Bem, 1993) and often through text (Scardina, 1972), gendered discourses may lead adults to perpetuate gendered discourses through their resources and classroom discourse (See Figure 4.1). The current study helps us better understand the messages teachers and curriculum may be conveying to kindergarteners, but it does not help us understand how kindergarteners are impacted by those messages. This cycle of gendered discourses may be acquired and repeated both in the classroom and the outside world. Therefore, I examined how teacher discourse connects with classroom resources to influence kindergartener's understanding of gender and gender roles as they pertain to math.

\section{Figure 4. 1}

Formation of Gender Schema 


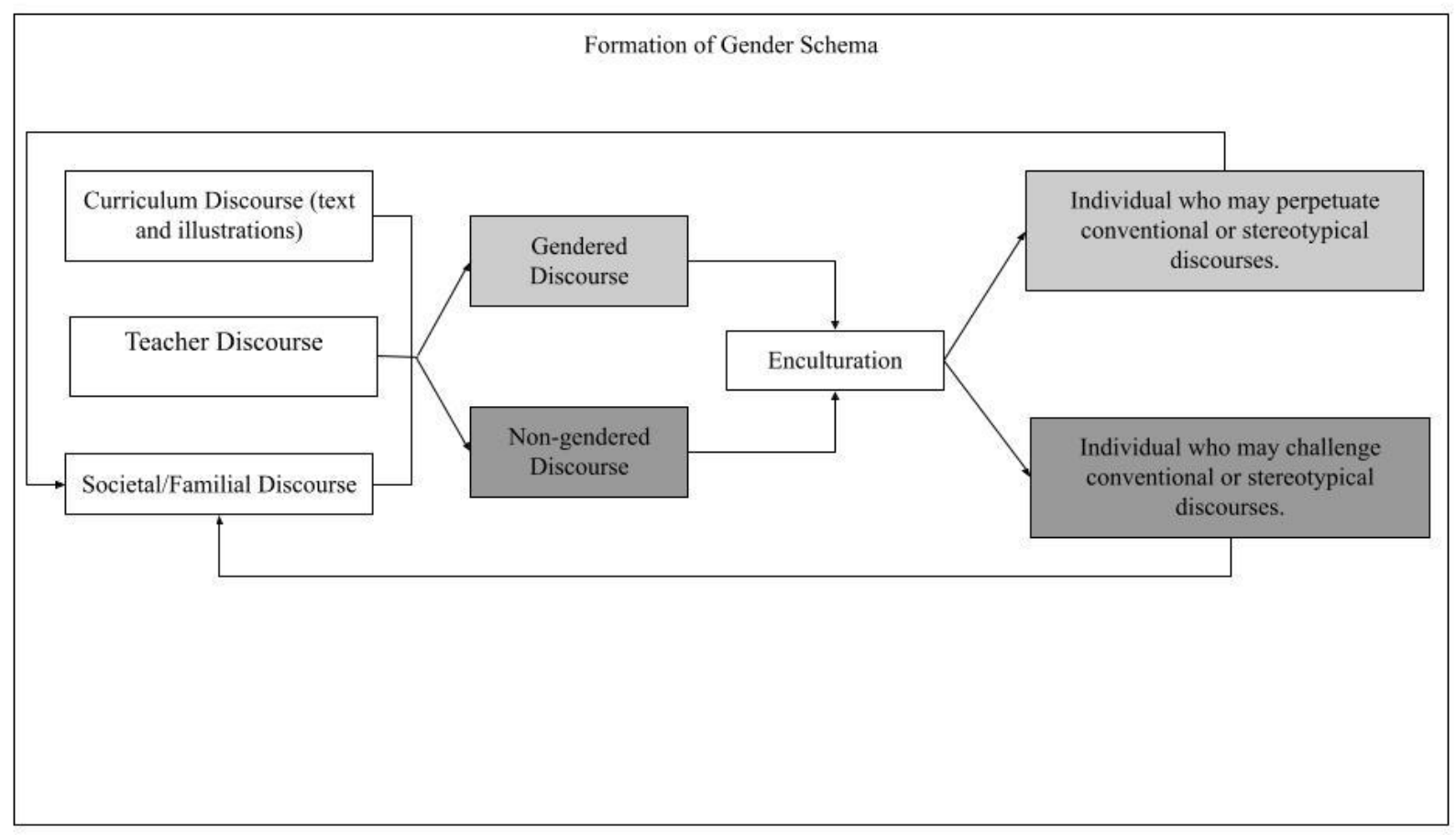

Note. Developed by the author after reading Bem, 1993.

\section{Findings}

Aligning with the order of my research questions, I describe the findings from each research question separately starting with findings from the intended curriculum. Then, I describe the findings related to teacher perceptions from my second research question. Finally, I integrate findings from both research questions in my discussion.

\section{Intended Curriculum: Quantity and Quality of Gendered Representation}

After analyzing the text and illustrations in the four curriculum pieces, I determined five findings: (1) textual representations of students and adults are predominantly non-gendered; (2) when feminine and masculine pronouns are used, the masculine pronouns is always positioned first; (3) girls and boys are represented similarly in terms of frequency and intensity in both text and illustrations; (4) the illustrations in the resources predominantly used by the teacher 
represent girls observing boys more often than boys observing girls; and (5) adult women are represented while adult men are not represented.

\section{Inclusive and Non-gendered Representations in Text}

Overwhelmingly, the curriculum uses non-gendered, gendered singular and plural nouns and pronouns, and collective nouns to represent students and humans. I counted 3,887 singular and plural nouns referring to students and their families. Of those 3,887 , there were 21 uses of him or her or he or she. Finally, there were 30 instances of his or her, which were not included in the 3,887 because they are possessive pronouns.

\section{Reinforcing the Androcentric Binary: Masculine Pronouns Always Used First}

Of the 51 times both girls and boys were referenced together through gendered pronouns, the masculine pronoun was positioned first every time. For example, in lesson 6.5, gendered pronouns are used twice in the teacher manual: (1) "This activity builds upon the Survey Routine (page 32) as each child conducts his or her own survey and then graphs the results" (UCSMP, 2012d, p. 292 ), and (2) "Allow each child to share his or her graph and pose questions for other children to answer based on the graph" (UCSMP, 2012d, p. 293). This example is illustrative of all instances of gendered pronouns when both the masculine and feminine form are used.

Writing both the masculine and feminine pronouns is more gender inclusive than using only the masculine pronoun to encompass everyone; however, there are ways to reference everyone without reinforcing the gender binary. In the curriculum materials, there are examples where a singular non-gendered subject such as "each child" is used in conjunction with both gendered and non-gendered possessive nouns. For example, in Lesson 5.1 the directions state: "Give each child a sheet of paper and help him or her fold it into thirds" (UCSMP, 2012d, p. 237). Then, in Lesson 4.8, the directions state: "Give each child a copy of the Dice-Throw Grid 
and their own pair of dice" (UCSMP, 2012d, p. 205). Both examples are grammatically correct and illustrate that the curriculum can and does refrain from reinforcing the gender binary in its text some of the time.

\section{Girls and Boys are Represented Similarly}

When girls and boys are represented in text and illustration, they are represented similarly regarding frequency and intensity. In other words, there are similar counts for frequency of representation and girls and boys are represented in similar ways. I first describe the frequency and intensity of how girls and boys are represented in the text and illustrations separately. Then, I describe how those representations differ between the teacher and student resources.

Gendered Representations in Text. Separate from the singular and plural nouns in the texts, I counted 26 gendered representations of humans. For example, many suggested number problems included names of potential students and gendered pronouns: "Maggie is inviting 6 friends to her birthday party. She made 7 invitations. Did she make too many or not enough? How many extras did she make?” (UCSMP, 2012d, p. 301). Other occurrences included names,

pronouns, possessive nouns that gender a noun, and the terms girl and boy. Girls are represented slightly more frequently with 13 occurrences than boys with 11 occurrences. I counted 2 instances as gender ambiguous because the names were Sam and Adrian, which have been used for both girls and boys.

When disaggregated by category, I found that girls, boys, and the other two occurrences separated into five of the 10 categories: (1) part of the setting, observed someone else, received help, (2) made something, displayed a skill, (3) competed, (4) cooperated, shared, helped, complied, and (5) identification, setting and solving of problems. Although the counts were similar, girls were represented more often than boys as part of the setting, observing someone, 
receiving help, and competing. In lesson 6.9, the teacher manual suggests a number story, "Mary has 5 bears and 3 ducks. Does she have more bears or more ducks?” (UCSMP, 2012d, 300). In this example, "Mary" is not an active figure in the number story. Her name could be replaced with another name or noun. She is part of the setting of the problem. Boys were represented more often than girls as displaying a skill and identifying, creating, or trying to solve a problem (See Table 4.3).

\section{Table 4. 3}

Frequency of Representations of Gendered Figures by Category in Text

\begin{tabular}{lccc}
\hline Category & Girl & Boy & $\begin{array}{c}\text { Gender Neural } \\
\text { or Ambiguous }\end{array}$ \\
\hline Part of setting, observed someone else, received help & 9 & 7 & 1 \\
Made something, displayed a skill & 0 & 1 & 1 \\
Competed & 2 & 0 & 0 \\
Cooperated, shared, helped, complied & 0 & 1 & 0 \\
Identification, setting and solving of problems & 1 & 2 & 0 \\
\hline Total & 12 & 11 & 2 \\
\hline
\end{tabular}

Overall, girls were represented slightly more frequently than boys when referenced in the text of curriculum materials. Although girls were represented slightly more frequently as part of the setting, observing someone else, or receiving help, the difference is small. Because there are so few references to gender in the text of the curriculum, there are few differences between how girls were represented in comparison to boys.

Gendered Representations in Illustrations: Frequency and Intensity. In addition to textual representations, there were several illustrative representations of girls and boys. Overall, I counted slightly more representations of girls than boys with six illustrations coded as gender neutral or gender ambiguous (See Table 4.4).

Table 4. 4

Frequency of Representations of Gendered Figures by Category in Illustrations 


\begin{tabular}{lccc}
\hline Category & Girl & Boy & $\begin{array}{c}\text { Gender Neural } \\
\text { or Ambiguous }\end{array}$ \\
\hline Part of setting, observed someone else, received help & 6 & 7 & 4 \\
Made something, displayed a skill & 0 & 1 & 0 \\
Competed & 4 & 2 & 0 \\
Repeated or elaborated on a process already learned & 15 & 16 & 0 \\
Cooperated, shared, helped, complied & 6 & 3 & 1 \\
Identification, setting and solving of problems & 7 & 4 & 1 \\
\hline Total & 38 & 33 & 6 \\
\hline
\end{tabular}

When disaggregated by category, I found that girls, boys, and the other six occurrences separated into six of the 10 categories: (1) part of the setting, observed someone else, received help, (2) made something, displayed a skill, (3) competed, (4) repeated or elaborated on a process already learned, (5) cooperated, shared, helped, complied, and (6) identification, setting and solving of problems. For example, Figure 4.2 shows girls cooperating in an experiment (top picture), observing the boy while he is displaying a skill (bottom left), and competing (bottom right), while Figure 4.3 shows boys repeating or extending a previously learned activity (all pictures). Boys were represented slightly more often than girls as part of the setting, observing someone, receiving help, displaying a skill and repeating or elaborating on a process already learned. When taking into account text and illustrations, the largest difference is when students are represented as competing. 
Figure 4. 2

Illustrative Representations of Girls
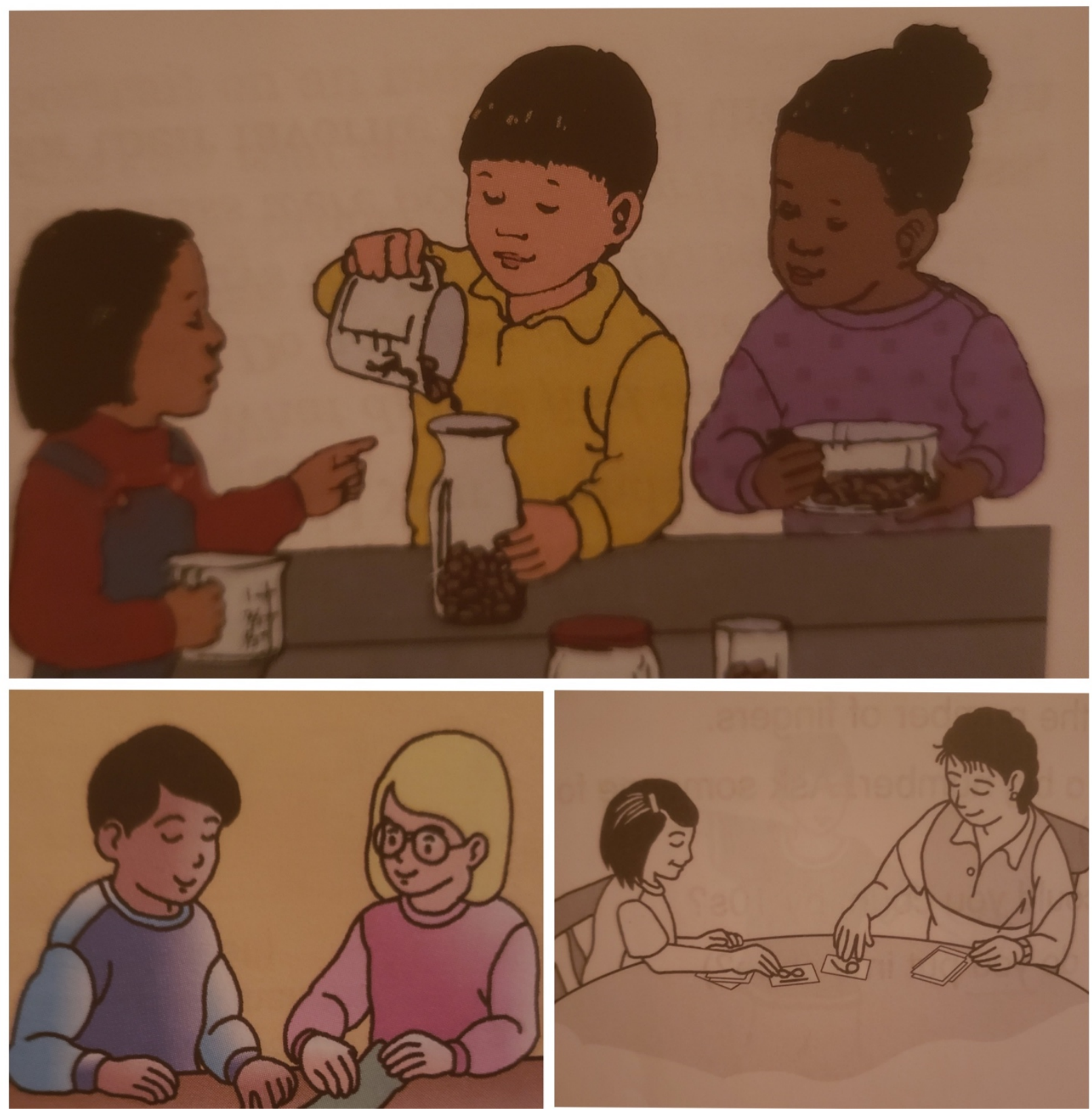

Note: Illustrations from Teacher Manual and Math Masters-Compilation. Reprinted from

Everyday mathematics: Math Masters [Reprinted with permission], Kindergarten, \& Everyday mathematics: Teachers guide to activities, Kindergarten (pp. 32, 59, 247), by UCSMP, 2012, McGraw-Hill Education. Copyright 2012 by McGraw-Hill Companies, Inc. 
Figure 4. 3

Illustrative Representations of Boys
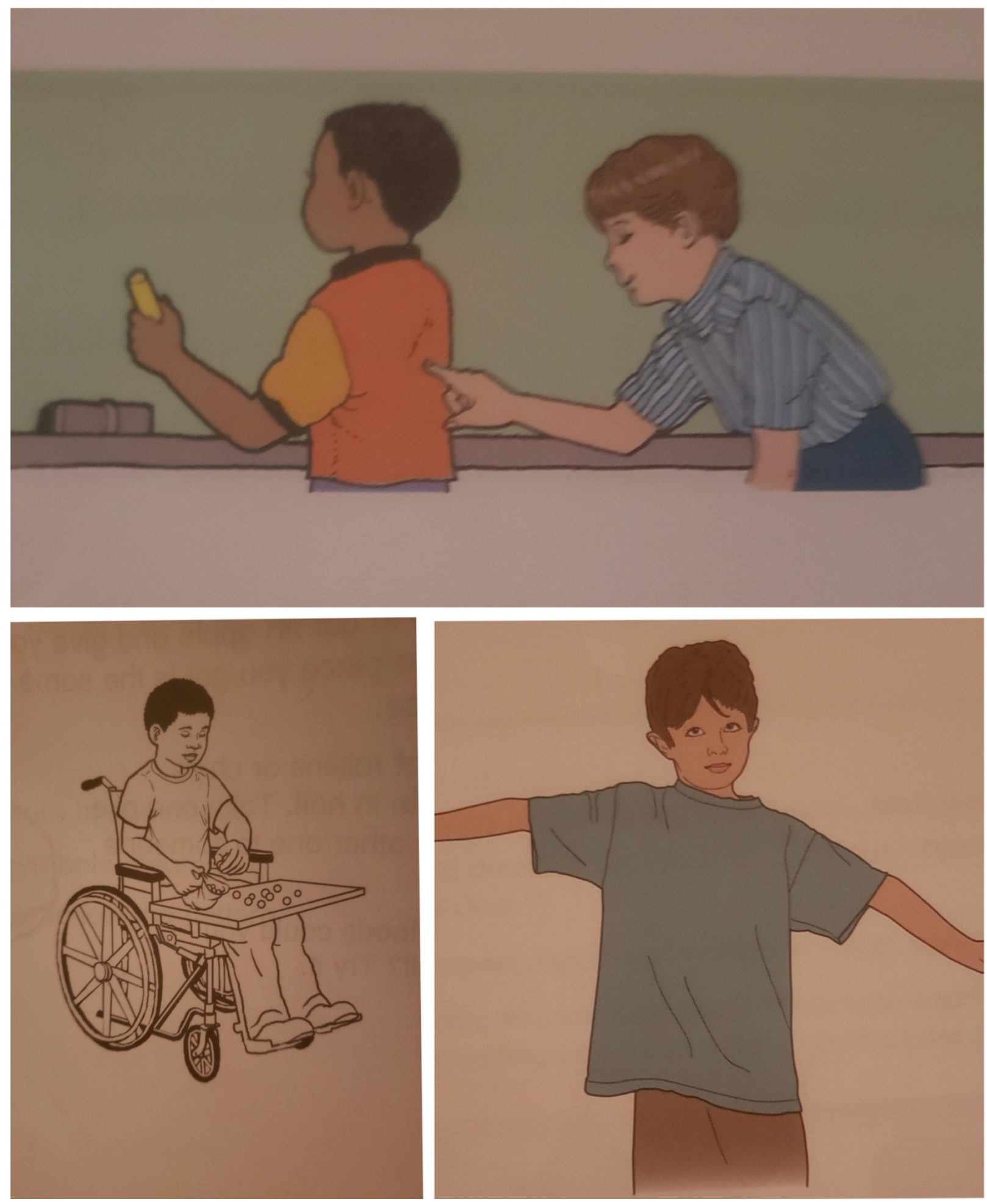
Note: Illustrations from Teacher Manual and Math Masters-Compilation. Reprinted from Everyday mathematics: Math Masters [Reprinted with permission], Kindergarten, \& Everyday mathematics: Teachers guide to activities, Kindergarten (pp. 50, 139, 146), by UCSMP, 2012, McGraw-Hill Education. Copyright 2012 by McGraw-Hill Companies, Inc.

One important note is that girls were represented as competing in six examples, while the boys were represented as competing in two examples. In stereotypical situations, one might expect to see boys competing more than girls, but that was not the case in the few examples in the curriculum. Overall, the difference between representation in both text and illustration indicates very little difference in representation of girls in comparison to boys (See Table 4.5).

\section{Table 4. 5}

\begin{tabular}{lccc} 
Frequency of Representations of Gendered Figures by Category in Text and Illustrations \\
\hline & Girl & Boy & Gender Neural \\
Category & 15 & 14 & 5 \\
\hline Part of setting, observed someone else, received help & 0 & 2 & 1 \\
Made something, displayed a skill & 6 & 2 & 0 \\
Competed & 15 & 16 & 0 \\
Repeated or elaborated on a process already learned & 6 & 4 & 1 \\
Cooperated, shared, helped, complied & 8 & 6 & 1 \\
Identification, setting and solving of problems & 50 & 44 & 8 \\
\hline Total & & \\
\hline
\end{tabular}

Unequal Representation between Teacher Resources and Student Resources. When the data are disaggregated by resource, the representations of girls and boys slightly differs between resources (See Table 4.6). Of the four analyzed resources, only three included gender representations. Of those three, the teacher uses and sees the teacher manual and math masters workbook most frequently. The students see the center activity cards and the math masters workbook pages most frequently. When comparing teacher resources to student resources, one can see that girls and boys are more likely to be shown as part of the setting or observing, more 
likely to be shown repeating or expanding upon a learned skill, more likely to be shown helping or cooperating, and more likely to be shown identifying, setting, or solving problems in the teacher resources.

\section{Table 4. 6}

Representations of Girls and Boys by Resource

\begin{tabular}{lcccc}
\hline \multirow{2}{*}{ Categories } & \multicolumn{2}{c}{ Teacher Resources } & \multicolumn{2}{c}{ Student Resources } \\
\cline { 2 - 5 } & Girls & Boys & Girls & Boys \\
\hline $\begin{array}{l}\text { Part of setting, observed someone else, received } \\
\text { help }\end{array}$ & 5 & 7 & 1 & 2 \\
Made something, displayed a skill & 0 & 0 & 0 & 1 \\
$\begin{array}{l}\text { Competed } \\
\text { Repeated or elaborated on a process already }\end{array}$ & 2 & 0 & 4 & 2 \\
learned & 9 & 13 & 8 & 7 \\
Cooperated, shared, helped, complied & 6 & 3 & 1 & 0 \\
Identification, setting and solving of problems & 7 & 4 & 1 & 0 \\
\hline \begin{tabular}{l} 
Total \\
\hline
\end{tabular} & 29 & 27 & 15 & 12 \\
\hline
\end{tabular}

In contrast, in the student resources, girls and boys are more likely to be shown competing than in teacher resources. One similarity between both sets of resources is that children are unlikely to be represented making something or displaying a skill. It seems interesting that students would not be represented making something or displaying a skill as often; however, this could be the case because many of the illustrations and text pieces that depict students creating something or showing a skill are repetitions or extensions of an activity learned in class and thus coded as repetition and not creating or displaying a skill.

Although there are few differences between how girls are represented in comparison to boys, there are differences in the extent to which students get to see these representations. For example, girls are stereotypically less competitive than boys, but in the student resources, girls 
and boys get to see depictions of girls competing in games at a higher frequency than boys. Likewise, girls are stereotypically characterized as helpers, while boys are often less noted for their cooperative traits. The teacher gets to see representations of boys as helpers and cooperators, which counters the stereotype. Those representations are not in resources that students see. How do these representations influence how their audience makes sense of the roles of girls in comparison to boys?

\section{Girls Watch Boys more than Boys Watch Girls}

Because some illustrations included both girls and boys, there were 43 illustrations total. There were 15 illustrations with only girls and 11 illustrations with only boys. One of the boy illustrations was used twice for different lessons and another was only slightly modified for another lesson. There is only one illustration of boys together and it is of two boys practicing writing their numbers by writing on a partner's back and then the other writing on the board. Likewise, there is only one illustration of girls together and it shows a girl and an adult woman, presumably her mother, playing a math game.

There were 14 illustrations of girls and boys together. In four of those illustrations, girls are illustrated as observing boys. Two illustrations appear to depict a boy observing a girl. Although a small percentage of the total number of pictures, these illustrations are important because they reinforce androcentrism by focusing on the boy figure and depicting the boy(s) as worthy of girls' and the teacher's attention.

Girls Observing Boys. The first example of girls watching a boy was presented in the first unit of the teacher manual (UCSMP, 2012d), lesson 1.7 (See Figure 4.4). In this illustration, the students were comparing volume through experimentation. The boy is positioned in the center with agency. He was in the act of pouring beans from one container to another. The girls 
in this illustration were likewise overshadowed by the placement and representation of the boy in the illustration. The boy was actively participating in the experiment while the girls looked on and helped. Their gaze and body positions point towards the boy while he looks at what he is doing. One might expect the student conducting the action to look at what they are doing, but that is not always the case, as illustrated in the next example.

Figure 4. 4

\section{Teacher Manual, Lesson 1.7}

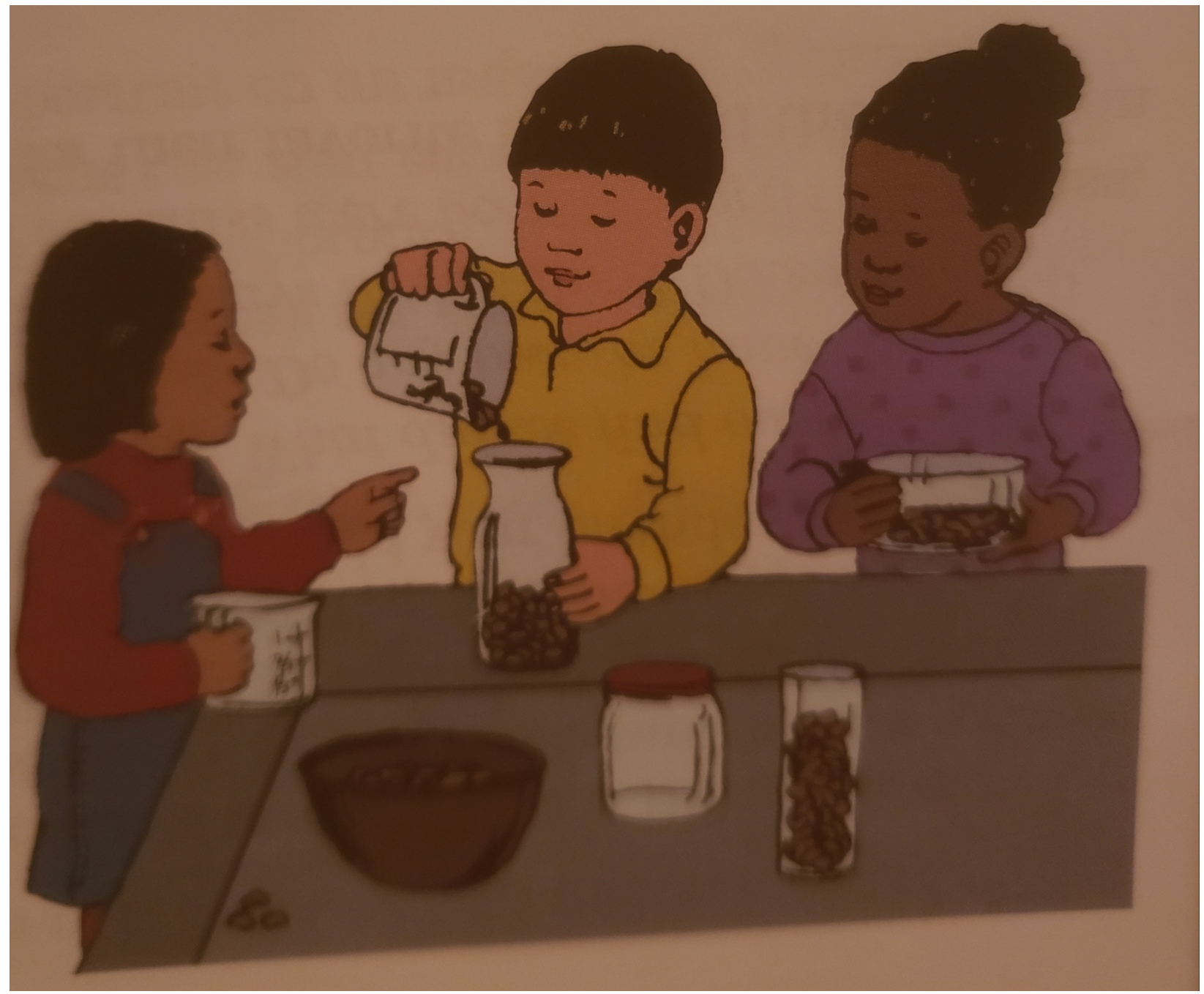


Note: Illustration from Teacher Manual-Lesson 1.7. Reprinted from Everyday mathematics:

Teachers guide to activities, Kindergarten (p. 59), by UCSMP, 2012, McGraw-Hill Education. Copyright 2012 by McGraw-Hill Companies, Inc.

Unlike Figure 4.4, all figures in Figure 4.5 were depicted showing agency; however, the gaze of the figures privileges boys. In this illustration, all students were coded as cooperating. At least one of the girls appeared to be looking at a boy while she worked. However, it is my interpretation that all three girls were looking at the boys in that illustration. In this illustration, the only example of a boy looking at a girl while she works is the boy hanging the paper chain. This makes sense as it would be difficult to hang a paper chain evenly without looking at the height of the other person's side.

The two figures positioned furthest left in Figure 4.5 send a different message from the two figures positioned furthest left in Figure 4.4. In Figure 4.4, the girl appears to be talking to the boy, using hand gestures to communicate. While she is doing this, her gaze and body positioning are pointed toward the boy. In turn, the boy is positioned facing her, but his gaze is on his task. In contrast, the boy in Figure 4.5 appears to be communicating with the girl who is stirring the punch. It appears he might be handing her the spoon. In this case, the boy is positioned slightly toward the girl, but his gaze in on his task, handing the spoon. However, the girl is not focused on her task, but looking at the boy. One could certainly argue that the girl needs to look at the boy if he is handing her the spoon. It is my interpretation that both illustrations show a boy focused on his task with girls focused on the boy, regardless of their level of agency. Girl students are not the only figures to privilege boys through gaze, as will be shown in the next illustration. 


\section{Figure 4. 5}

Teacher Manual, Project 4

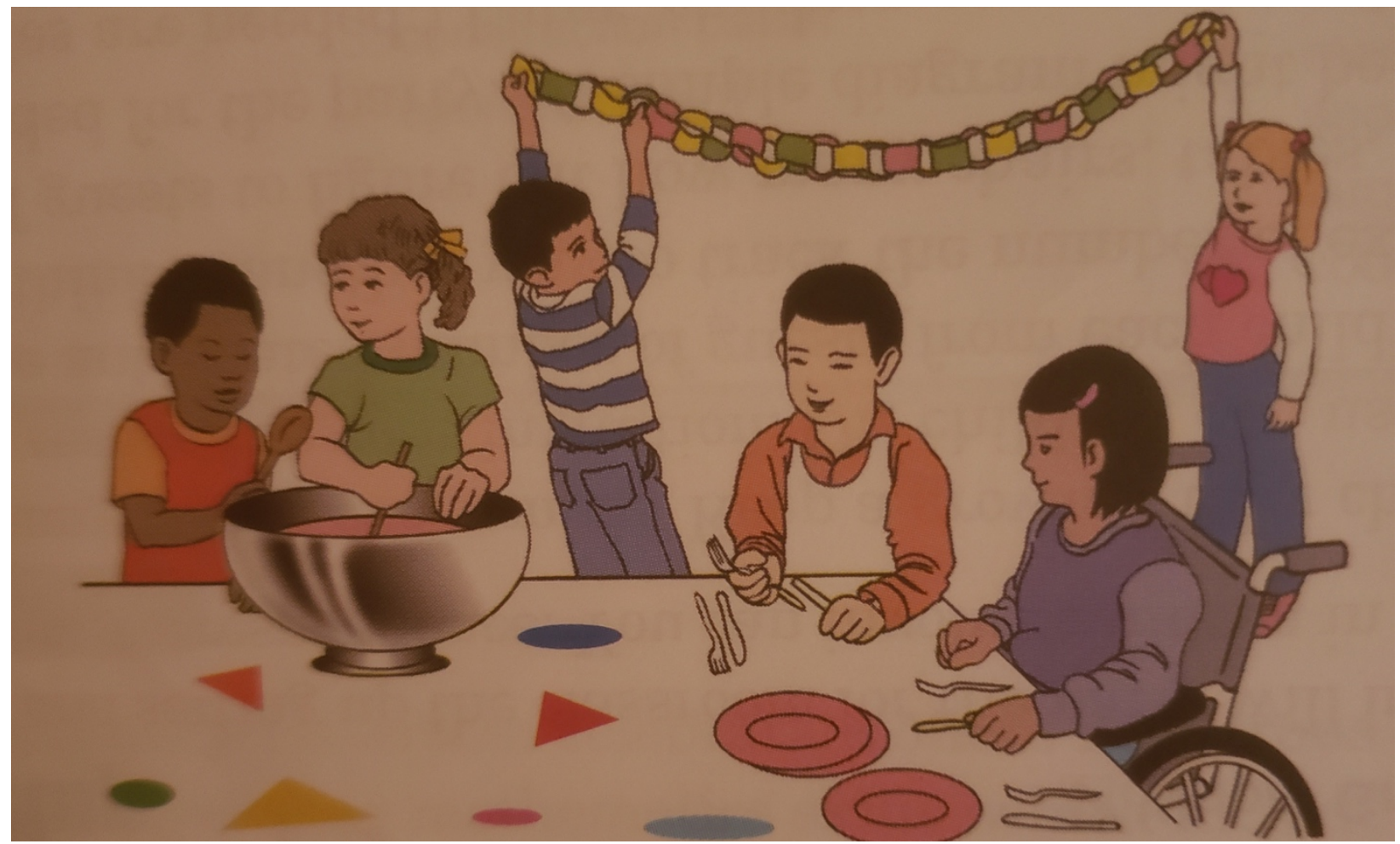

Note: Illustration from Teacher Manual-Project 4. Reprinted from Everyday mathematics:

Teachers guide to activities, Kindergarten (p. 224), by UCSMP, 2012, McGraw-Hill Education. Copyright 2012 by McGraw-Hill Companies, Inc.

In Figure 4.6, a larger group of children and their teacher were shown holding numbers and participating in a number identification activity. The children holding the number 10 were both coded as solving a problem as they were identifying themselves as holding the number 10 by kicking their foot in the air. For the most part, girls and boys appeared to be observing both the boy and girl kicking. The teacher seemed to be looking at the boy kicking. This illustration captures the well-researched idea that teachers give boys more attention than girls in the classroom (Sadker \& Sadker, 1994). Not only did illustrations in the teacher manual depict girls watching boys, but they also depict a teacher centering a boy in the class with her gaze. 
Sometimes the illustration is less clear, but when coupled with the text, the message conveyed to the audience is clearer, as will be shown in Figure 4.7.

\section{Figure 4. 6}

Teacher Manual, Lesson 2.11

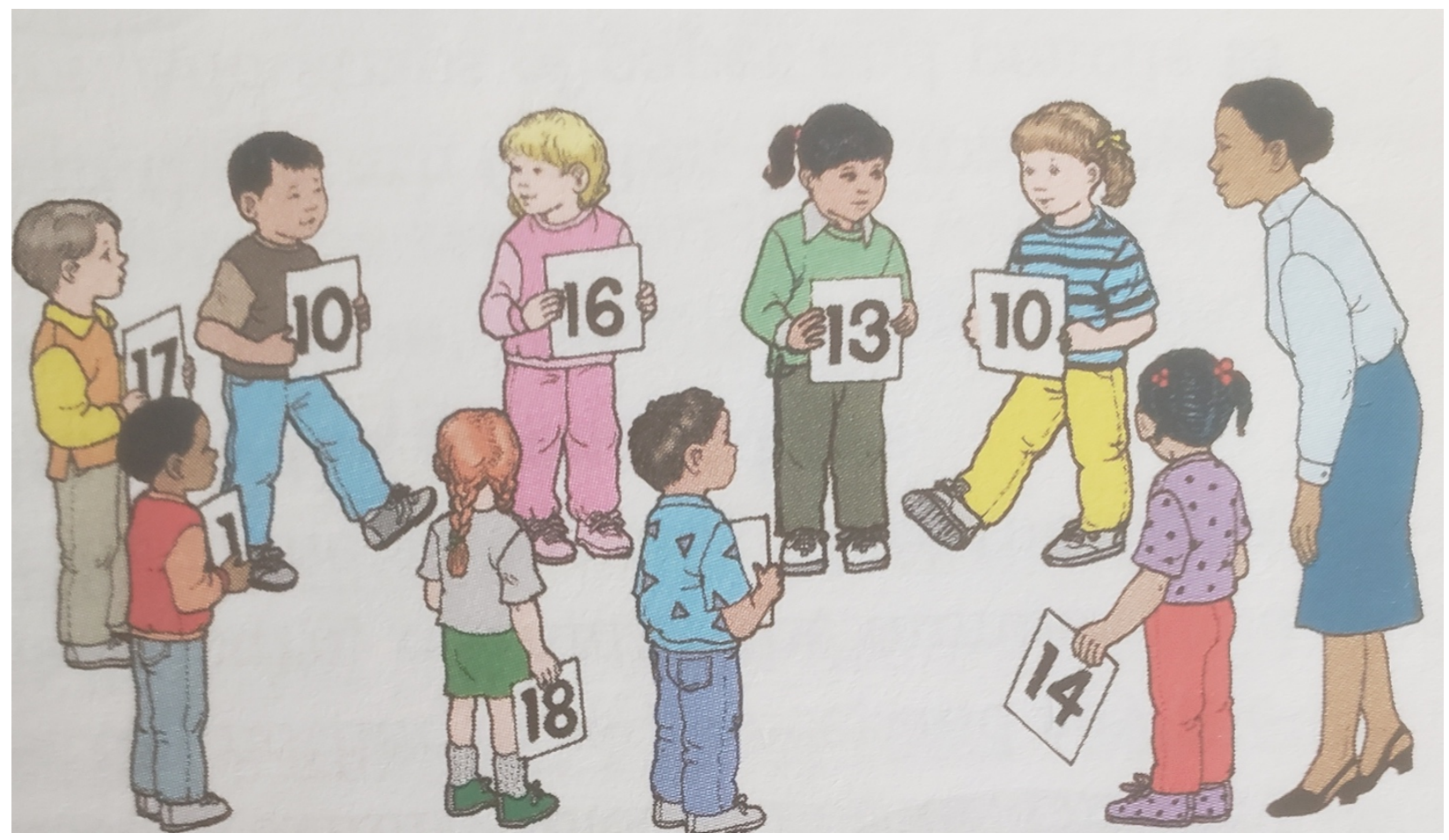

Note: Illustration from Teacher Manual-Lesson 2.11. Reprinted from Everyday mathematics:

Teachers guide to activities, Kindergarten (p. 110), by UCSMP, 2012, McGraw-Hill Education. Copyright 2012 by McGraw-Hill Companies, Inc.

In Figure 4.7, the illustration showed a boy and girl happily working together to measure something using a paper foot cutout. In this illustration, the boy and girl appeared to be looking at what the boy was doing. It is my interpretation that they are both looking at what the boy is doing because of the positioning of the eyes. The boy was shown with his eyelids seemingly closed, which suggests he is looking straight down, which is where his hands were positioned. 
The girl in the picture does not have her eyelids closed at all, which suggests she is not looking directly down where her hands are but further out from her body.

\section{Figure 4. 7}

Teacher Manual, Lesson 5.6

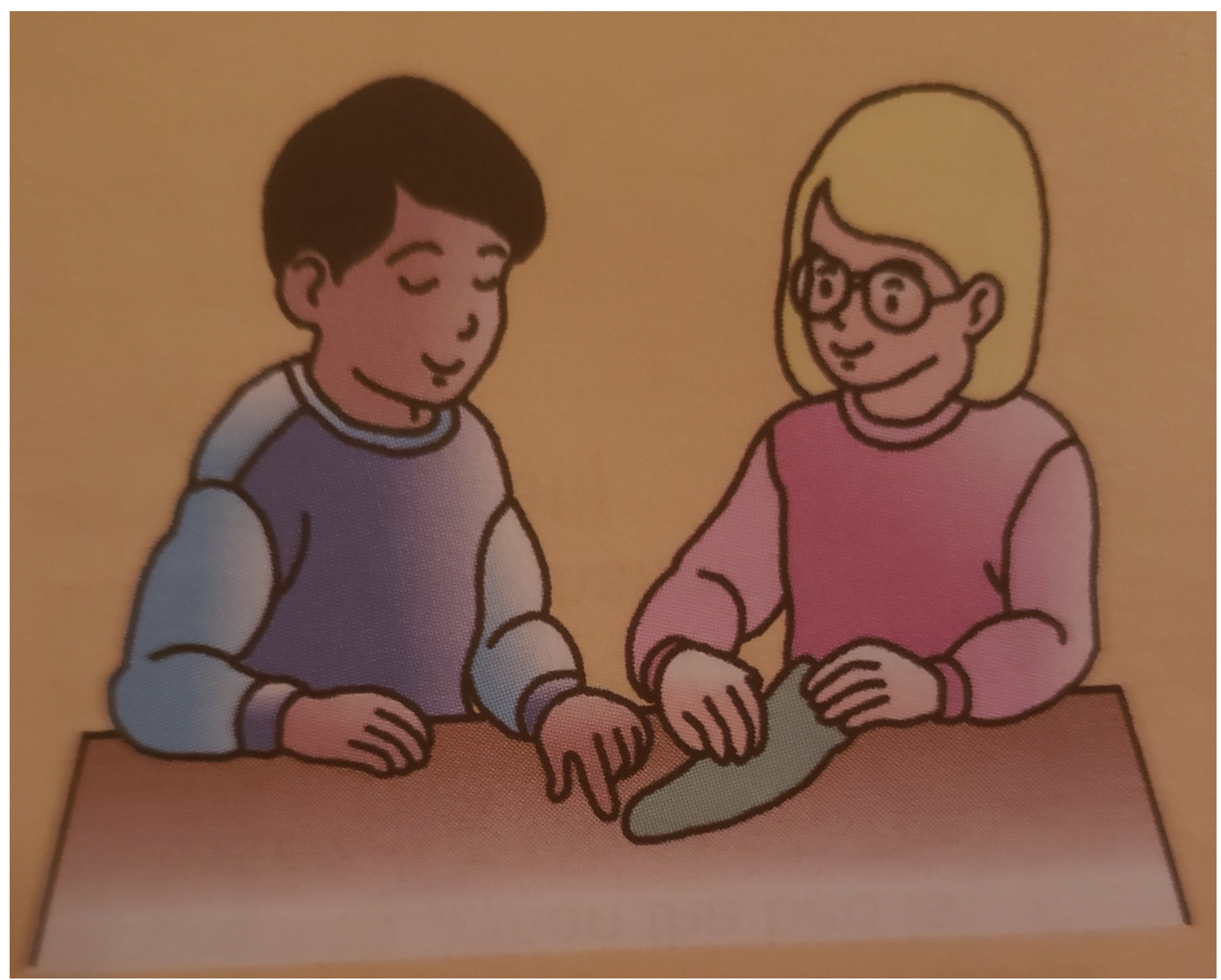

Note: Illustration from Teacher Manual-Lesson 5.6. Reprinted from Everyday mathematics:

Teachers guide to activities, Kindergarten (p. 247), by UCSMP, 2012, McGraw-Hill Education.

Copyright 2012 by McGraw-Hill Companies, Inc.

This interpretation is strengthened when one examines the text connected to the illustration. The directions in the text state: 
Demonstrate how to keep track of the end of the toe and put the heel in front of it, just as they did with their own feet. This is known as 'marking off.' Working with a partner might help them mark off and keep track of the counts as they measure. (Pair children who understand the concept of marking off with those who are having difficulty with it.) (UCSMP, 2012d, pp. 247-248).

Likewise, the caption under the illustration clarified which student was marking off: "One child marks off the end of the toe with his finger while the other child moves the foot cutout so the heel is right in front of the first child's finger" (UCSMP, 2012d, p. 247). When coupled with the text explanation, the illustration suggests that the boy student was depicted as knowledgeable and the girl student needed help. If that was the case, then it makes sense that both students were looking at what the boy was doing as he is the leader in this partnership. Although subtle, the message in the text in connection with the illustration suggests that the boy understands what to do and is paired with a girl who may be having difficulty with the skill.

Boys Observing Girls. There are two pictures that depict boys looking at girls, while the girls look at their work or do not look back at the boys. However, these two illustrations convey very different messages about the dynamics between the students. One illustration is located in the teacher manual while the other illustration is located in the activity cards, a resource for students.

In Figure 4.8, the illustration from the teacher manual showed a girl walking the number line while a boy watches her. In this illustration the girl appeared to be looking at the ground and holding her arm with her feet close together. Those gestures suggest she is apprehensive, insecure, or unsure. When completing a math task, those feelings are not atypical; however, the boy in the illustration was depicted in a completely different way. Although he was not 
completing the task, his body language suggested confidence. He is standing with his legs spread slightly, facing the girl and the reader. He had his arms crossed in front of his body. It is important to note that the interpretation of the power dynamic in this illustration includes increased power on the basis of gender and race. This illustration depicts a white boy in a powerful position observing a Black girl who appears to show insecurity. This illustration perpetuates both the stereotypical power dynamics between boys and girls, but also between white boys and Black girls.

\section{Figure 4. 8}

Teacher Manual, Lesson 4.1

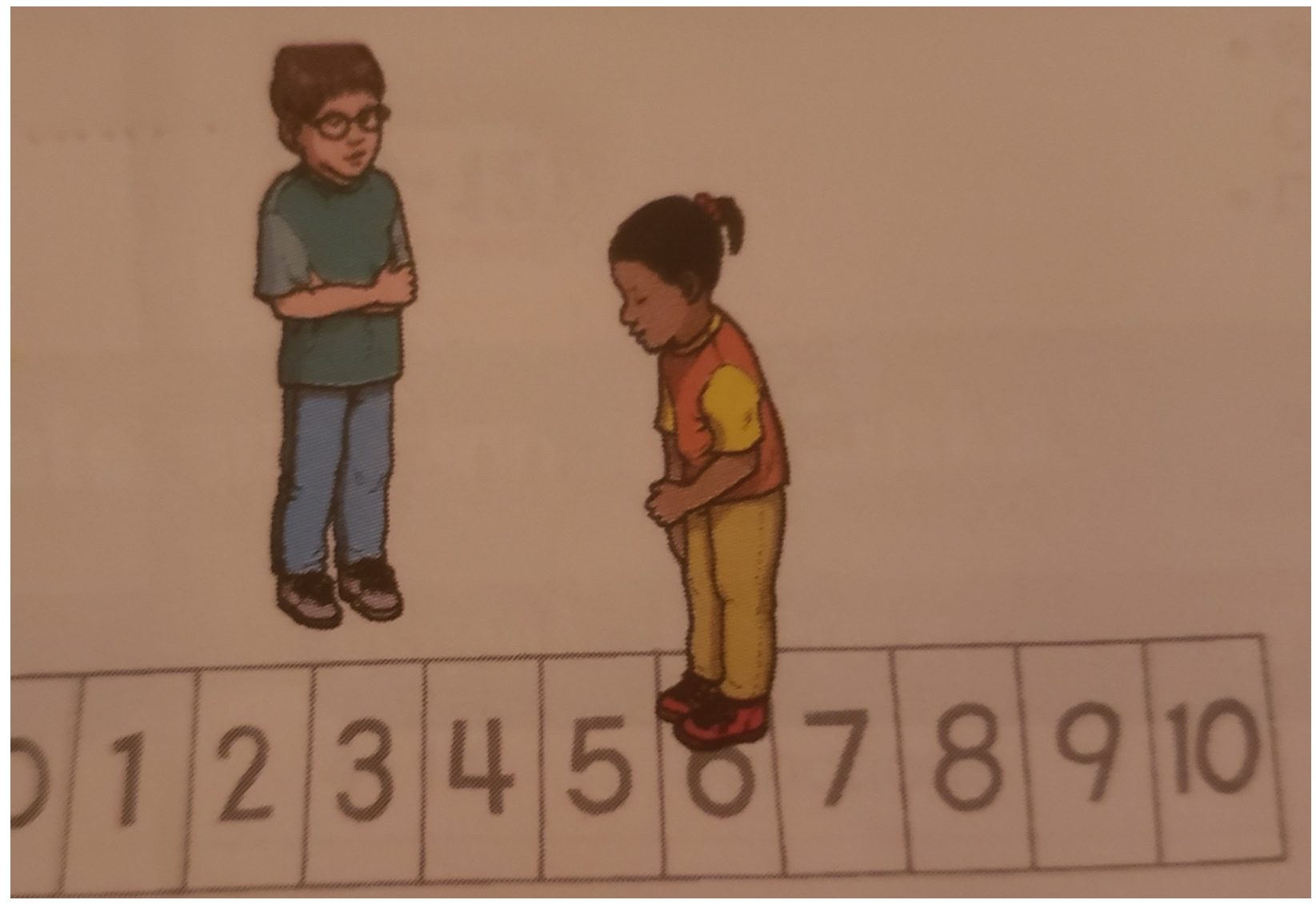


Note: Illustration from Teacher Manual-Lesson 4.1. Reprinted from Everyday mathematics:

Teachers guide to activities, Kindergarten (p. 188), by UCSMP, 2012, McGraw-Hill Education. Copyright 2012 by McGraw-Hill Companies, Inc.

In contrast to the illustrations in the teacher manual, Figure 4.9 depicts a girl and boy happily playing a math game. The boy appeared to be looking at the girl while she takes her turn playing the game, while the girl appeared to be looking at the cards and tokens in front of her. This is an example of a girl focused on her task and her partner using gaze to center her in this illustration.

\section{Figure 4. 9}

\section{Activity Card, Lesson 4.2}

[Copyright permission could not be obtained for this illustration. Please see page 16 of the Center Activity Cards from the resource cited below.]

Note: Illustration from Center Activity Cards-Lesson 4.2. Reprinted from Everyday Mathematics Center Activity Cards (p. 16), by UCSMP, 2012, McGraw-Hill Education. Copyright 2012 by McGraw-Hill Companies, Inc.

Although there are few pictures, the teacher manual and activity card convey different messages about who is most important in the illustration or during an activity. The teacher manual depicts four illustrations where girls appeared to be observing boys or observing boys' tasks. In contrast, only one illustration and part of another showed a boy doing the same. In the illustration where only the boy appeared to be observing the girl, the body language of both figures suggests an unequal power dynamic. Finally, the illustration of a boy observing a girl while she completes a task is located in the activity cards, a student resource. Teachers and students may be receiving different and unequal messages about the figures privileged during activities, and I argue that the teacher manual depicts these situations with gender bias. 


\section{Unequal Representation of Adults-Women are Helpers and Men are Absent}

Throughout the curriculum materials, there is no mention of men in text or illustrations. In contrast, there are five representations of adult women in text and illustrations - grandma, mom, and teacher. In three of the examples, the adult women were part of the setting and are observing. In two examples, the women were helping the student play a game or complete an activity. In one example an adult woman, presumably the child's mother, is shown measuring the child (See Figure 4.10). These examples reinforce the stereotype that adult women are the caregivers, and adult men are not. In this activity, families are encouraged to practice measuring at home and comparing those measurements (UCSMP, 2012b).

\section{Figure 4. 10}

Math Master, Project 2 


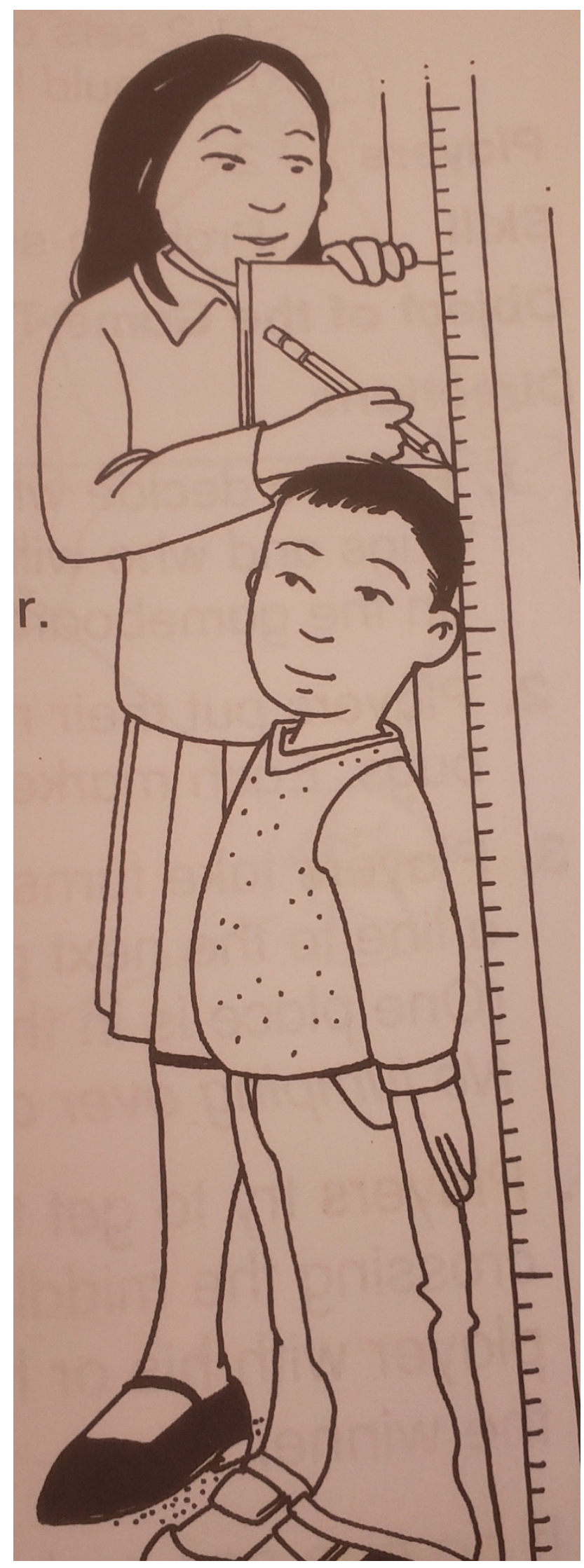


Note: Illustration from Math Masters-Project 2. Reprinted from Everyday mathematics: Math

Masters, Kindergarten (p. 67), by UCSMP, 2012, McGraw-Hill Education. Copyright 2012 by

McGraw-Hill Companies, Inc. Reprinted with permission.

\section{Conclusions from Curriculum Analysis}

Overall, girls and boys are referenced through inclusive gendered pronouns like he or she and non-gendered singular and plural nouns like child and children. When gendered pronouns are used, the masculine pronoun is always positioned first. Although typical of writing in the western hemisphere, positioning the masculine pronoun first is not a requirement and subtly reinforces androcentrism.

Comparatively, there are far fewer representations of gendered text and illustrations. Girls are represented slightly more frequently in both text and illustrations. This difference increases when adult women are included in the count for girls. Increased frequency of girls in math curriculum aligns with other studies of curriculum where researchers have found an increase in representation of girls throughout the 20th and 21st centuries (Blumberg, 2007). When coding for differences, the largest difference is that girls are shown as competing more often that boys. This finding challenges the stereotypical representation of girls as less competitive than boys. However, there are more similarities between how girls and boys are represented than there are differences in their representation.

The most prominent differences come from positioning, gaze, and gesture in the illustrations. When girls and boys are illustrated together, boys are positioned in a more prominent location and in some pictures, the gaze of the students and teacher increase the importance of the boys. These representations are more likely to be seen by only the teacher because they are located in the teacher manual. Finally, adult men are absent from the text and 
illustrations. Adult women are represented minimally but are represented. All of their representations reinforce that adult women and not men are the caretakers and helpers. Although one could argue there is not enough information to show patterns in representation. I argue that the small number of gendered representations makes each illustration and text example even more important to constructing an understanding of gender roles or in the case of the teacher, reinforcing or challenging more cemented understandings of gender roles within society. Additionally, the messages conveyed through representations in text and illustrations can be altered or reinforced by how the teacher addresses those representations.

\section{Teacher Discourse: What Teachers Say About Girls and Boys}

In addition to examining the intended curriculum, I also examined teachers' perception of gender and its relation to equity in the classroom using Critical Discourse Analysis (CDA) as the methodology. In this analysis, I noticed three major themes: (1) teachers and books play an integral role in shaping kindergarteners' understanding and schema, (2) teachers witness gender segregation and sexist comments in kindergarten while simultaneously expressing that kindergarteners are too young to recognize gender stereotypes, and (3) when gender segregation does come up in the classroom, teachers reinforce gender desegregation and equitable treatment for all students. While exploring participant responses related to gender segregation and conversations around gender desegregation in the classroom, I found that participant language did not suggest equitable treatment for all students; therefore, I examined the Discourses in which participants participated in relation to "ways of being."

In examining the $\mathrm{D} /$ discourses in these interviews, I found that participants engaged in patriarchal Discourses when describing "ways of being" in connection to the picture book, How Big is a Foot? (Myller, 1962). I also explored participant discourse related to "ways of 
representing" and "ways of interacting." In addition, I found that when participants represented girls in comparison to boys and described their interactions, they more frequently mentioned boys, more frequently positioned boys first in their stories, and explicitly and implicitly suggested that boys, not girls or teachers, seem to be the gatekeepers for equitable treatment on the basis of gender.

\section{Teachers and Books Influence Children}

After interviewing all four participants, it became clear that all of them view kindergartners as students who are eager to learn and students who soak up knowledge like a sponge. In reference to what knowledge students acquire, Ms. Johnson even likened her students to sponges, “And so they're just like little sponges." Through examining these interviews, participants believe teachers have a great deal of power when working with students. They have power through their words and lessons. Several participants mentioned how using picture books and other types of literature can be a powerful way to connect and grow student understanding.

Teachers have the Power to Influence Student Understanding. Throughout all four interviews, the participants placed themselves in a position of power and/or placed their students in a position of passive followers. For example, several participants mentioned, "They're 5," with the implicit and sometimes explicit assumption that " [a] 5 year old would [say] oh Okay [italics added for emphasis on imitation of student]. And then go on.” In this example, Ms. Wilson is explaining how because of the student's age, a teacher can give a direction or explain an idea and the student would go along with that idea without any critical thinking or pushback. This is further illustrated in the few comments where she compares teaching kindergartners to teaching older students: 
Especially the younger ones, they're like, oh, okay [italics added to denote imitation of student], you know what I mean, they don't really push back that much...When I taught fourth graders, there's definitely more pushback, probably, because it's just been a little more like, ingrained in them per se,... Um, so just an overall more like welcoming atmosphere towards things that they're at one point we're more rigid in their brains. I guess um just situations like that.

In this quote, Ms. Wilson is explaining why she believes her kindergarteners are more welcoming of the ideas she presents in class in comparison to the fourth graders she previously taught. She believed that the fourth graders had deeper set beliefs and were less likely to have their schema altered based upon conversations with the teacher. Ms. Johnson recognized how impactful her role as a teacher could be and warned against pushing "agendas" onto students: And when you're teaching children know that they think everything that you say, rises and falls with the sun. So you've got to be very careful on how you approach and not you know, I don't ever believe in pushing a political agenda or, or any agenda on a child, but address the issues, honestly, as you can, and uh know that they believe everything you say, um and...embrace that...

In this quote, the participant discusses how her words and ideas influence her students and warns against pushing a political agenda.

All four participants believe they impact their students through the words they use and the ideas they share. Because they believe in their impact, it is important to examine the words and resources they use to represent gender and equity. The words and ideas they choose to use during their interviews provide a snapshot of their beliefs and how they may present ideas in their own classroom. 
Literature can Reinforce or Challenge Ideas. In addition to teacher discourse, picture books and other types of literature seem to influence student understanding and sense-making. All four participants have used literature to reinforce ideas, supplement their instruction in academic subjects and to promote growth in social emotional development. Two of the participants focused on the importance of using literature to engage students and introduce concepts. For example, Ms. Cooper mentioned, "I did tend to use a lot of literature to introduce the conversations that I want to have around, you know, whatever it is, when it comes to equity and representation." Likewise, Ms. Wilson confidently explained how using a story during math instruction is a good pedagogical choice, "I think that's always good to do in math to somehow integrate a story because obviously, kids that age love listening to stories, and they can connect well to that." Because all four participants use literature in their instruction and believe that the teacher and books play important roles in transferring knowledge and ideas to children, it is important to specifically examine the ways in which teachers use literature to introduce and discuss equity in the classroom.

Teachers' Presentation of Literature Reinforces or Challenges Ideas. Participants shared they all use books to varying degrees and in different situations. Books can be used to reinforce objectives and ideas but can also be used to challenge stereotypes and representations. The participants were split on whether or not it was appropriate to discuss issues of equity in books outside of lessons about equity.

When asked about addressing equity through books, most participants mentioned that they address equity during read aloud and social studies lessons. For example, Ms. Johnson explained what resources she uses to introduce racial and gender equity in social studies: 
I read a book called Grace for President. And I like to emphasize the fact that, you know, what, we need a girl president, you know, because this is what...the story is all about. Or when we're talking about the uh racism, you know, when we're talking about uh Black History Month, you know, I'll read a lot of books, and we'll talk about slavery.

Ms. Wilson also introduces of equity in social studies lessons:

um, no the only like the other places, it'll [issues of equity] come up sometimes is if we're learning about something in social studies or history, and I have to explain to them, you know, the, the differences for whether it's a woman or a person of color, or whoever...if it's something where I know it's a lesson, I said about social studies, or history or a book we're gonna read, and it's something I know, they're gonna have, like questions about I'll address like, before we read it, you know, or before we talk about it.

Although Ms. Wilson did not mention bringing up issues of equity in books outside of read aloud or social studies lessons, she did mention modifying lessons by replacing books with personal stories or changing the wording of the book as she read if she thought the book showcased inequities.

Ms. Cooper felt like using a book with apparent inequities provided opportunities for a teachable moment and expansion of a lesson. Unlike Ms. Johnson, she did not feel limited to the objective or subject matter. She felt like addressing the inequity was equally as important as meeting the objective:

you know, they think you could [sic] still use it and then have, if it's like, well, if I am going to use this book, I'm going to make sure I have this conversation along with this book and...be able to do both. 
Even though participants were split on the extent one should address inequities in books, all three examples show how the participants might address inequities while using picture books.

\section{Gender Segregation: Are Kindergarteners Too Young to Make Sense of Gender?}

Throughout all four interviews, the participants echoed one another that kindergarten children are too young to recognize and understand gender stereotyping. These comments align with Bem's (1993) gender schema theory, which suggests that children in that age range do not have a concrete understanding of gender or gender roles. Experiences in early childhood are what shapes a child's understanding of gender and gender roles (Bem, 1993). What is missing from participants' understanding is that adults generally have a more cemented view of gender roles and gender stereotyping, which they unknowingly perpetuate or challenge on a daily basis. For example, while all participants mentioned that students are too young to recognize and understand gender stereotypes, they all brought up examples of student-created gender segregation in the classroom and on the playground.

In order to explain why they believe students are too young to notice gender stereotypes, two participants explained that their students do not vocalize gender segregation in books, they have not learned stereotypes, and so, according to their logic, gender stereotypes do not come up in kindergarten. For example, when asked about how characters were represented in the book, How Big is a Foot? (Myller, 1962), Ms. Smith mentioned multiple times that her students have never noticed that there were mostly boys in that story:

and my students have never been like that's all boys and...I mean I guess you can look at the pictures...You can obviously hear the pronoun. But if they pick up on that...my students have never said, you know, that book is full of boys, you know, I mean they've never really said that about any book but they're five... I don't think they'd come in, 
noticing that only boys do that or only girls do that, they just, um and that probably has a lot to do with their age they haven't learned those stereotypes that are out there yet... These are little tiny people they're five years old and they, and you know most of them have not been exposed to stereotypes,

Ms. Smith's explanation of how students come to understand gender stereotypes seems like she may believe that children cognitively acquire gender stereotypes and that acquisition of gendered stereotypes is inevitable.

Likewise, Ms. Johnson mentioned that issues of gender inequity rarely come up, "It usually with 5 year olds, it very rarely comes up. If anything, we're...talking about someone not playing with me, you know?" Both of these participants felt that the students were too young to know about gender stereotypes and did not notice those stereotypes.

Children Categorize by Gender. What is most interesting about the argument that kindergarteners are too young to recognize gender stereotypes is the constant reiteration that kindergartners know she is a girl or woman and he is a boy or man. This suggests a misunderstanding of gender. When a child identifies another child as a girl or boy, they are making an assumption based on gendered traits. For example, Ms. Smith mentions a few times that her students know who is a boy and who is a girl, "I mean obviously they know, 'oh he's a boy and she's a girl' but, um, to know that... but my kids at 5 years old are gonna know that you're gonna think that the queen is a girl and a king as a boy." Likewise, Ms. Johnson states:

And that time I just have to be honest with you. They look at each other as male and female. And I know this world is changing every day and people are not wanting to take that. That stand, but you know, and kindergarten, we're still male and female. 
In this quote, the participant is explaining that even though she believes the students are too young to understand gender stereotypes, she says that her students categorize other children into a binary gender system, even though those are not the only two genders on the spectrum. In addition to often defining children as girl or boy, the participants described scenarios of gender segregation that have come up in the classroom. Although participants may feel that children are too young to make sense of gender and gender dynamics, Bem's (1993) gender schema theory suggested that young children form their understanding of gender during these years; therefore, I would argue that a teacher's choice to address or ignore gender dynamics in the classroom and literature consistently contributes to a child's understanding of gender and gender roles.

\section{Gender Segregation and Gender Desegregation}

Despite claims from participants that kindergarteners do not come into kindergarten knowing or understanding gender stereotypes, they provided examples of gender segregation that are stereotypically gendered. According to Diekman and Murnen (2004), two ways that gender segregation can occur are: (1) small children are shown acting out only gender-typed jobs in role play; and (2) gender is a primary method of categorization, and/or the basis of widespread generalizations (i.e., "Boys do this, but girls do this."). For the purposes of this study, I categorized instances similar to Diekman and Murnen's (2004) definitions of gender segregation and instances that appear to be the opposite, or an attempt at the opposite, as gender desegregation.

This next section includes findings most closely connected to teacher perceptions. First, I will describe the findings from teacher discourse of the intended curriculum or their perceived enactment of the intended curriculum, focusing on "ways of being" and "ways of representing." Then I will provide findings that support the teacher participants' participation in and 
perpetuation of androcentric Discourses. Next, I will share findings from teacher discourse of gender-segregated scenarios in the classroom and their responses to those scenarios, focusing on "ways of interacting" and "ways of representing." Finally, I will share findings related to how teacher participants challenge gender stereotypes through books, guest speakers, and pictures.

Teacher Perceptions: Teacher Discourse about the Intended Curriculum. Part of the interview required participants to analyze a picture book used in a lesson from the Everyday Mathematics curriculum. How Big is a Foot? (Myller, 1962) is one of only a few books that is part of the core activities of the lesson in the teacher manual (UCSMP, 2012d), which means that it is strongly encouraged since the remainder of the lesson relies on background knowledge from the story. The summary from the curriculum states:

The king decides to have a bed made for the queen's birthday. He marks off the dimensions of the bed with his feet and gives them to the head carpenter, who gives them to his apprentice. When the bed is delivered, it is too small. The apprentice must figure out why this has happened. (The king's feet are longer than the apprentice's feet!) (UCSMP, 2012d, p. 248).

Gender Segregation in How Big is a Foot? Based upon the summary and background knowledge of medieval Europe, one can probably conclude that this story includes mostly men characters. In explaining whether or not this text conveys different messages about women in comparison to men, three participants revealed they believed that the story showed the men as problem solvers and the one woman in the story, the queen, as a passive receiver of the king's gift. For example, Ms. Wilson stated:

I think it's definitely conveying that men are problem solvers, whereas women are just passive and can don't need to, like they don't worry about that, like the men are the 
problem solver. So the woman don't need to be, essentially. Um Or they're not even like smart enough...The king had this brilliant idea. And it's like the queen [sic; king] didn't even ask for the queen's input or help. Or if she wanted it.

Ms. Smith did not believe that this story conveyed different messages about women in comparison to men: "So I don't know...I just don't see that it per se, you know that this specific book shows you know. I don't know. Yeah, and I I mean, I don't, I don't see that it gives a message." And finally, Ms. Johnson mentioned that she thought it did convey that the king had more control than the queen, but that was appropriate and an accurate representation of the time period: “and how he's represented um is appropriate, because it's actually his gift to the queen. And how how that monarchy would function." Ms. Johnson brings up ways of being when she implied that the power dynamics are okay because that was the way things were.

Ways of Representing and Ways of Being: That's Just How It Is. According to Rogers and Wetzel (2014), "ways of being" include discursive features such as transitivity, tense, voice, modality, mood, nominalization, and appraisal, while "ways of representing" include discursive features such as information focus, lexical relations, lexicalization, re-lexicalization, pronouns, and exclusion (See Appendix E). For the purpose of these findings, I focused on the following discursive features: information focus, lexicalization, pronouns, exclusion, tense, and appraisal. Ms. Johnson, Ms. Cooper, and Ms. Smith all brought up that the story reflected the era in which it was written and the era in which it was set (See Table 4.7, for examples).

\section{Table 4. 7}

Ways of Being and Representing in How Big is a Foot?

\begin{tabular}{lcll}
\hline Participant & Line(s) & $\begin{array}{l}\text { Gender } \\
\text { Reference(s) }\end{array}$ & Text Example \\
\hline Ms. Smith & $173-177$ & Girls and Boys & $\begin{array}{l}\text { The queen is a woman and the king is a man } \\
\text { and most of those jobs at the time were, um } \\
\text { you know, men. }\end{array}$
\end{tabular}




\begin{tabular}{|c|c|c|c|}
\hline Ms. Smith & $181-188$ & Girls & $\begin{array}{l}\text { Uh you know, it might be, you, if you look at } \\
\text { the thing it might be odd if one of them } \\
\text { [supporting characters] was a woman, you } \\
\text { know, if one of them [supporting characters] } \\
\text { was a woman. }\end{array}$ \\
\hline Ms. Johnson & $151-154$ & Boys & $\begin{array}{l}\text { So, you know, and and, you know, minus } \\
\text { England right now, but the men are always } \\
\text { portrayed as the one in control. }\end{array}$ \\
\hline Ms. Johnson & 275 & Boys & $\begin{array}{l}\text { It was a more male dominated world. It } \\
\text { probably still is a more male dominated world }\end{array}$ \\
\hline Ms. Cooper & $168-169$ & Boys & $\begin{array}{l}\text { Like, yeah, like, when they wrote this book, } \\
\text { this is, you know, typically was kind of the } \\
\text { king in charge. }\end{array}$ \\
\hline Ms. Cooper & $170-176$ & Girls & $\begin{array}{l}\text { But, you know, look at England, there's, you } \\
\text { know, it's a queen, and she's } 90 \text {, and, you } \\
\text { know, like, she's in charge of the country, you } \\
\text { know, like, there's kind of we can tie in and } \\
\text { use it as a as the lesson. }\end{array}$ \\
\hline
\end{tabular}

Note. This table includes examples from participant interviews relevant to ways of being and ways of representing.

Out of the six examples mentioned, participants focused on a masculine figure alone four times, a feminine figure twice, and both feminine and masculine figures once, with the feminine figure positioned first in the sentence. In Ms. Smith's example in lines 173-177, she positions a feminine figure first, but the majority of the sentence is about a masculine figure and the power structures pertaining to men during that time period. Similarly, Ms. Smith's second comment focuses entirely on feminine figures but casts them as the "other" and makes the idea of gender desegregation strange in this context despite the fact this story is utilized during a time when many occupations are arguably less segregated by gender. Without explanation of the setting, the participant upholds the power structure between women and men from medieval Europe or even the 1960s, the decade in which the book was published, and conveys to students that those power structures are normalized and typical. 
Unlike Ms. Smith, Ms. Johnson focused on only boys. When given the opportunity to name a feminine character, Queen Elizabeth II, she chose to use the phrase, "minus England right now." Feminine figures are excluded from her explanations and she reiterates that "men are always portrayed as the ones in control," going as far to say that "it [the world] is still a more male dominate [place]."

Finally, Ms. Cooper echoes Ms. Smith and Ms. Johnson by repeating that it makes sense that "the king [was] in charge." She comes closer to naming a feminine character that breaks the stereotype but falls short. She references Queen Elizabeth II by describing her as a "queen, and she's 90, and, you know, like, she's in charge of the country...” Their references to Queen Elizabeth II may not be explicit exclusion but a continuation of the linguistic pattern in the story. The king and queen in the story do not have names and are only referred to as "the king/queen." Although, the naming of powerful women is excluded in these responses, they may be excluded because of a mirroring of the linguistic pattern in the story.

After reviewing the participant responses, the message seemed to be that gender segregation and status inequality was permissible as long as it fit the time period. The focus on men and the upholding of these power structures as "normal for the time period" contribute to the message of status inequity between genders. Because children are constructing their understanding of gender and gender roles in kindergarten, the burden falls on the teacher to point out and discuss examples of status inequality between genders.

Products and Perpetuators of Androcentrism. During the interview, participants reviewed data related to representation in the picture book, How Big is a Foot? As previously mentioned, most participants noticed that men were represented more frequently and in more active ways than the queen. In conversations with the participants, two described how they had 
not or would not have noticed the imbalance in representation before our discussion. Ms. Wilson described how she skims through books and doesn't think too critically about how they represent characters if they are not part of a read aloud:

...When you sent the story, I honestly just kind of like skim through it. And a lot of times for like books that are related, especially to something like math, or I know, that's just like the starting point, I'll just kind of like, skim through it and be like, okay, we're good to go. Um, so I don't like always think about them in this way. Where as I do that a lot more of like our big read aloud books we do now in class.

Ms. Smith echoed this sentiment and seemed insecure about never noticing the imbalance as she had taught this lesson several times. During the interview, Ms. Smith asked me if I noticed any imbalance the first time I read the story because she had never thought about it:

So, can I ask you this real quick like did you cuz you heard the story right you were in here when I read the story...And, Did you notice it [the gender bias]. Did you, Did it come right to you that because I mean honestly I mean I've written this all down but I'm like it did not even cross my mind. I mean, this never crossed my mind and my students have never been like that's all boys...I'm just so curious if, like the first time you heard second time you heard it you're like, you know what, that's all.

Ms. Wilson and Ms. Smith's comments illustrate how pervasive androcentrism is and how difficult it can be to challenge.

In contrast, Ms. Johnson seemed to recognize the gender bias and androcentrism in the story, but chose not to challenge the idea, "So um this story was written in a time where it was a more male dominated world. It probably still is more male dominated, but I choose not to teach that way." Her role in participating in and perpetuating androcentrism is clearer in her comments 
about toys that can be brought in for rainy day boxes, individual boxes where students keep personal items for use during indoor recess:

Um when children bring their rainy day boxes to school, you know, I show samples of all different kinds of toys. And, you know, people, you know, I'm probably just as guilty of it will put a gender spin on different items, you know, like Polly Pockets, or those little mini things, or little cars or little this or whatever.

In these comments, she voiced that she probably does perpetuate gender bias in her encouragement to bring in toys, but also said, "I tried to address it as neutral as possible." Ms. Johnson's response to androcentrism is to address it with neutrality rather than challenge the stereotype. Three of the four participants shared comments that illustrate how they are part of an androcentric society and how they may perpetuate it either intentionally or unintentionally.

Teacher Perceptions: Gender Segregation in the Classroom. Throughout the interviews, participants most frequently discussed instances of children saying that "boys do/like this, but girls do/like this." The most prominent example among all participants was about boys liking the color pink. Every participant referenced a story about a boy liking the color pink at least once, if not more frequently, in her interview. For example, Ms. Cooper stated, "Oh, is that you know, sometimes someone might refer to the color pink is a girl color." In addition to comments about "girl colors," more than one participant mentioned one other common example of gender segregation: playing sports on the playground. Often, these stories included boys not welcoming girls into their sport. For instance, Ms. Wilson explained that after she had a conversation with students about being more welcoming on the playground, she noticed that children were genuinely more welcoming: 
So um, I would say like, just looking back on when I've had those conversations before, like, kids being more welcoming to like a girl joining them to play soccer during recess...just because they have to or because the teacher's watching, but actually like being welcoming towards it and being like, okay, this is actually fine.

In contrast, Ms. Smith mentioned how sports teams for kindergarten-aged children are often coed, meaning both girls and boys play on the same team. She specifically addressed two examples: soccer and t-ball. Therefore, participants have witnessed gender segregation in their spaces, but also provided examples of gender integration. The common thread between comments about gender segregation in the classroom is who is reinforcing gender segregation.

\section{Boys are Gatekeepers to Equitable Treatment: Ways of Interacting and Ways of}

Representing. In addition to how participants represented gender dynamics and equity in their responses, I focused on how they described interactions between girls and boys and how they represented those interactions. I concentrated on "ways of interacting" and "ways of representing." For the purpose of these findings, I have focused on cohesion, information focus, lexicalization, pronouns, and exclusion.

Ms. Wilson, Ms. Johnson, and Ms. Smith all discussed gendered scenarios of student interactions. In each response, participants explicitly or implicitly implied that boys are the gatekeepers for equitable treatment, by naming or implying that boys were the students responsible for including, excluding, and teasing based on gendered activities and preferences (See Table 4.8). Not all participants implicitly or explicitly identified boys as perpetuators of gender segregation when describing classroom scenarios, but no participants implicitly or explicitly identified girls as perpetuators of gender segregation.

\section{Table 4. 8}

References to Boys as Perpetrators of Gender Segregation 


\begin{tabular}{lcc}
\hline \multirow{2}{*}{ Participant } & \multicolumn{2}{c}{ Boys } \\
\cline { 2 - 3 } Ms. Johnson & Implied & Explicit \\
Ms. Smith & 0 & 1 \\
Ms. Wilson & 0 & 2 \\
Ms. Cooper & 2 & 1 \\
\hline Total & 0 & 0 \\
\hline
\end{tabular}

Two examples where participants explicitly stated that boys contributed to gender

segregation came up in interviews with Ms. Johnson and Ms. Smith. While describing a scenario where a child attempted to reinforce gender segregation while discussing favorite colors, she stated: "You know, I had a boy a year ago and his favorite color was pink, and someone [emphasis added] made and issue of it, another boy [emphasis added] made an issue of it..." In this example, Ms. Johnson starts off by not gendering the child reinforcing gender segregation, but in the next clause, identified that someone as a boy in the class.

Similarly, in response to how a kindergartener might know about gender stereotypes, Ms. Smith suggested that older siblings may be the culprits, "Um they, you know, I'm, I'm sure the ones with older brothers might have heard thing, brothers and sisters have probably heard things." In this statement, she first identified older brothers as the individuals who might teach younger students about gender stereotypes, but then quickly included sisters as well. In her haste to include sisters, she continued to position the masculine sibling before the feminine sibling signaling that although she is attempting to be inclusive, the masculine sibling is positioned more often and more prominently in her explanation. Finally, in explaining a situation that might happen in the classroom, Ms. Smith stated:

Like I said, we don't tell anybody they can't play, so everybody can play together and they, you know, if if someone comes and says, you know, he [emphasis added] won't let me play, we then, we talk about it. 
In sharing a story that might happen in her classroom, she gendered the person excluding others, and gendered that child as masculine through the pronoun, "he."

Not all responses explicitly referenced boys as the gatekeepers to equitable treatment. Ms. Wilson brings up three examples that included interactions between girls and boys dealing with gender segregation in the classroom and playground. In one example, she did explicitly mention boys as the ones standing up for girls and allowing them to play with them. Her other two examples were less explicit. In the first example, she described a scenario that occurred during recess:

So um, I would say like, just looking back on when I've had those conversations before, like, kids [emphasis added] being more welcoming to like a girl joining them to play soccer during recess, if that's the thing you know, that's the issue and not doing it. After reading this quote, the question is: to which kids is she referring? If the group is being more welcoming to "a girl," it is reasonable to assume that it is boys and not girls who are the ones attempting to be welcoming, presumably after excluding. In Ms. Wilson's second example, she gave general examples of what has happened in her classroom, “Oh, boys can't like this color. Girls can't like this color. Girls can't do this. We [emphasis added] can't do that." Ms. Wilson transitioned from exclusive terms like girls and boys to the inclusive "we" in the last sentence. Based on the structure of her statement, one could assume that the last sentence represents boys. Using a more inclusive term to represent boys and not girls can lead one to believe that boys are included while girls are "the other," a reinforcement of androcentrism. Even in this description of gender segregation, boys are being upheld as the baseline for how girls are compared. 
Similarly, Ms. Smith also implied that boys are the gatekeepers to equitable treatment when describing how her students intermingle, "the boys play with boys, and girls play with girls, girls play with boys, I mean it. They just intermingle with one another..." Following the structure of the narrative, I expected Ms. Smith to finish her statement with boys play with girls. She excluded that statement from her narrative. This can be interpreted in two ways: (1) She excluded it because it is implied based on the structure of the narrative or (2) she excluded it because in her classroom boys are less welcoming to playing with girls. Based upon comments from other participants about how boys and girls interact in their classrooms, I believe that the second interpretation is reasonable as it aligns more with other comments.

The discourse used to describe gender segregation more prominently positioned boys in the narratives. Boys were not only the group of students being excluded or teased for liking a "girl color," but they were the group excluding others if they believed they did not conform to traditional masculine norms such as girls playing sports or boys liking pink. Because gender segregation does occur in kindergarten spaces, the participants described how they addressed those inequities.

Teacher Response is Gender Desegregation. Every single time a participant brought up a personal story of gender segregation in the classroom, she noted that she made sure to let children know that all children could do or like the activity or thing in question. For example, Ms. Wilson recalled a time when her students mentioned that "oh, boys can't like this color. Girls can't like this color. Girls can't do this. We can't do that." In her response, she emphasized that "girls or boys can do this, we can all enjoy this together." Additionally, many of the participants explained how they create a more inclusive classroom space by rotating through 
classroom jobs, calling on equal numbers of girls and boys to answer questions, and creating rules so that groups like Student Council include both girl and boy representatives for each class.

Even though the participants reiterated inclusion and acceptance of all, the language in their responses tells a less equitable story. In exploring how girls are represented in comparison to boys, I noticed boys are mentioned more frequently than girls in examples and boys are positioned first more frequently than girls when girls and boys are mentioned in the same example. Therefore, I focused on the following discursive features in the narratives: information focus, pronouns, and lexicalization.

Ways of Representing. After exploring all gendered examples of stories among the four interviews, I found that the participants mentioned gendered students, figures, and things 113 times. These gendered instances included mentions of only girls, only boys, and both girls and boys. Examples were originally categorized into five categories: classroom examples, How Big is a Foot? examples, classroom resources, future ideas, and societal norms. After categorizing the examples, I examined the classroom examples more closely and separated out examples where participants described responses to gender segregation, examples of gender desegregation in their classrooms, and hypothetical examples of gender desegregation that could happen in their classrooms.

Boys are Represented more Frequently than Girls and Positioned First. I counted 31 instances where participants used gender in their explanations. Participants mentioned examples with both girls and boys more frequently than mentioning examples with only girls or only boys (See Figure 4.11). Participants described examples with only boys more than examples with only girls. Additionally, when both girls and boys were mentioned in the same thought, line, or story, boys were positioned first in the sentence more frequently than girls. 


\section{Figure 4. 11}

Ways of Representing Girls and Boys

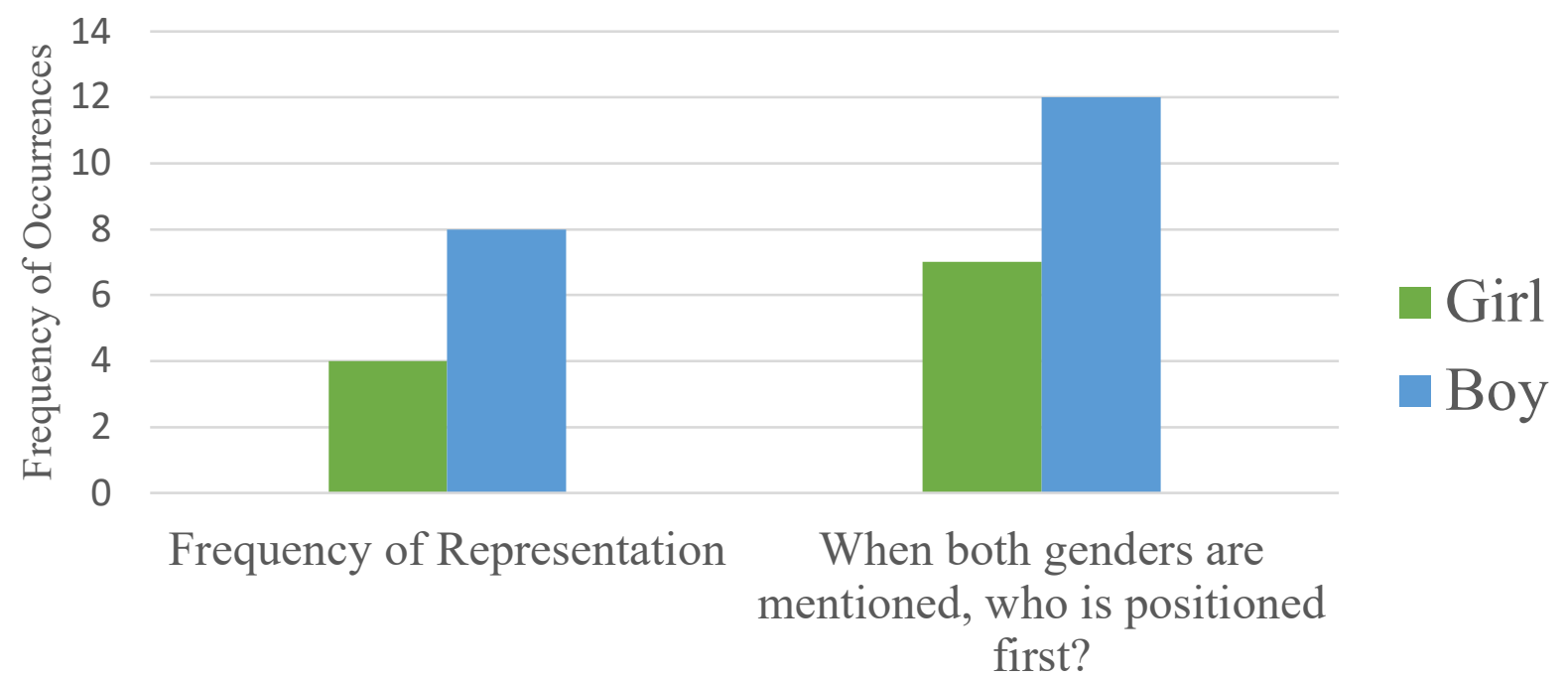

One Step Further: Desegregation through Literary and Pictorial Representations. In addition to addressing issues of gender segregation through gender desegregation, many participants described how they attempt to challenge occupational stereotypes by introducing counter stereotypes through literature and pictorial representations. Participants were asked about the resources they use to introduce or reinforce gender equity in their classrooms. Most of the participants focused on increasing representation for girls and did not mention non-stereotypical representations for boys. For example, Ms. Cooper, Ms. Wilson and Ms. Johnson all mentioned books that show women in non-traditional roles. For example, in response to how she introduces issues of gender equity in her classroom, Ms. Wilson discussed how she does not have specific books about gender equity, but does try to include books that represent women in nonstereotypical occupations and ways:

So my like, go to books that I like to show my kids aren't they're not like, the topic of them isn't like gender equity, but I try to, like, have books where like girls are depicted as the scientists or the mathematicians or, you now, in the stories and stuff like that, um, 
whereas roles where they might not traditionally see them in. And so that that way, it's just exposed to them, I guess, in that way.

In addition to books, Ms. Cooper mentioned guest speakers and pictures around the classroom as a way to increase non-stereotypical representation in the classroom. She also focused on representing women in STEM fields, "And in terms of guest speakers, you know, things like having a female scientists come in to be guest speakers."

When discussing introducing and addressing issues of equity in the classroom and representation, only two participants brought up representation of boys. When discussing representation in books, Ms. Cooper brought up books that include vignettes about famous men, but she was unable to give any titles related to those books. After describing opportunities for guest speakers, she mentioned the importance of discussing stay at home dads to speak as well, "I guess what we could talk about stay at home dads too, and that that's kind of broken, you know, that stereotype that it's more, more common to have dad staying at home as the parent as well." Her language is much less certain when bringing up this representation, which is evident in her use of the words "guess" and "kind of." Similarly, Ms. Johnson mentioned having pictures of "mommies and daddies" in the play area to represent boys as caretakers, "And I have a have pictures of boys and girls dressed up like mommies and daddies or doctors. And they're holding babies in rocking chairs, and they're the sweetest pictures ever." Even though both participants mentioned representing boys in a non-traditional role as a caretaker, their focus seemed to be on increasing non-traditional representation for girls.

\section{Conclusion}

After examining teachers' perception of gender and its relation to equity in the classroom using Critical Discourse Analysis (CDA) as the methodology, I found three major themes: (1) 
teachers and books play an integral role in shaping kindergarteners' understanding and schema, (2) teachers witness gender segregation and sexist comments in kindergarten while simultaneously expressing that kindergarteners are too young to recognize gender stereotypes, and (3) when gender segregation does come up in the classroom, teachers reinforce gender desegregation and equitable treatment for all students in their discussion with me. Upon closer examination of the $\mathrm{D} /$ discourse of participant narratives, I found that participant language did not suggest equitable treatment for all students. Androcentric Discourses were upheld in discussions concerning the picture book, How Big is a Foot? (Myller, 1962) and boys were represented more frequently, prominently, and as gatekeepers to equitable treatment in the classroom. Finally, teachers shared how they reinforce non-stereotypical representations of occupations through books, guest speakers, and pictures, but the focus was mainly on representing girls nonstereotypically. After examining the $\mathrm{D} /$ discourses in the intended curriculum and of kindergarten teachers, I was able to draw conclusions between the findings and connect them to existing literature and gender schema theory.

\section{Discussion}

After analyzing both the intended curriculum and teacher perceptions, three connections emerged: (1) teachers and curriculum predominantly use inclusive and non-gendered language;

(2) teachers and curriculum represent girls and boys similarly; and (3) gender bias through language and illustrations is subtle. Further examination of subtle gender bias revealed that boys are privileged in language and intentional non-stereotypical representations of girls are more prevalent than non-stereotypical representations of boys.

Figure 4.12 shows how the main findings connect with the sub-findings. 


\section{Figure 4. 12}

\section{Discussion of Findings}

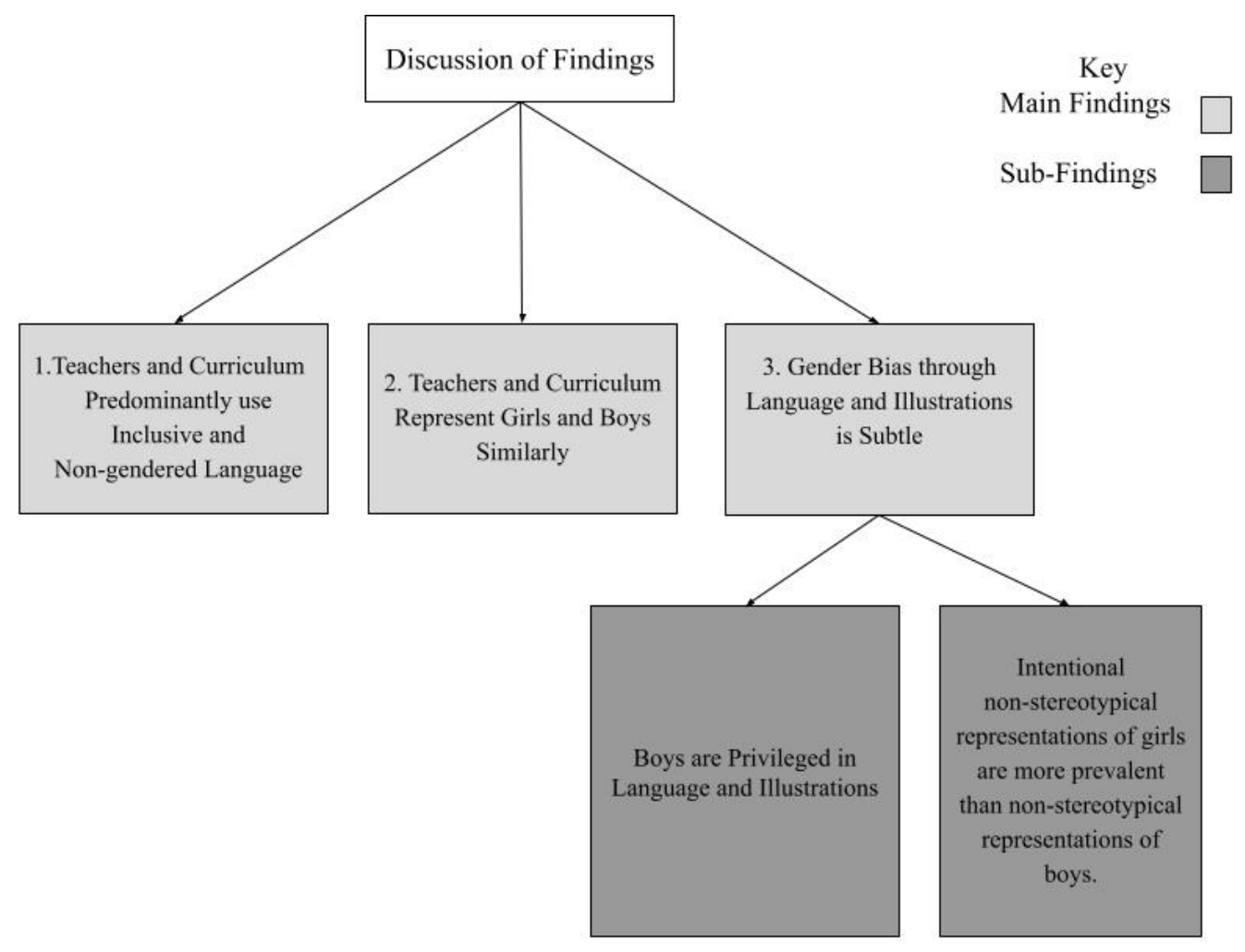

Note. Developed by author.

In this discussion, I explain why these findings may have emerged, describe how they align with or counter existing literature, how they connect with Bem's (1993) gender schema theory, and provide implications for future research.

\section{Teachers and Curriculum Predominantly use Inclusive and Non-gendered Language}

Examination of curriculum and teacher discourse illustrate that the language used is more inclusive and gender-neutral than exclusive and gendered. The curriculum and teachers used a variety of terms to refer to students in inclusive, gender-neutral ways such as: child, children, they, them, students, kids, etc. In their review of literature on math and gender, Lubienski and Ganley (2017) suggested that researchers agree there are more similarities between girls and 
boys regarding mathematical thinking, approaches, and performance than there are differences. I believe that the use of more inclusive and gender-neutral language in curriculum and by teachers is reflective of the sentiment that there are more similarities between girls and boys than differences. It makes sense that curriculum writers and teachers would refer to girls and boys together using inclusive terms because the vast amount of similarities between them require frequency in inclusive language.

\section{Teachers and Curriculum Represent Girls and Boys Similarly}

Findings from this study align with trends of curriculum analysis that show an improvement in the frequency and intensity of representation in textbooks (e.g., Blumberg, 2007). Additionally, similar to findings from Sadker and Zittleman (2009) teachers focus on all children and address explicit sexism in the classroom. Although findings suggest subtle gender bias, teachers and curriculum do seem to represent girls and boys similarly in their discourse.

\section{Curriculum Connections}

Aligning with other studies of gender representation in elementary math textbooks, the frequency of representation of girls and boys has become more equal over time (Blumberg, 2007; D. Sadker \& Zittleman, 2009). However, having a more equal representation in quantity of girls and boys may have more to do with the age of the audience of this book than the year this book was published. Weitzman and Rizzo (1976) found that there was more equal representation of girls and boys in illustrations in early elementary textbooks than in middle-grade textbooks. Further examination of this curriculum in other grade levels is necessary to determine whether or not the more equal representation of girls and boys is a sign more equitable times or aligns with Weitzman and Rizzo's (1976) findings. In contrast to the findings in Northam (1982) and Walkerdine (1998), I found that these curriculum materials showed more equitable 
representation in how girls and boys were represented. Because previous studies (e.g., Northam, 1982; Walkerdine, 1998) did not include textbooks intended for such a young audience, the more equitable representation in how girls and boys are depicted may be a result of the age of intended audience or part of a trend of more equitable representation.

Aligning with Northam (1982) and Walkerdine (1998), this study found that girls were depicted as observing and part of the setting more frequently than boys and boys were depicted as solving problems or displaying a skill more frequently than girls. Two notable differences from previous studies is that the curriculum materials in this study depicted girls competing more often than boys and depicted boys as cooperating more often than girls, both of which are counter to traditional gender stereotypes about girls and boys. This study illustrated some progress in more equitable representations and included depictions that countered traditional stereotypes found in previous studies.

\section{Teacher Discourse Connections}

Not only did my study find that the math curriculum represented girls and boys more equitably than previous studies of math curriculum, but teachers also discussed their students using non-gendered or inclusive terms more frequently than not. Aligning with Sadker and Zittleman's (2009) observations of classrooms, the teachers in this study noticed explicit sexism in the form of gender segregation and addressed those moments with explanations normalizing gender desegregation. In general, their focus was on all children. However, the teacher participants were unaware of more subtle sexism until it was pointed out. For example, after analyzing the book, How Big is a Foot?, two of the participants mentioned they had not previously noticed the androcentric Discourses in the story. This view also aligns with suggestions made by Sadker and Zittleman (2009). Recorded as the first lesson in the final 
chapter of their book, Still Failing at Fairness: How Gender Bias Cheats Girls and Boys in

School and What we can do about it, they stated, "Some inequities, including gender bias, simply fly below people's radar. To make progress, people have to learn how to 'see' subtle bias" (Sadker \& Zittleman, 2009). In other words, it is common for subtle inequities to go unnoticed until teachers and others learn how to notice them in the midst of a fast-paced classroom.

\section{Summary}

Learning to notice subtle gender bias seems especially important considering how girls were represented in comparison to boys in the teacher manual (UCSMP, 2012d) of the math curriculum. Although subtle, the illustrations in the teacher manual send clear messages about who is the do-er and who is the watcher. Sadker and Zittleman (2009) consistently reference examples where teachers give boys more attention and feedback, while girls watch. Gender bias may sometimes be subtle, but reflects what others have seen in classrooms already.

\section{Gender Bias through Language and Illustrations is Subtle}

As stated previously, overwhelmingly teachers and curriculum represent students through non-gendered or gender-inclusive language. Additionally, both teachers and the curriculum represented girls and boys similarly in terms of frequency and intensity; however, gender bias in teacher discourse and in the curriculum persist. Findings from the curriculum and participant interviews suggest that boys are privileged in both language and illustrations. Similarly, findings suggest that non-stereotypical representations of both girls and boys are needed in order to address bias against boys and to create a more equitable classroom environment. These findings are more impactful because if gender bias is subtle in this well-researched and carefully developed curriculum, less subtle bias are likely to exist to a greater degree in less carefully developed curricula. 


\section{Boys are Privileged in Language and Illustrations}

Boys are privileged in language and illustrations through pronoun positioning in the curriculum and teacher discourse. Positioning masculine pronouns first perpetuates androcentric Discourses in the classroom. Additionally, reinforcing the gender binary through use of gendered pronouns may seem inclusive, but I will illustrate how seemingly innocuous language can influence student understanding of gender.

Pronoun Positioning Reinforces Androcentrism. Although the quantity and quality of gender representation has improved since previous studies of textbooks (e.g., Northam, 1982; Walkerdine, 1998; Weitzman et al., 1972) and appears more equitable, the curriculum materials and the participants in this study position boys before girls more often than the converse. For decades, the masculine pronoun was used to encompass all individuals. Presently, it is common to see both feminine and masculine pronouns used as illustrated by this study. Positioning the masculine pronoun before the feminine pronoun reinforces androcentric ideals. The masculine pronoun may no longer be the androcentric way of including all individuals, but positioning it first then positions the feminine pronoun as the "other" or the afterthought. This seems especially likely when the conjunction "or" is used with the pronouns. Always positioning the masculine pronoun first in speech and text reinforces masculine-centeredness.

Reinforcement of Gender Binary through Inclusive Pronoun Usage. Although more inclusive than simply using the masculine pronoun to encompass everyone, the math curriculum and teachers do reinforce the gender binary when they use "boys and girls," "he and she," and "his or her." Hilliard and Liben (2010) 'found that teachers merely mentioning 'boys' and 'girls' as groups in the classroom produces more rigid stereotyping among students (as cited in 
Lubienski \& Ganley, 2017, p. 654). These studies illustrated how seemingly innocuous gendered language can contribute to young children's gender stereotyping.

Girls as Passive Observers. As illustrated in the current study, the curriculum depicts girls watching boys more frequently than boys watching girls. Curriculum illustrations even include a teacher privileging a boy with her gaze and she watches the boy solve the problem, rather than watching the girl. These findings align with previous studies of curriculum and classroom interactions. Similar to Weitzman and Rizzo (1976), this study found that girls are represented as passive observers who watch boys more frequently than the converse.

Additionally, girls and teachers watching and privileging boys with their gaze reflect what Sadker and Sadker (1994) found in their observation of elementary classrooms. Such illustrations send the message that girls are observers of doers, most of which are depicted as boys. Because these illustrations are mostly in the teacher manual, these messages may reinforce what many teachers are already unintentionally doing in their own classrooms, giving boys more attention.

\section{Non-stereotypical Representations of Girls and Boys are Needed}

Findings from curriculum and teacher discourse illustrate that boys seem to be the individuals reinforcing exclusion from activities and likes, adult men are absent from the math curriculum and mentioned minimally in non-stereotypical ways by teachers, and teachers focus on representing girls in non-stereotypical occupations. These findings align with previous studies of representation in text and classrooms. When considered together, findings suggest that nonstereotypical representations of both girls and boys are needed to create a more equitable classroom environment and in extension, society.

Exclusive Boys. Throughout the interviews, teacher participants shared stories of boys in their classroom reinforcing gender segregation with both girls and other boys. This is 
unsurprising as studies have shown boys are treated more harshly and criticized for taking on more feminine attributes and behaviors than girls who take on more masculine attributes and behaviors (Fagot, 1977; D. Sadker \& Zittleman, 2009; Stoddart \& Turiel, 1985). Therefore, boys seem to punish others for not conforming to gender roles because they are more harshly punished for nonconforming behavior. These exclusive behaviors may be connected to behavioral expectations borne from patriarchal Discourse and lack of inclusive, non-stereotypical representations.

Representation Matters. Sadker and Zittleman (2009) argued the importance of representation in combating gender bias in classrooms. Unlike Weitzman and Rizzo (1976) who found that men are shown in a greater variety of occupations, this study did not show men at all in the math curriculum. The absence of men in this curriculum align with what Northam (1982) found, which is that fathers are largely absent or rarely mentioned. Similar to Weitzman and Rizzo (1976) who found that women are shown almost exclusively as mothers and housewives, this study found women represented similarly as mothers, grandmothers, caretakers, and teachers. Sadker and Zittleman (2009) argued, "Gender stereotypes and the lack of female characters contribute negatively to children's development, limit their career aspirations, frame their attitudes about their future roles as parents, and even influence personality characteristics" (p. 92). The curriculum sends a message that adult men do not help their children with homework or participate in educational activities at home, and women are limited to care-taking roles.

In contrast to representations of men and to representations of women in the curriculum, teachers did seem to intentionally represent women in some non-stereotypical occupations and mentioned representing men as caretakers. Several participants mentioned intentionally reading 
stories, inviting guest speakers, or showing pictures that depict girls as the president or in STEM fields. By representing women in a variety of roles, stereotypical and non-stereotypical, teachers provide opportunities for girls and boys to see women in a variety of occupations and ways; therefore, teachers are able to provide a more well-rounded and inclusive vision of women in society.

Although teachers briefly mentioned representing men as caretakers, their representation was limited. I argue that Sadker and Zittleman's (2009) statement about lack of women characters extends to boys in both teacher and curriculum/text discourse. Only two participants suggested representing adult men in this way with no consideration for other non-traditional occupations. The other two participants did not mention non-stereotypical occupations for men at all. Lack of representation for boys and men may also "limit their career aspirations and frame their attitudes about their future roles as parents" (Sadker \& Zittleman, 2009, p. 92). Perhaps including more non-stereotypical representations in the classroom and curriculum will allow boys to feel more comfortable exhibiting nonconforming behaviors; thereby, they may allow others to demonstrate nonconforming behaviors without fear of punishment or segregation.

\section{Connection to Gender Schema Theory}

After examining the discourse of kindergarten teachers and the discourse in a kindergarten math curriculum, it is clear that gendered and non-gendered discourses were present. What is not clear from this particular study is to what degree those discourses enculturate children and shape their understanding of gender and gender roles, particularly related to math. Gender schema theory suggests that discourses enculturate young children and shape how they view the world. Children spend their lives constructing their view of the world and shaping perceptions through their own discourses in combinations with Discourses with a 
"D." Figure 4.13 shows the clear connection between the studied discourses and findings. What is less clear and is represented by a dotted line is to what degree those discourses influence children. Further studies are needed to better understand how gendered and non-gendered discourses in the classroom shape young children's understanding of gender, specifically their understanding of the relationship between gender and math.

\section{Figure 4. 13}

\section{Connection Between Findings and Gender Schema Theory}

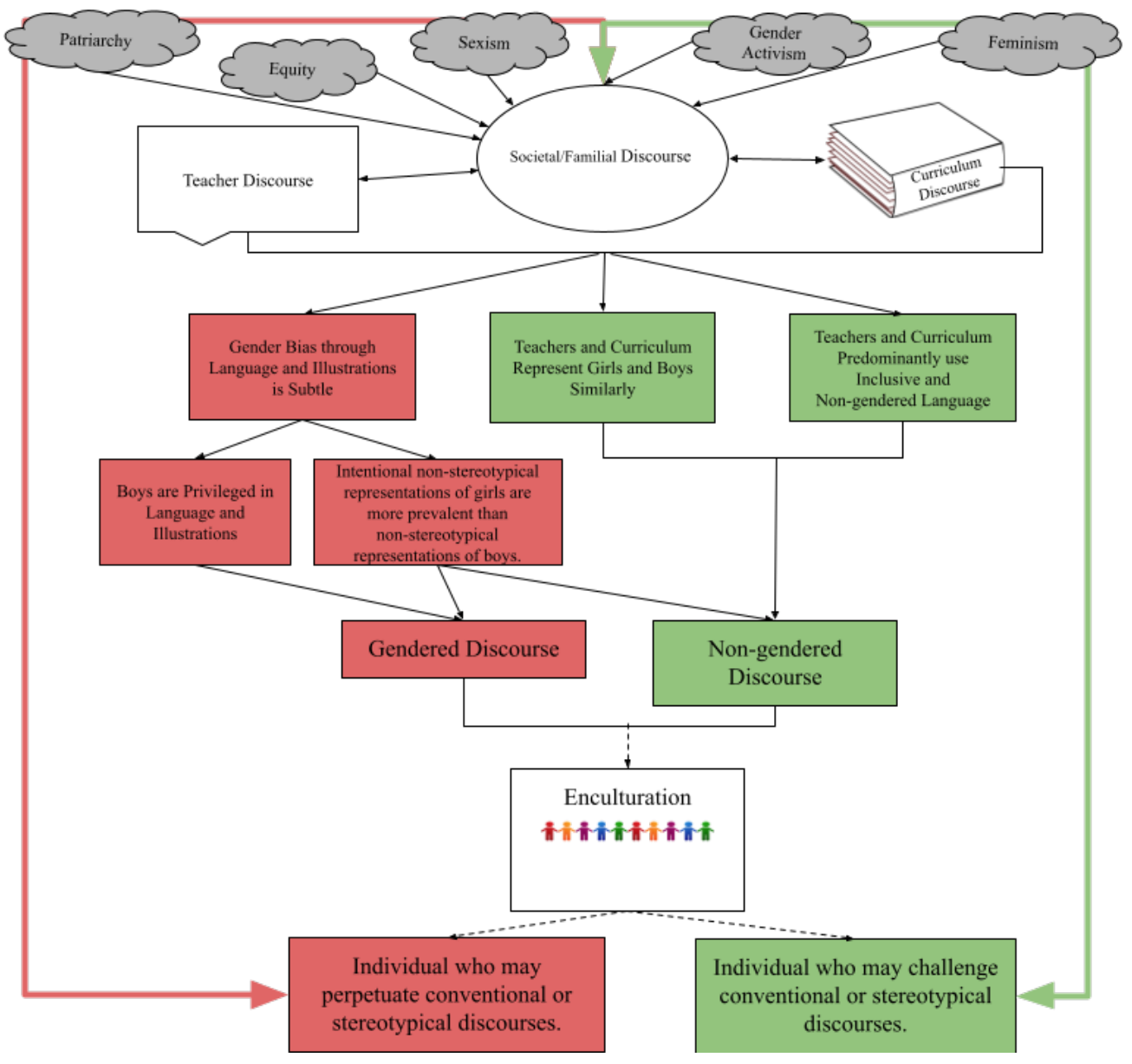

\section{Implications for Future Research}

As stated previously, this study helped us better understand the messages kindergarten teachers and math curriculum may convey to kindergarten students, but it did not help us better 
understand how gendered and non-gendered discourses influence young children and their views of math and gender. After conducting this study, I suggest three areas for future research. Gender research has been conducted for decades; however, we must continue to research using more nuanced methodologies and theories.

\section{Connection Between Intended Curriculum, Teacher Perception and Enacted Curriculum}

Although it was not possible to observe in classrooms while this study was conducted due to the Covid-19 pandemic, this study suggests that further research is needed to connect the intended curriculum and teacher perceptions to the enacted curriculum. Future researchers should critically examine what is said during interviews in connection with what is said and done within the classroom setting to further illustrate "ways of interacting," "ways of being," and "ways of representing" in the kindergarten mathematics classroom. For example, researchers should examine the frequency and type of interactions between teachers and girls and teachers and boys, the frequency, length, and context of interruptions between teachers, girls, and boys, and how teachers represent girls in comparison to boys as math students, mathematicians, or doers of math to help us better understand the discourse between teachers and students in the kindergarten math classroom. Additionally, if possible, student perceptions should also be included in these studies to examine the extent to which gendered messages and actions influence student understanding of gender, identity, and math.

\section{Intersectional Analysis of Curriculum and Supplemental Materials}

After interviewing participants and analyzing the curriculum materials, participant viewpoints and text and illustrative data from the curriculum materials suggest that factors such as race or ethnicity, class, and ability should be considered in future studies. Several authors have suggested an intersectional approach to mathematical studies as implications for future research 
in their reviews of literature surrounding gender and math (e.g., Ganley \& Lubienski, 2017;

Leyva, 2017). Future researchers can better understand how students are represented in curriculum by taking into consideration the many identities students possess.

\section{Intentional Non-stereotypical Representations of Boys}

Finally, the findings from the study suggest that future research that examines intentional non-stereotypical representations of boys and men may help us better understand gender desegregation, gender attitudes, and gender norms in early childhood and beyond. This study showed a lack of intentional non-stereotypical representations of boys and men. Combined with teacher participants' comments about exclusion caused by boys based on gendered activities and previous research concerning reactions to boys' cross-gendered behaviors (e.g., Fagot, 1977), further exploration into representations of boys is needed to better understand gender norms and limitations stemming from gender norms for both boys and girls. Furthermore, researchers should explore how consistent, intentional use of non-stereotypical representations of boys and men influence girls' and boys' understanding of gender in connection with career-choice. 


\section{Section Five: Contribution to Practice}

Following the structure of the EdD dissertation structure, this section includes a practice piece that will be given to the organization. I have chosen to submit a report to the organization, including a two-sided flyer than can be printed or emailed to faculty. I have chosen this method to disseminate my findings and recommendations because I want to clearly share my findings while also providing recommendations for how to address the findings. This report will be given to the Lower School Director and the current Mathematics Department Chair as they are the two individuals who can enact any recommendations from this report. The following is the document I plan to share.

\section{Introduction}

Over the past 2 academic school years, I have worked with teachers and administrators in this organization to conduct a study of teacher and curriculum discourse. The purpose of this study was to examine the role of the teacher and instructional materials in a kindergarten mathematics classroom using the following research questions: (1) How does the Everyday Mathematics kindergarten curriculum and supplemental curriculum materials position and write about girls in comparison to boys?, and (2) How do teachers describe girls in comparison to boys and position them when discussing their beliefs about mathematics instruction and equity in the kindergarten classroom? This study helped us better understand the messages teachers and curriculum convey to young children about gender and math in this organization.

The purpose of this report is to share findings from that study and provide recommendations for how the organization may address these findings and connect them to the diversity and inclusion work that is already being done at the organization. Additionally, I have provided a two-sided flyer of tips and tools that can be printed and given to teachers or emailed. 


\section{Problem of Practice}

During the past few years, this organization has shown dedication to improving how they address diversity and inclusion through the formation of parent committees dedicated to equity, the hiring of an outside equity consultant, and conducting a book audit in the Lower School. Although the focus of all of these initiatives has mainly been racial and ethnic diversity, representation of gender should be included. It is clear that gender equity is also important to the organization, as in the past few academic years teachers supported a high school student who created opportunities for girls practicing STEM at the organization as part of a fellowship program.

Despite clear efforts to create a more equitable environment in the organization, the textbook selection policy at the organization does not include consideration of gender representation and subtle sexism and gender bias continue to persist in elementary classrooms and curriculum materials. Although there have been improvements in explicit gender bias in many classrooms, curriculum, and literature, we know that more subtle gender bias occurs in many classrooms. Subtle gender bias in the mathematics classroom may contribute to students' understanding of gender in relation to math.

\section{Background of Study}

In order to explore how girls are represented in comparison to boys in the classroom and curriculum materials, I conducted a study where I closely examined the language used by four current and former teachers in interviews and the language and illustrations used in the curriculum materials. I examined four math curriculum resources (See Table 5.1). In order to examine the language, I counted gendered and non-gendered language such as she, he, they, children, etc. I also examined what the figures were doing in sentences and illustrations. For 
example, I examined who was displaying a skill in comparison to who was helping classmates or sharing.

\section{Table 5. 1}

\section{Details of Analyzed Curriculum Resources}

\begin{tabular}{ccc}
\hline & & Teacher and/or Student \\
Analyzed Resource & Number of Pages or Units & Resource \\
\hline Everyday Mathematics teacher & 8 units (128 lessons) and 8 & Teacher \\
manual & Projects & Teacher and Student \\
math masters workbook & 143 & Teacher and Student \\
activity cards & 38 & Student \\
student workbook & 36 &
\end{tabular}

Additionally, I examined the language teacher participants used to introduce issues of equity and gender equity in their classroom and how they plan to teach or have taught lesson 5.7 from the math curriculum. I closely looked at how girls and boys were represented through their positioning in the sentence, the word choice associated with girls and boys, and the frequency of gender neutral/inclusive or gendered terms used to describe students and figures in the story.

\section{Results}

1. Teachers and curriculum predominantly use inclusive and non-gendered language,

2. Teachers and curriculum represent girls and boys similarly, and

3. Gender bias through language and illustrations is subtle. Further examination of the language showed that:

a. Boys are privileged in language and illustrations, and

b. Intentional non-stereotypical representations of girls are more prevalent than nonstereotypical representations of boys. 


\section{Recommendations}

1. In connection with the first result, teachers should continue to intentionally use inclusive and non-gendered language to further develop a welcoming classroom community and to limit reinforcement of a gender binary.

a. For example, when teaching math, teachers can increase the use of gender-neutral names in story/word problems. In lesson 4.11, the text suggest the following word problem: "Kim had 7 new books at school. She took 3 home today. How many of her books are left at school?" (p. 210). One way to make this more gender-neutral would be to change it to something like this: Alex had 7 new books at school. They took 3 home today. How many of their books are left at school? Changing the proper noun to a gender-neutral name and changing the pronouns to the singular they and their can make a story problem more inclusive.

b. Teachers can include non-binary characters and figures in word problems and examples by using the singular "they," "them," and "their" instead of gendered pronouns.

c. Teachers can discontinue categorizing students by gender for activities, games, or transitions in the classroom. For example, in lesson 4.14, the text suggests using the category of girl or boy to play the game Who Am I Thinking Of?: "For example, if someone asks, 'Is it a girl?' and you answer yes, the girls remain standing and the boys sit down. If children then ask 'does she have blue on?' and your answer is no, then all the girls wearing blue sit down" (p. 217). Teachers can and should find other ways to categorize students. Some common categorization 
examples are color of shirt, height, hair color, birth order, birthday month, age, etc.

d. Teachers can intentionally position girls and boys equally as doers of math in examples, directions, and word problems. Additionally, teachers can skim word problems in the text for who is doing the math and who is watching math being done.

e. Teachers can continue to look out for inclusive language in texts and intentionally modify exclusive language like policeman or woman engineer to lessen the stereotype and promote more inclusion. The text already does this by using the term fisherperson instead of fisherman in lesson 4.14.

2. In connection with the second result, I recommend adding language to the textbook selection policy that considers gender representation as the current policy does not include this language. This addition may help ensure that future textbooks are equitable in their representation of gender. In order to examine textbooks for gender bias, this organization can use a tool provided for teachers and administrators created by David Sadker and Karen Zittleman: https://www.sadker.org/curricularbias.html.

3. In connection with the third result, I have provided three recommendations:

a. Teachers can be more intentional about their pronoun use. I recommend teachers replace saying he or she with the singular they to promote inclusivity. While making the switch to the singular they and them, I encourage teachers and administrators to place the feminine pronoun first when speaking. If it feels odd to refer to students as she and he or her and his, then that is a sign that positioning the masculine pronouns first is normalized. 
b. In addition to intentionally providing opportunities to show girls and women in non-stereotypical ways (occupations, activities, traits, etc.), teachers can also intentionally provide ample opportunities to show boys and men in nonstereotypical ways. Here is a short list of picture books recommended during the participant interviews, the book, Still Failing at Fairness (Sadker \& Zittleman, 2009), and The New York Times article "Twelve Books for Feminist Boys and Girls" (Miller, 2018) that depict boys and men in non-stereotypical ways:

i. William's Doll by Charlotte Zolotow

ii. Julián Is a Mermaid by Jessica Love

iii. Franny's Father is a Feminist by Rhonda Leet

iv. Teddy's Favorite Toy by Christian Trimmer

v. Stories for Boys who Dare to be Different by Ben Brooks

vi. Henry's Baby by Mary Hoffman and Susan Winter

vii. Daddy Makes the Best Spaghetti by Anna Grossnickle

viii. Boy, You're Amazing by Virginia L. Kroll and Sachiko Yoshikawa

c. Administrators should provide and encourage professional development connected with anti-bias education, including topics surrounding gender bias in the classroom and class materials. One organization that provides professional development related to gender bias is GLSEN. Additionally, administrators can encourage a book club discussion of the book Still Failing at Fairness by David Sadker and Karen Zittleman, a resource cited often in this study. Finally, I would be willing to come and present on how and when gender schemas are formed and why our messaging matters in all grades, not just kindergarten. I can provide 
resources and support during teacher work days. Of course, there are many resources available beyond what has been mentioned. I encourage administrators to talk with the new Diversity, Equity, and Inclusion Coordinator for more resources related to gender bias in education.

\section{Conclusion}

Overall, the math curriculum and kindergarten teachers use language that is gender neutral or inclusive in reference to students. Teachers expressed that they address explicit sexism when it comes up in class, usually in the form of gender segregation (girls only do this/boys only do this). However, subtle gender bias exists in classrooms and in curriculum materials as illustrated by previous research and this study. Young children are forming their gender identities and understanding of gender during and throughout kindergarten and childhood; therefore, it is imperative that teachers learn to discern subtle gender bias in their own words and actions and text and pictorial representations in their curriculum and classroom resources.

\section{References}

Khan, B., Robbins, C., \& Okrent, A. (2020). The State of U.S. Science and Engineering 2020. National Center for Science and Engineering Statistics (NCSES). https://ncses.nsf.gov/pubs/nsb20201/

Lubienski, S. T., \& Ganley, C. M. (2017). Research on gender and mathematics. In Compendium for Research in Mathematics Education. The National Council of Teachers of Mathematics, Inc.

Miller, C. C. (2018, December 19). Twelve Books for Feminist Boys and Girls. The New York Times. https://www.nytimes.com/2018/12/19/upshot/twelve-books-for-feminist-boysand-girls.html 
National Assessment of Educational Progress. (2019). NAEP Report Card: Mathematics. https://www.nationsreportcard.gov/mathematics

Sadker, D., \& Zittleman, K. R. (2009). Still Failing at Fairness: How Gender Bias Cheats Girls and Boys in School and What we can do about it. Scribner.

The University of Chicago School Mathematics Project. (2012a). Everyday Mathematics Center Activity Cards (Common Core State Standards). McGraw-Hill.

The University of Chicago School Mathematics Project. (2012b). Everyday Mathematics Math Masters (Common Core State Standards). McGraw-Hill.

The University of Chicago School Mathematics Project. (2012c). Everyday Mathematics My First Math Book (Common Core State Standards). McGraw-Hill.

The University of Chicago School Mathematics Project. (2012d). Everyday Mathematics Teacher's Guide to Activities (Common Core State Standards). McGraw-Hill. 

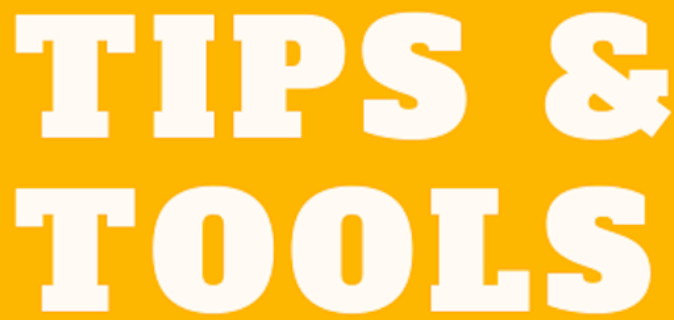

\section{To Create a More Gender Equitable Classroom}

Here are some tips, accompanied with the tools, to create a more gender equitable classroom based upon my research.

\section{How to Encourage} Gender-inclusiveness during Math
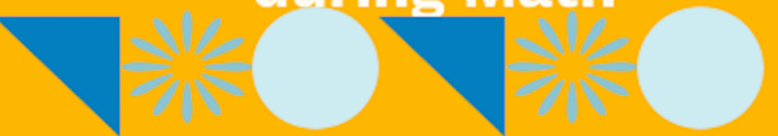

- Increase the use of gender-neutral names in story/word problems.

- Discontinue categorizing students by gender and choose an attribute such as clothing color, height, birth order, birthday, etc.

- Continue to look out for inclusive language in texts and intentionally modify exclusive language like policeman or woman engineer to lessen the stereotype and promote more inclusion.

- Include non-binary characters and figures in word problems and examples.

- Seek our professional development to increase understanding of how gender is constructed.

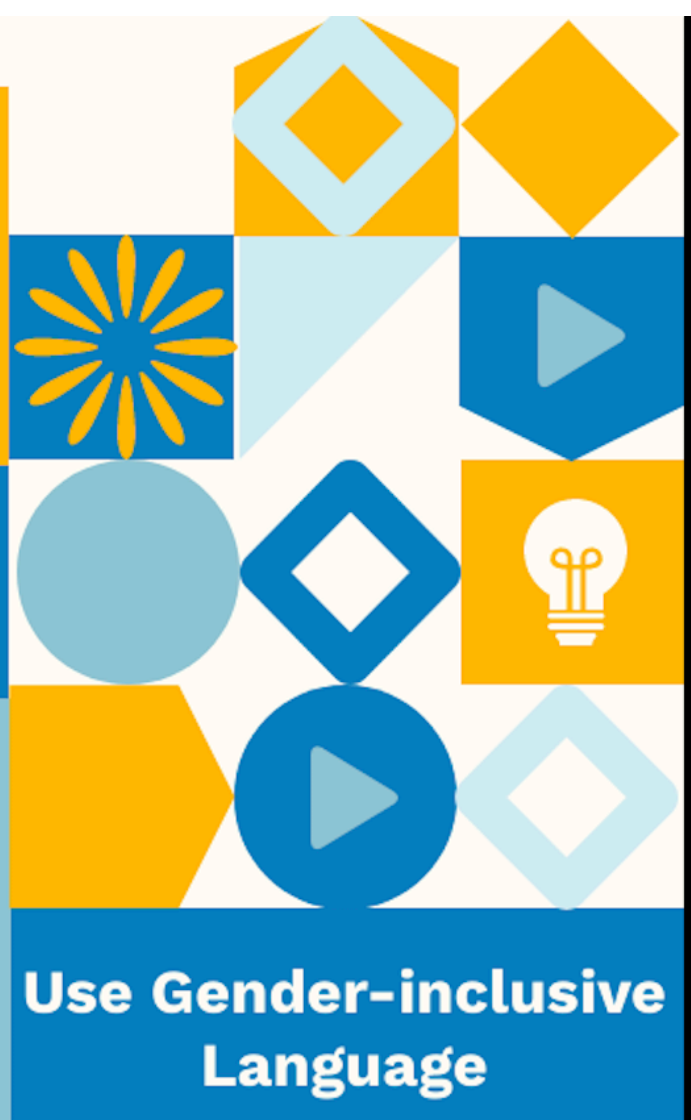

According to the United Nations, "using gender-inclusive language means speaking and writing in a way that does not discriminate against a particular sex, social gender or gender identify, and does not perpetuate gender stereotypes."

\section{Resources}

- U.N. Toolbox fo Gender-inclusive Language

- U.N. Guidelines

- How Do We Make Math Class More Inclusive of Trans and Non-binary. Identities

- Still Failing at Fairness by David Sadker and Karen Zittleman 


\section{Examine Textbooks and Picture Books for Gender Bias}

\section{Seven Forms of Bias in Curricular Materials}

Check out this list of ways you can spot subtle gender bias in books. You have the power to challenge gender stereotyping in your classroom!
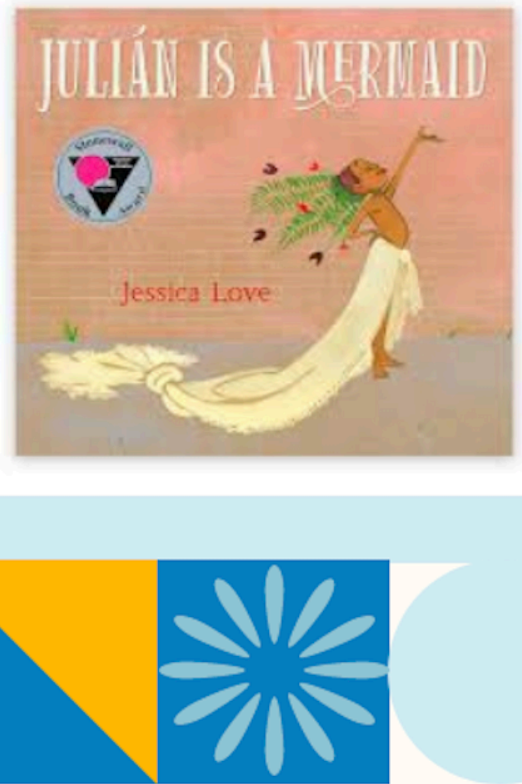

Be more intentional about your pronoun usage. I recommend teachers replace saying he or she with the singular "they" to promote inclusivity and to avoid reinforcing a gender binary. In addition to making the switch to the singular "they" and "them", I encourage teachers and administrators to place the feminine pronoun first when using gendered pronouns. If it feels odd to refer to students as she and he or her and him, then that is a sign that positioning the masculine pronouns first is normalized. Language makes a difference, and this simple switch can normalize not gendering figures and gendering figures as feminine.
- William's Doll by Charlotte Zolotow

- Julián Is a Mermaid by Jessica Love

- Franny's Father is a Feminist by Rhonda Leet

- Teddy's Favorite Toy. by Christian Trimmer

- Stories for Boys who Dare to be Different by Ben Brooks

- Henry's Baby by Mary Hoffman and Susan Winter

- Daddy Makes the Best Spaghetti by Anna Grossnickle

- Boy,You're Amazing by Virginia L. Kroll and Sachiko Yoshikawa

\section{Change up your Languaǵe...}
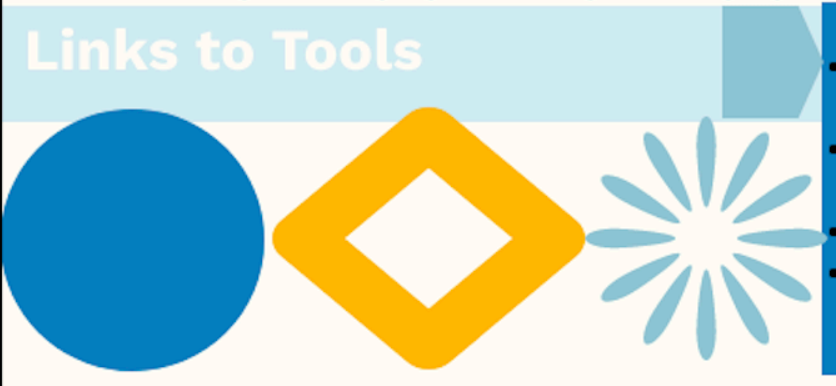

https://wmw.un.org/en/gender-inclusivelanguage/

- https://www.un.org/en/gender-inclusivelanguage/toolbox.shtml

https://www.sadker.org/curricularbias.html

https://wnw.glsen.org/blog/how-do-wemake-math-class-more-inclusive-trans-andnon-binary-identities

powered by

PIKTOCHART 


\section{Section Six: Scholarly Practitioner Reflection}

Completing the coursework and dissertation for the EdD program has influenced my practice as an educational leader and scholar. As an educational leader, I believe completion of this program and my dissertation has led to an increase in my cultural awareness and encouraged my transformation from a leader of children to a leader of adults. As a scholar, this program has inspired me to continue researching and given me the tools to enhance my critical thinking in a time when that is sorely lacking in our society. Because I do not truly believe that, after this program, there is a separation between educational leader and scholar, I will also reflect on how this experience has shaped my identity as a scholarly practitioner.

\section{Increased Cultural Awareness}

Although this program only required one course specifically focused on culture and diversity, I appreciated how much the rest of the coursework had components that were dedicated to increasing cultural awareness. In many of our classes, we used a critical lens when discussing case studies, research interests, and data. For example, in our leadership theory course, Dr. Douglas centered the voices of Black leaders when choosing guest speakers and case studies. He continually reinforced viewing leadership discussions within a historical context where not all people were allowed in certain spaces. He encouraged us to engage in critical discussions when participating in case study activities where race, class, and community were integral considerations when approaching a solution. This continual reminder to include diverse voices in leadership spaces has influenced how I view spaces and how I think about which voices are heard and unheard in my own settings.

I have always thought of myself as an ally to historically marginalized groups; however, this program made me reflect on how I identify myself and others and interact with those 
different than me, including students and families. I spend a lot of time reflecting on interactions with and the assumptions I make about others. I am now always questioning why I interacted in this way with one person, but not another. For example, I have become hyper aware of how I correct students, the frequency with which I correct students, and if I correct students for the same behaviors. I definitely make mistakes and correct some students more than others. Being aware of this helps me improve my interactions and create a more equitable environment.

Overall, I am more thoughtful in my interactions and more empathetic.

\section{Transforming from Leader of Children to Leader of Adults}

At the start of this journey, I was a fifth-grade teacher. I ended my career in fifth grade at the same time I finished coursework. Since then, I have substitute taught in preschool through grade 12, taught undergraduates in two education courses, and facilitated a "pod school" during the pandemic, which included first, second, and fourth grade children. Although I am still a leader of children, I have also become a leader of adults. This program helped me increase my knowledge of andragogy (Merriam \& Bierema, 2014) and gave me opportunities and tools to instruct adults. During my first semester teaching college students, I pulled out my adult learning theory textbook more than once to modify my expectations and teaching. During this program, I learned how much I loved teaching adults and solidified my decision to transition into higher education.

\section{Scholar}

Not only did this program and dissertation influence me as a practitioner, but also as a scholar. I have always loved learning, but I never identified as a researcher or scholar before this program. This program awakened a passion I did not know existed within me. I am leaving this program so inspired to research and make a difference in education. 


\section{Inspired to Research}

As I eluded to, I am more enthusiastic about research now than I have ever been. I see the world in questions and constantly feel my curiosity piqued. I have always loved learning, but the act of researching elevates that love to a whole new level. I look forward to transitioning into higher education where I can combine my passions for teaching and researching. I dream of conducting longitudinal studies about gender and education and conducting more curriculum analysis. When I read about scholars of gender and education, I am awed by their decades of work. I want to influence the world of education positively through working with preservice teachers and my research.

\section{Critical Thinking in a Necessary Time}

I will never forget the first assignments from this program-summer one, annotations of articles. I had not examined scholarly articles like this in a very long time. I was challenged to critically think about the information presented. I am so appreciative of those assignments. Throughout this program, I have been encouraged and pushed to think critically about data, methodologies, and findings. This last year of the program has been marked by events outside the academic setting: the murder of yet another Black man at the hands of police, an attempted coup and subsequent insurrection at the Capitol, and a poorly managed pandemic response. This time has been marred with rampant misinformation and skepticism of scientific research. I feel more confident in my ability to understand and discern research and news. I do not know if my perception of scientific research and my consumption of news media would be vastly different if I had never participated in this program, but I feel grateful for the skills I learned that I now often use outside of my academic setting. 


\section{Both Educational Leader and Scholar}

After 4 years in this program, I do not feel there is much separation between practitioner and scholar. As this program often touts, we are now scholarly practitioners. That is exactly how I feel. I believe both are "hats" we wear on a daily basis. One may take a more prominent role over the other sometimes, but they never leave us entirely. Now that I have reflected on how this program and dissertation have influenced my identities as an educational leader and scholar, I will reflect on how this program and dissertation have influenced my identity as a scholarly practitioner.

\section{Imposter Syndrome}

Throughout my undergraduate program, previous graduate program, and early teaching career, I relied on my natural talents and competencies. I often felt confident and that new things came easily to me. This program and this dissertation have challenged how I perceive my capabilities and knowledge. I always thought of myself as a talented teacher who built authentic relationships with students easily, mastered teaching the content knowledge in my grade level, and managed my classroom with enthusiasm and consistency. Because of this program, I have become even more reflective of my interactions with students, critical of my teaching methods, and cognizant of the classroom environment. I know I have gained knowledge and skills I did not previously possess, but I realize there is so much more knowledge and experience out there waiting for me. Most days, I overthink interactions I have as a leader and worry that I am not actually knowledgeable enough to speak on a subject. I believe learning so much in this program and meeting so many incredible educators through it has heightened my insecurities as a leader and scholar; however, I know that I am a more thoughtful and analytical educational leader and scholar because I completed this program and dissertation. 


\section{Data-driven Decision-Maker}

My insecurities have spurred my desire to make decisions on the basis of data. In my various roles, I combine my leader and scholar "hats" in order to make the most informed decision in a setting. I sometimes question my perception of scenarios and enactment of policies and am therefore extremely motivated to look at the scenario through a researcher's lens. I strive to collect and interpret data through the methods and lenses taught in this program. For example, in the past year, I started teaching undergraduates. Because this was my first experience with

this, I constantly gathered feedback from students and used scores from assignments to determine how clear my expectations were, how consistent my grading was, and how connected my assessments were to my actual instruction. I embraced ambiguity and attempted to stay flexible and use data to improve my instruction. I hope to use data to inform decisions on a larger scale in the future.

\section{Conclusion}

After 4 years, I can say I am truly changed, for the better. This program and dissertation challenged me and helped me grow more than anything else in my life so far. Although I have insecurities about being an educational leader and scholar, I feel more knowledgeable and capable of being an effective leader and responsible scholar than before this program. So, I end this part of the journey with this dissertation. As so many have often said, "This is not the end. It is just the beginning." 


\section{Semi-structured Interview}

\section{APPENDIX A}

\section{$1^{\text {st }}$ Interview}

Date:

Time:

Hi there! My name is Alexandria Otis. Thank you so much for agreeing to participate in my study. This is the first of two interviews. The first interview includes some demographic questions as well as questions about your experiences with math. The purpose of this interview is to better get to know you as an individual and as a teacher. There are no right or wrong or desirable or undesirable answers. I would like you to feel comfortable saying what you really think and how you really feel. Before the second interview, I will share a lesson from the Everyday Mathematics text including the math master pages and picture book. During the second interview, I will ask you questions about the lesson and how you might teach or how you have taught that lesson. Finally, I will ask specific questions about how ideas and characters are represented in that lesson.

As a reminder, I am recording this Zoom meeting. Is that okay? The purpose of this is so that I can get all the details but at the same time be able to carry an attentive conversation with you. I assure you that all your comments will remain confidential. Neither you nor your comments will be identifiable in my final project.

Before we get started, please read the consent form I emailed you before this meeting. Please verbally consent when you are ready to begin.

\section{Part I}

- Name

- Race/Ethnicity, If you feel comfortable answering, with which race/ethnicity do you identify?

- Gender, If you feel comfortable answering, which pronouns would you like me to use when referring to you?

- What type of school setting? (urban, suburban, rural, etc.)

- Years of teaching experience/what grades have you taught? 
- How would you describe the students in your classroom? (math ability, demographics, behavior, etc.)

- What are the policies for choosing math curricula in your school?

- How do you choose what to use for your math curriculum?

- How many years have you been teaching math using the Everyday Mathematics curriculum?

\section{Part II}

- How would you describe your math ability?

- What experiences have shaped your perception of your math ability?

\section{Part III}

- How would you describe your ability as a math teacher?

- What challenges do you face when teaching math?

- What are your strengths as a math teacher?

\section{Part IV}

- To what extent do you believe your perception of your own math ability shapes how you teach math?

- To what extent do you believe your perception of your own math ability shapes your perception of your students' math ability?

\section{Part V}

- What are some of the common stereotypes about math ability and interest that you see reproduced in classrooms? How do you see them reproduced in classrooms? In schools? In society?

- Why do think these stereotypes continue to persist? 
Thank you very much for taking the time to participate in the first interview. Your time is much appreciated. Our second interview is scheduled for . After this meeting ends, I will email you a lesson from the Everyday Mathematics curriculum. Please take some time to look at the lesson, picture book, and math master pages before our second interview. During the second interview, I will ask questions pertaining to that lesson and picture book. You may contact me with any questions you have or if you decide you do not want to be included in the study. Do you have any questions before we finish for today?

\section{Semi-structured Interview}

\section{$2^{\text {nd }}$ Interview}

Hi there! Thanks again for participating in this study. As a reminder, I am recording this Zoom meeting. Are you okay with that? Today, I am going to ask you questions about the lesson I sent before this meeting. Have you had a chance to go over the lesson and the picture book?

If yes, then start the questions.

If no, then...Please take 5 minutes or so to look over the lesson, math master pages, and picture book. When you are ready, please let me know.

\section{Part I}

- Have you taught this specific lesson before?

- If yes, then tell me about how you teach this lesson.

If no, then what do you notice about this lesson?

- How might you teach this in your classroom?

\section{Part II}

- Thank you for sharing your insights. In the next section of this interview, I am going to show you some data of how four of the characters are represented in the book that this lesson is based upon. Share screen of table. 
- In the picture book, How Big is a Foot? (Myller, 1962), there are 7 main and secondary characters, excluding the collective "people." Of the 7 characters, one is depicted as a woman, while the other six are depicted as men: the King, the Queen, the Prime Minister, the Chief Carpenter, the apprentice, the jailer, and the sculptor. We know these characters are women or men because of the pronouns used in the text and the illustrations of beards.

- What do you notice about how characters are represented?

- What message(s) do you think the text conveys about men in comparison to women?

- Does this information change how you view this book or how you would teach this book?

\section{Part III}

Thank you so much for sharing your insights on this specific book. I would now like to ask you some questions about equity in your classroom.

- How do you introduce issues of equity in your class?

- What steps do you take to familiarize your students with the topic?

- Do you introduce issues of gender and gender equity in your class?

$\circ$ How?

- What steps do you take to familiarize your students with the topic?

- What range of instructional approaches and strategies do you enact when teaching about gender equity and stereotypes?

- How did your students respond? What outcomes of learning did you observe?

- To what extent have you noticed that students' behavior has changed since being introduced to gender issues and gender stereotypes? Has this changed the dynamics of the classroom? 
- What resources do you use to support you in this work? Can you share some of your favorite children's books, internet resources, curriculum materials, classroom posters, play materials, etc.?

- What advice, if any, do you have for beginning teachers who are committed to fostering gender equitable classrooms and challenging traditional gender stereotypes through their teaching?

Thank you very much for taking the time to participate in this study. Your time is much appreciated. You may contact me with any questions you have or if you decide you do not want to be included in the study. I will send you information regarding how to access this study when it is approved by my dissertation committee. Do you have any questions before we finish?

Protocol adapted from (Altermatt et al., n.d.) 


\section{APPENDIX B}

\section{Gendered Names}

\begin{tabular}{|l|l|l|}
\hline Names coded as Feminine & Names Coded as Masculine & $\begin{array}{l}\text { Names coded as Gender } \\
\text { Ambiguous }\end{array}$ \\
\hline Mary & Simon & Adrian \\
\hline Cindy & Patrick & Sam \\
\hline Juana & Brian & \\
\hline Yasmin & Leo & \\
\hline Serena & Marcos & \\
\hline Maggie & Jake & \\
\hline Jane & Dayon & \\
\hline & Joe & \\
\hline & Eric & \\
\hline
\end{tabular}




\section{Inclusive/Gender Neutral Nouns}

\begin{tabular}{|l|l|}
\hline Singular Nouns & Plural Nouns \\
\hline Child & Children \\
\hline They & They \\
\hline Partner & Them \\
\hline Pair & English Language Learners \\
\hline Person & Partners \\
\hline Individual & Pairs \\
\hline The group & Individuals \\
\hline Small group & Small groups \\
\hline The class & Students \\
\hline Each other & People \\
\hline Another & Others \\
\hline You & You \\
\hline I & We \\
\hline Everyone & Us \\
\hline Anyone & Some \\
\hline Someone & Those \\
\hline No one & Players \\
\hline Six-year old & Volunteers \\
\hline Actor & Helpers \\
\hline Player & Kindergarteners \\
\hline Volunteer & \\
\hline Helper & \\
\hline Friend & \\
\hline Classmate & \\
\hline Him or Her & \\
\hline He or She & \\
\hline
\end{tabular}




\section{APPENDIX D}

\section{Textbook Analysis Categories}

\begin{tabular}{|c|c|}
\hline Category & Examples/Definitions \\
\hline $\begin{array}{l}\text { 1. Part of the setting, observed someone } \\
\text { else, received help }\end{array}$ & $\begin{array}{l}\text { "Mary and Jane are wearing blue tops } \\
\text { today. Joe is wearing a blue top too. How } \\
\text { many children in our class are wearing } \\
\text { blue tops?" } \\
\text { Names of characters in a song or title of a } \\
\text { game. } \\
\text { Figures are part of the setting. The might } \\
\text { be used to as an example for what they are } \\
\text { wearing, being, or eating, but are not } \\
\text { actively solving the problem presented. }\end{array}$ \\
\hline 2. taught, explained processes to others & \\
\hline 3. Made something, displayed a skill & Built something \\
\hline 4. planned, initiated, invented & \\
\hline 5. performed, played tricks, boasted & Acted out a scripted scenario \\
\hline 6. competed & $\begin{array}{l}\text { Represented in the directions of a game or are } \\
\text { playing the game. }\end{array}$ \\
\hline $\begin{array}{l}\text { 7. repeated or elaborated upon a process } \\
\text { already learned }\end{array}$ & $\begin{array}{l}\text { Practicing a skill at home after learned at } \\
\text { school. } \\
\text { Extending a skill by using their bodies to } \\
\text { show a skill. }\end{array}$ \\
\hline 8. cooperated, shared, helped, complied & $\begin{array}{l}\text { Students worked in a group. } \\
\text { Adult helped a child. } \\
\text { Classroom jobs such as paper passer, snack } \\
\text { help, greeter, etc. }\end{array}$ \\
\hline 9. corrected another's behavior, & ex., calm down, said Ann \\
\hline $\begin{array}{l}\text { 10. Identification, setting and solving of } \\
\text { problems }\end{array}$ & $\begin{array}{l}\text { They identify, create or try to solve a problem } \\
\text { presented by the teacher. }\end{array}$ \\
\hline
\end{tabular}

Adapted from Northam, J. (1982). Girls and boys in primary maths books. Education 3-13,

10(1), 11-14. https://doi.org/10.1080/03004278285200041 


\section{APPENDIX E}

\section{CDA Framework/Guiding Questions}

\begin{tabular}{|c|c|c|}
\hline \multicolumn{3}{|c|}{$\begin{array}{c}\text { GENRE } \\
\text { "WAYS OF INTERACTING" }\end{array}$} \\
\hline Discursive Feature & Description & Questions to Ask of the Text \\
\hline Cohesion & $\begin{array}{l}\text { Lexical or grammatical } \\
\text { features that help a text to } \\
\text { hang together across sentence } \\
\text { boundaries and form larger } \\
\text { units. }\end{array}$ & $\begin{array}{l}\text { What relations exist } \\
\text { between the clause } \\
\text { and the sentence? }\end{array}$ \\
\hline \multicolumn{3}{|c|}{$\begin{array}{c}\text { DISCOURSE } \\
\text { "WAYS OF REPRESENTING" }\end{array}$} \\
\hline Discursive Feature & Description & Questions to Ask of the Text \\
\hline Information Focus & $\begin{array}{l}\text { Themes are represented in the } \\
\text { first part of the clause and are } \\
\text { generally the known } \\
\text { information. } \\
\text { Rhemes include the new } \\
\text { information and are generally } \\
\text { included in the last part of the } \\
\text { clause. }\end{array}$ & $\begin{array}{l}\text { What ideas are } \\
\text { represented? } \\
\text { - What information is } \\
\text { foregrounded by } \\
\text { being in the theme } \\
\text { position? }\end{array}$ \\
\hline Lexicalization & The selection of wordings & $\begin{array}{l}\text { - How are ideas } \\
\text { represented through } \\
\text { word choice? }\end{array}$ \\
\hline Re-Lexicalization & Renaming/re-voicing & $\begin{array}{l}\text { - What is the level of } \\
\text { formality? } \\
\text { - What words or } \\
\text { phrases show up again } \\
\text { and again in the } \\
\text { transcript? }\end{array}$ \\
\hline Pronouns & $\begin{array}{l}\text { First/second/third person. } \\
\text { Inclusive/exclusive pronouns. } \\
\text { Sexist/Non-sexist pronouns. }\end{array}$ & $\begin{array}{l}\text { - Which pronouns are } \\
\text { used and where? }\end{array}$ \\
\hline Exclusion & $\begin{array}{l}\text { Suppression of information: } \\
\text { Topical silence; lexical } \\
\text { silence; presuppositional } \\
\text { silence. }\end{array}$ & $\begin{array}{l}\text { - What information is } \\
\text { being excluded? }\end{array}$ \\
\hline \multicolumn{3}{|c|}{$\begin{array}{c}\text { STYLE } \\
\text { "WAYS OF BEING" }\end{array}$} \\
\hline Discursive Feature & Description & Questions to Ask of the Text \\
\hline Tense & $\begin{array}{l}\text { Tense sets up when an event } \\
\text { occurs in time. }\end{array}$ & $\begin{array}{l}\text { - When is this process } \\
\text { occurring? }\end{array}$ \\
\hline
\end{tabular}




\begin{tabular}{|l|l|l|}
\hline Appraisal & $\begin{array}{l}\text { Systems of evaluation that are } \\
\text { used to negotiate social } \\
\text { relationships by } \\
\text { communicating attitudes } \\
\text { (affect, judgment, and } \\
\text { appreciation. }\end{array}$ & $\begin{array}{l}\text { What kinds of } \\
\text { attitudes are } \\
\text { negotiated in the text? } \\
\text { What is the strength } \\
\text { of the feelings } \\
\text { involved? How are } \\
\text { values sources and } \\
\text { positions aligned? }\end{array}$ \\
\hline
\end{tabular}

Adapted from Rogers, R. \& Wetzel, M. M. (2014). Designing critical literacy education through critical discourse analysis: Pedagogical and research tools for teacher-researchers. Routledge. 


\section{BIBLIOGRAPHY}

Altermatt, E. R., Jovanovic, J., \& Perry, M. (1998). Bias or responsivity? Sex and achievementlevel effects on teachers' classroom questioning practices. Journal of Educational Psychology, 90(3), 516-527.

Austin, J. L., \& Howson, A. G. (1979). Language and mathematical education. Educational Studies in Mathematics, 10(2), 161-197.

Bailey, S. M. (1993). The current status of gender equity research in American schools. Educational Psychologist, 28(4), 321-339. https://doi.org/10.1207/s15326985ep2804_3

Banilower, E. R., Smith, P. S., Weiss, I. R., Malzahn, K. A., Campbell, K. M., \& Weis, A. M. (2013). Report of the 2012 national survey of science and mathematics education. Horizon Research, Inc.

Becker, J. R. (1981). Differential treatment of females and males in mathematics classes. Journal for Research in Mathematics Education, 12, 40-53.

Bem, S. L. (1993). The Lenses of Gender. Yale University.

Bigler, R. S. (1995). The role of classification skill in moderating environmental influences on children's gender stereotyping: A study of the functional use of gender in the classroom. Child Development, 66, 1072-1087.

Bohnsack, R. (2009). The interpretation of pictures and the documentary method. Historical Social Research, 34(2), 296-321. https://doi.org/10.12759/hsr.34.2009.2.296-321

Bolman, L. G., \& Deal, T. E. (2013). Reframing Organizations (5th ed.). Jossey-Bass.

Carraher, T., Carraher, D., \& Schliemann, A. (1987). Written and oral mathematics. Journal for Research in Mathematics Education, 18(2), 83-97. 
Cuevas, G. J. (1984). Mathematics learning in English as a second language. Journal for Research in Mathematics Education, 15(2), 134-144.

Cvencek, D., Meltzoff, A. N., \& Greenwald, A. G. (2011). Math-gender stereotypes in elementary school children: Gender stereotypes. Child Development, 82(3), 766-779. https://doi.org/10.1111/j.1467-8624.2010.01529.x

Duffy, J., Warren, K., \& Walsh, M. (2002). Classroom interactions: Gender of teacher, gender of student, and classroom subject. Sex Roles, 45(9/10), 579-593.

Fagot, B. I. (1977). Consequences of moderate cross-gender behavior in preschool children. Child Development, 48, 902-907.

Fagot, B. I., \& Hagan, R. (1985). Differential reactions to assertive and communicative acts of toddler boys and girls. Child Development, 56, 1499-1505.

Fairclough, N. (2010). Critical Discourse Analysis: The Critical Study of Language (2nd ed.). Routledge.

Fennema, E., Peterson, P. L., Carpenter, T. P., \& Lubinski, C. A. (1990). Teachers' attributions and beliefs about girls, boys, and mathematics. Educational Studies in Mathematics, 21(1), 55-69. https://doi.org/10.1007/BF00311015

Gee, J. P. (2014). An Introduction to Discourse Analysis Theory and Method (4th ed.). Routledge.

Good, T. L., Sikes, J. N., \& Brophy, J. E. (1973). Effects of teacher sex and student sex in classroom interaction. Journal of Educational Psychology, 65, 74-87.

Gumperz, J. J. (2015). Interactional sociolinguistics: A personal perspective. In D. Tannen, H. E. Hamilton, \& D. Schiffrin (Eds.), The Handbook of Discourse Analysis (pp. 309-323). John Wiley \& Sons, Inc. https://doi.org/10.1002/9781118584194.ch14 
Gunderson, E. A., Ramirez, G., Levine, S. C., \& Beilock, S. L. (2012). The role of parents and teachers in the development of gender-related math attitudes. Sex Roles, 66(3-4), 153166. https://doi.org/10.1007/s11199-011-9996-2

Hale, J. A. (1993). Interaction of student teacher with kindergarten males and females [Paper presentation]. Annual Meeting of the Southern Early Childhood Association. Biloxi, MS. Halliday, M. (2004). Halliday's Introduction to Functional Grammar (4th ed.). Routledge.

Harrop, A., \& Swinson, J. (2011). Comparison of teacher talk directed to boys and girls and its relationship to their behaviour in secondary and primary schools. Educational Studies, 37(1), 115-125. https://doi.org/10.1080/03055691003729260

Herbel-Eisenmann, B., Meaney, T., Pierson Bishop, J., \& Heyd-Metzuyanim, E. (2017). Highlighting heritages and building tasks: A critical analysis of mathematics classroom discourse literature. In Compedium for Research in Mathematics Ecuation (pp. 722-765). The National Council of Teachers of Mathematics, Inc.

Hilliard, L. J., \& Liben, L. S. (2010). Differing levels of gender salience in preschool classrooms: Effects on children's gender attitudes and intergroup bias: Effects of gender salience on stereotypes and bias. Child Development, 81(6), 1787-1798. https://doi.org/10.1111/j.1467-8624.2010.01510.x

Khan, B., Robbins, C., \& Okrent, A. (2020). The state of U.S. science and engineering 2020. National Center for Science and Engineering Statistics (NCSES). https://ncses.nsf.gov/pubs/nsb20201/

Kuhn, D., Nash, S. C., \& Brucken, L. (1978). Sex role concepts of two- and three-year-olds. Child Development, 49(2), 445-451. 
Leyva, L. A. (2017). Unpacking the male superiority myth and masculinization of mathematics at the intersections: A review of research on gender in mathematics education. Journal for Research in Mathematics Education, 48(4), 397-433. https://doi.org/10.5951/jresematheduc.48.4.0397

Li, Q. (1999). Teachers' beliefs and gender differences in mathematics: A review. Educational Research, 41(1), 63-76. https://doi.org/10.1080/0013188990410106

Lloyd, G. M., Cai, J., \& Tarr, J. E. (2017). Issues in curriculum studies: Evidence-based insights and future directions. In Compendium for Research in Mathematics Education (pp. 824852). National Council of Teachers of Mathematics.

Lubienski, S. T., \& Ganley, C. M. (2017). Research on gender and mathematics. In Compendium for Research in Mathematics Education (pp. 649-666). The National Council of Teachers of Mathematics, Inc.

Martin, C. L., \& Ruble, D. N. (2010). Patterns of gender development. Annual Review of Psychology, 61(1), 353-381. https://doi.org/10.1146/annurev.psych.093008.100511

Merriam, S. B., \& Bierema, L. L. (2014). Adult Learning: Linking Theory and Practice. John Wiley \& Sons, Inc.

Merriam, S. B., \& Tisdell, E. J. (2016). Qualitative Research: A Guide to Design and Implementation (4th ed.). Jossey-Bass.

Miller, C. C. (2018, December 19). Twelve books for feminist boys and girls. The New York Times. https://www.nytimes.com/2018/12/19/upshot/twelve-books-for-feminist-boysand-girls.html

Mintzberg, H. (1979). The Structuring of Organizations. Prentice Hall. 
National Assessment of Educational Progress. (2019). NAEP Report Card: Mathematics. https://www.nationsreportcard.gov/mathematics

Northam, J. (1982). Girls and boys in primary maths books. Education 3-13, 10(1), 11-14. https://doi.org/10.1080/03004278285200041

Pimm, D. (1987). Speaking mathematically: Communication in mathematics classrooms. Routledge \& Kegan Paul.

Riegle-Crumb, C., \& Humphries, M. (2012). Exploring bias in math teachers' perceptions of students' ability by gender and race/ethnicity. Gender \& Society, 26(2), 290-322. https://doi.org/10.1177/0891243211434614

Robinson, J. P., \& Lubienski, S. T. (2011). The development of gender achievement gaps in mathematics and reading during elementary and middle school: Examining direct cognitive assessments and teacher ratings. American Educational Research Journal, 48(2), 268-302. https://doi.org/10.3102/0002831210372249

Rogers, R., \& Wetzel, M. M. (2014). Designing critical literacy education through critical discourse analysis: Pedagogical and research tools for teacher-researchers. Routledge.

Ryve, A. (2011). Discourse research in mathematics education: A critical evaluation of 108 journal articles. Journal for Research in Mathematics Education, 42(2), 167-198. https://doi.org/10.5951/jresematheduc.42.2.0167

Sabbe, E., \& Aelterman, A. (2007). Gender in teaching: A literature review. Teachers and Teaching: Theory and Practice, 13(5), 521-538.

Sadker, D., \& Zittleman, K. R. (2009). Still failing at fairness: How gender bias cheats girls and boys in school and what we can do about it. Scribner. 
Sadker, M., \& Sadker, D. (1986). Sexism in the classroom: From grade school to graduate school. The Phi Delta Kappan, 67(7), 512-515.

Sadker, M., \& Sadker, D. (1994). Failing at fairness: How America's schools cheat girls. Scribner.

Scantlebury, K., \& Kahle, J. B. (1993). The implementation of equitable teaching strategies by high school biology student teachers. Journal of Research in Science Teaching, 30, 537545.

Signorella, M. L., Bigler, R. S., \& Liben, L. S. (1993). Developmental differences in children's gender schemata about others: A meta-analytic review. Developmental Review, 13(2), $147-183$.

Simon, M. K., \& Goes, J. (2017). Dissertation and scholarly research: Recipes for success (2018th ed.). CreateSpace Independent Publishing Platform.

The University of Chicago School Mathematics Project. (2012a). Everyday Mathematics Center Activity Cards (Common Core State Standards). McGraw-Hill.

The University of Chicago School Mathematics Project. (2012b). Everyday Mathematics Math Masters (Common Core State Standards). McGraw-Hill.

The University of Chicago School Mathematics Project. (2012c). Everyday Mathematics My First Math Book (Common Core State Standards). McGraw-Hill. The University of Chicago School Mathematics Project. (2012d). Everyday Mathematics Teacher's Guide to Activities (Common Core State Standards). McGraw-Hill. Tiedemann, J. (2002). Teachers' gender stereotypes as determinants of teacher perceptions in elementary school mathematics. Educational Studies in Mathematics, 50, 49-62. 
Tomasetto, C., Mirisola, A., Galdi, S., \& Cadinu, M. (2015). Parents' math-gender stereotypes, children's self-perception of ability, and children's appraisal of parents' evaluations in 6year-olds. Contemporary Educational Psychology, 42, 186-198. https://doi.org/10.1016/j.cedpsych.2015.06.007

Vuletich, H. A., Kurtz-Costes, B., Cooley, E., \& Payne, B. K. (2020). Math and language gender stereotypes: Age and gender differences in implicit biases and explicit beliefs. PLOS ONE, 15(9), 1-22. https://doi.org/10.1371/journal.pone.0238230

Walkerdine, V. (1998). Counting girls out: Girls and mathematics (New). RoutledgeFalmer.

Walshaw, M., \& Anthony, G. (2008). The teacher's role in classroom discourse: A review of recent research into mathematics classrooms. Review of Educational Research, 78(3), 516-551. https://doi.org/10.3102/0034654308320292

Wang, M. T., \& Degol, J. L. (2017). Gender gap in science, technology, engineering, and mathematics (STEM): Current knowledge, implications for practice, policy, and future directions. Educational Psychology Review, 29(1), 119-140. https://doi.org/10.1007/s10648-015-9355-x

Weiss, I. R. (1987). Report of the 1985-86 National Survey of Science and Mathematics Education. (RTI/2938/00-FR; p. 235). Research Triangle Inst., Durham, NC. Center for Educational Studies.

Weitzman, L. J., Eifler, D., Hokada, E., \& Ross, C. (1972). Sex-role socialization in picture books for preschool children. American Journal of Sociology, 77(6), 1125-1150.

Yasin, M. S. M., Hamid, B. A., Keong, Y. C., Othman, Z., \& Jaludin, A. (2012). Linguistic sexism in Qatari primary mathematics textbooks. GEMA Online Journal of Language Studies 12(1), 53-68. 


\section{VITA}

Alexandria Otis was born in Decatur, IL, where she grew up with her parents and younger brother. Growing up, she found a passion for music and working with children. She had the opportunity to work with children at various day camps, which is when she decided her life's work would include children and their development. In 2007, she moved to Missouri to attend Truman State University, where she originally pursued a degree in vocal music. Her experiences at Truman coupled with her love of working with children inevitably inspired her to change her major and follow a different path.

Ultimately, she earned a Bachelor of Arts degree in English and a Master of Arts degree in Elementary Education from Truman State University in Kirksville, MO. Prior to attending the University of Missouri, she taught fifth-grade at a private independent school in the Midwest, where she was able to grow both professionally and personally with the support of colleagues. The encouragement and support she received while teaching inspired her to pursue an Educational Doctorate in the department of Educational Leadership and Policy Analysis at the University of Missouri.

During the program, Alexandria decided to leave her position as a fifth-grade teacher and pursue other educational opportunities, which included teaching undergraduates at a regional college and facilitating a pod school during the Covid-19 pandemic. Upon completion of her Doctorate, she plans to embark on a career in higher education, specifically teacher education. She hopes to continue researching representation in elementary texts, practices, and classrooms in addition to guiding the next generation of teachers. 